PROJECT CHARIOT -- FINAI REPORT

\author{
INVESTIGATION OF SEA-CIIFF BIRDS, \\ CAPE THOMPSON, ALASKA
}

AEC CONTRACT NO. AT $(04-3)-310$

\author{
I. Gerard Swartz \\ Department of Biological Sciences
}

University of Alaska

PATENT CLEARANCE OBTAINED, RELEASE TO

THE PUBLIC IS APPROVED. PFIOCEDURES THE PUR ON EILE IN THE RECGIVING SECTION.

\title{
May 1964
}

\section{LEGAL NOTICE}

This report was prepared as an account of Government sponsored work, Neither the United

States, nor the Commission, nor any person acting on behalf of the Commisiton:
A. Makes any warranty or representation, expressed or implied, with respect to the accu-
racy, completeness, or wefun

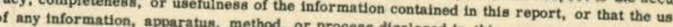
pivately owned rights; or B. Assumes any liab

ae of any information, appeses with reepect to the use of, or for damages resulting from the

As used in the above, "persor acting or process disclosed in thrs report.

ployee or commission" Includer any emsuch employee or contector of disseminates or with the Commigsion, or his employment with suction pursuant to his employment or contrac 


\section{DISCLAIMER}

This report was prepared as an account of work sponsored by an agency of the United States Government. Neither the United States Government nor any agency Thereof, nor any of their employees, makes any warranty, express or implied, or assumes any legal liability or responsibility for the accuracy, completeness, or usefulness of any information, apparatus, product, or process disclosed, or represents that its use would not infringe privately owned rights. Reference herein to any specific commercial product, process, or service by trade name, trademark, manufacturer, or otherwise does not necessarily constitute or imply its endorsement, recommendation, or favoring by the United States Government or any agency thereof. The views and opinions of authors expressed herein do not necessarily state or reflect those of the United States Government or any agency thereof. 


\section{DISCLAIMER}

Portions of this document may be illegible in electronic image products. Images are produced from the best available original document. 
This report was prepared as an account of Government sponsored work. Neither the United States, nor the Commission, nor any person acting on behalf of the Commission:

A. Makes any warranty or representation, expressed or implied, with respect to the accuracy, completeness, or usefulness of the information contained in this report, or that the use of any information, apparatus, method, or process disclosed in this report may not infringe privately owned rights; or

B. Assumes any liabilities with respect to the use of, or for damages resulting from the use of any information, apparatus, method, or process disclosed in this report.

As used in the above, "person acting on behalf of the Commission" includes any employee or contractor of the Commission, or employee of such contractor, to the extent that such employee or contractor of the Commission, or employee of such contractor prepares, disseminates or provides access to, any information pursuant to his employment or contract with the Commission, or his employment with such contractor.

In citing this manuscript in a bibliography the reference should be followed by the phrase: UNPUBLISHED MANUSCRIPT. 


\section{ERRATA}

\begin{tabular}{|c|c|c|}
\hline page & line & \\
\hline 3 & 4 & "1959" should read "1960" \\
\hline 58 & 3 & $\begin{array}{l}\text { ". • page } 12 . . . " \text { should read ". . . page } \\
\text { 53. . " }\end{array}$ \\
\hline 60 & 11 & "Uspenski, 1958" should read "Uspenski, 1956" \\
\hline 66 & 6 & "1.876" should read " $1.88 "$ \\
\hline 68 & 19 & "Ridgeway" should read "Ridgway" \\
\hline 119 & 1 & $\begin{array}{l}\text { "Biomass and food consumption at . . " should } \\
\text { read "Biomass and food consumption of adults } \\
\text { at.. ." }\end{array}$ \\
\hline 121 & 11 & "Table 27," should read "Table 29," \\
\hline \multirow[t]{2}{*}{123} & 14 & "lo" should read "16" \\
\hline & 15 & "2" should read "4" \\
\hline \multirow[t]{2}{*}{127} & & $\begin{array}{l}\text { After line } 27 \text {, add: "Peterson, R. T. } 1961 . \\
\text { A field guide to western birds. Houghton } \\
\text { Miflin Co., Boston. } 366 \text { p." }\end{array}$ \\
\hline & 28 & "Ridgeway" should read "Ridgway" \\
\hline 128 & 5 & $\begin{array}{l}\text { "Uspenski, S. M." should read "Uspenski, } \\
\text { S. M. 1956." }\end{array}$ \\
\hline
\end{tabular}




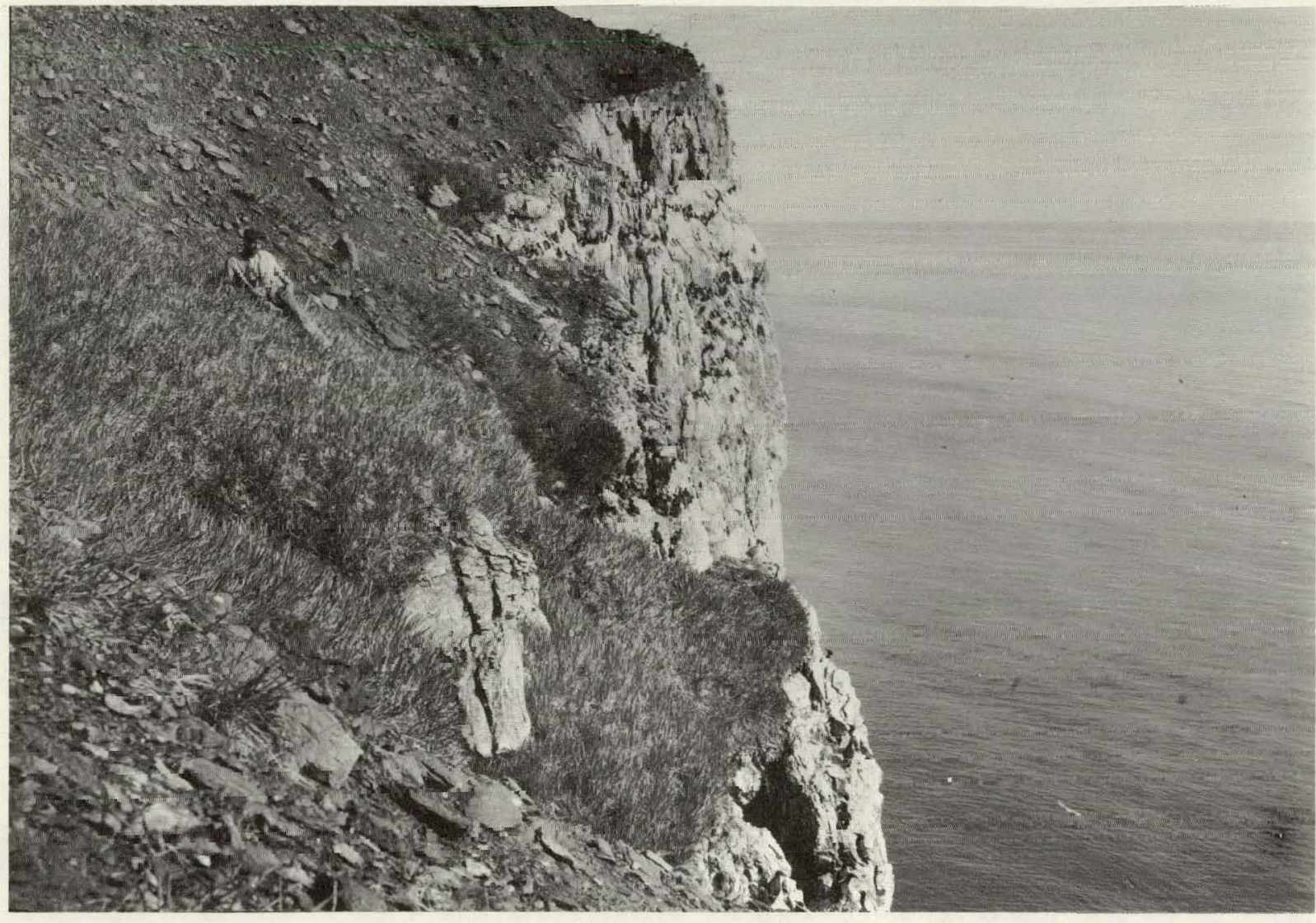

Typical cliff top and glaucous gull nest site. Colony 3, 9 July 1960.

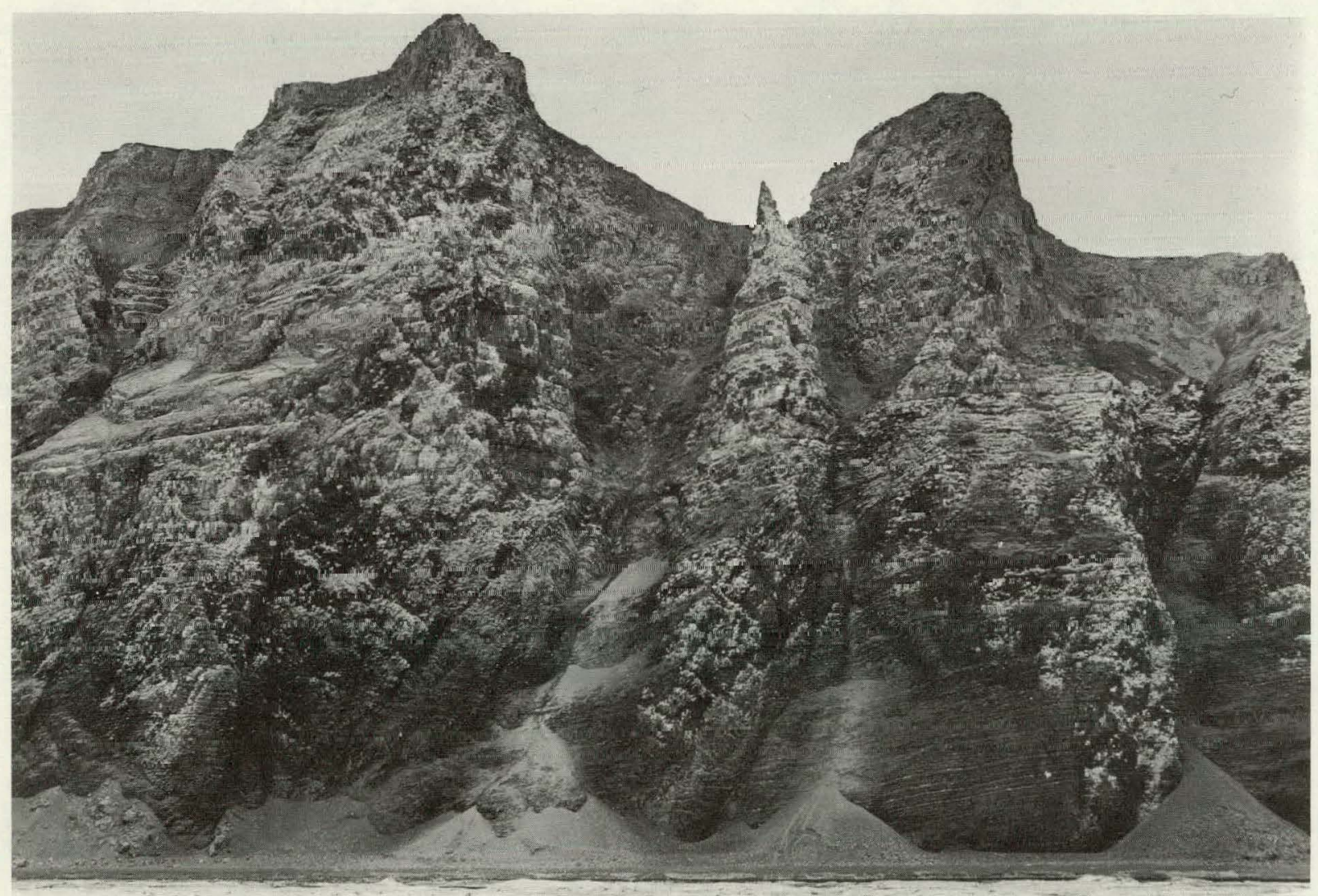

Colony 5 viewed from the ice, 14 June 1960. 


\section{PROJECT CHARIOT -- FINAL REPORT \\ INVESTIGATIONS OF SEA-CLIFF BIRDS,}

CAPE THOMPSON, ALASKA

by

L. Gerard Swartz

May 1964

TABLE OF CONTENTS

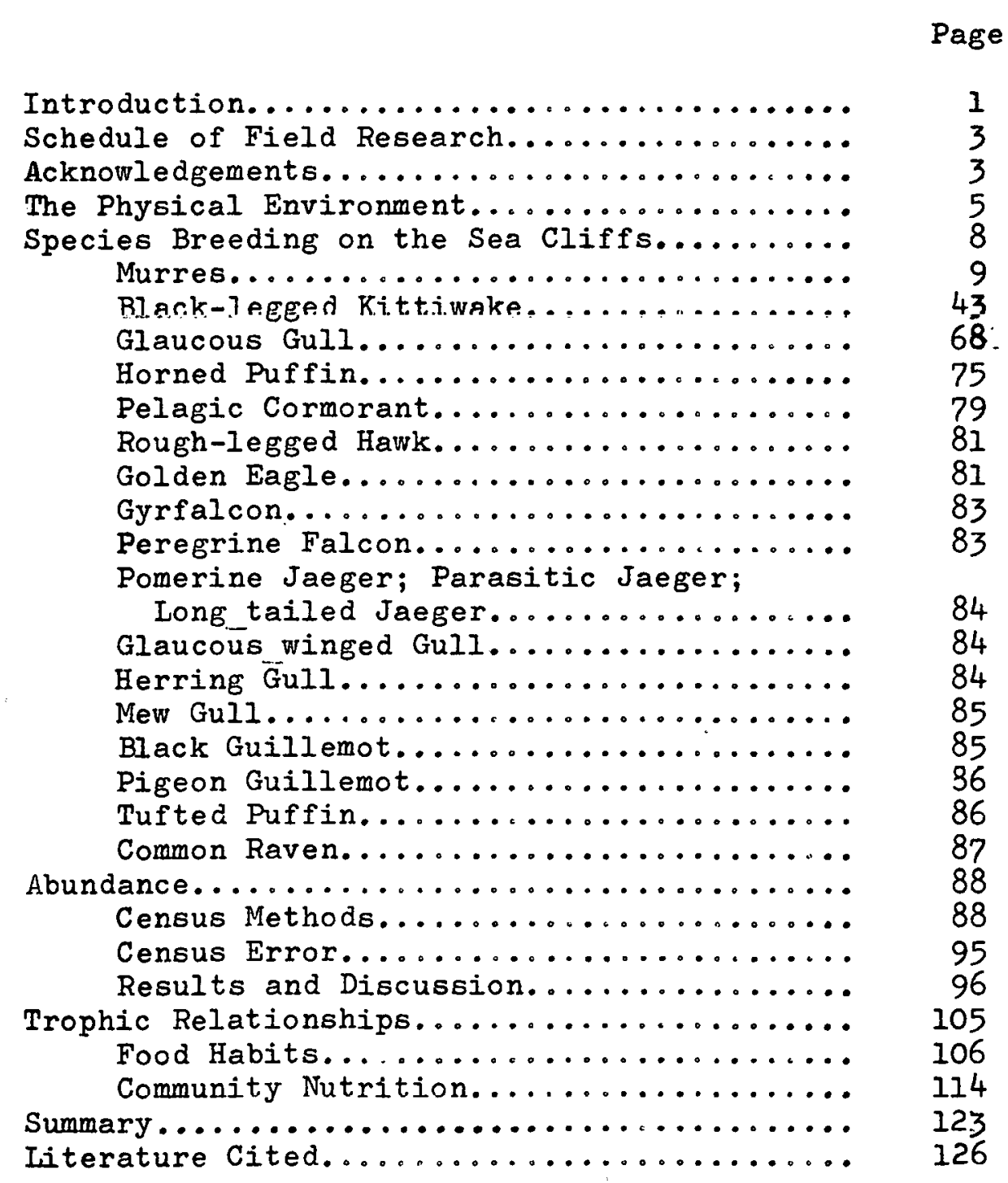


INTRODUCTION

Approximately seven miles of precipitous coastline between Ogotoruk Croek and Point Hope, Alaska, support colonial sea birds in numbers exceeding 400,000. These sea-bird colonies are perhaps the most immediately dramatic biotic feature of the Cape Thompson area and take part in an ecosystem of major importance. The primary objectives of this paper are to present data on ecology and breeding biology of the sea birds, on the species composition and abundance of the sea-bird fauna, and on the components and dynamics of the sea-bird ecosystem at Cape Thompson.

In contrast to the sea-bird colonies in the North Atlantic and western Soviet Arctic, those in the North Pacific Ocean and the Chukchi Sea remain poorly known, particularly those in the Chukchi Sea. Gabrielson and Lincoln (1959) have collated scattered information from the early days of Alaskan ornithology. Data gathered during the Russian period largely concern the area south of Bering Strait and, in common with that deriving from the early American expeditions, suffers from the short period of study and the incidental nature of ornithological studies. Knowledge of the colonies in the islands of the northern Bering Sea has been bolstered by three recent papers: Cade (1952) lists species observed on Sledge Island with notes on ecology and breeding biology; Fay and Cade (1959) list breeding birds on St. Lawrence Island and include ecological analyses; Kenyon and Brooks (i960) liat, with annotations, species observed on Little Diomede. Few papers, however, consider colonies north of Bering Strait. Grinnell (1900).includes data on Puffin and Chamisso Islands in Kotzebue Sound. Bailey (1925, 1948) cites his own observations north of the Strait and collates the observations of others on a number of colonial species.

Curiously, until the first published report (Wolfe, 1960) on the present studies, the large Cape Thompson colonies have remained essentially unknown to the scientific community, though a few brief references to these colonies exist prior to Wolfe (op. cit.). Four of these references result from the cruises of the U. $S$. Revenue 
Steamer THOMAS CORWIN in 1880 and 1881. Hooper (1881:48), speaking of the 1880 voyage, mentions ". . . a small party of natives encamped here, engaged in catching birds with nets." That these were breeding sea birds is clarified by his comments from the 1881 voyage (Hooper, 1884) to the effect that Cape Thompson is a favorite camping spot, partly because of the abundance of birds and eggs on the cliffs. Hooper (1884), Nelson (1883), and Muir (1917) comment briefly that sea birds were seen here in 1881. The only other record I have found was published by Hudson (1957:28) and contains a sight record from an airplane of murres ". . . swarming about sea cliffs. . . a few miles south of Point Hope." R. A. Gilmore landed for two hours at Cape Thompson on 25 August 1931, but did not publish his observations, though Bailey (1948) reports having examined two specimens of Uria lomvia taken by Gilmore at Point Hope. Gilmore's field notes (kept at the Museum of Vertebrate Zoology, University of California, Berkeley) contain several pages of observations of the colonies and notes on several of the species found breeding.

With the exception of colonies at Cape Lisburne, about 40 miles north, the Cape Thompson colonies are the northernmost on the western coast of North America. As such they possess considerable interest beyond their mere existance as a large and hitherto virtually unknown aggregation of breeding sea birds. Not only is the location potentially advantageous in investigating biological phenomena at a latitudinal extreme, but the body of basic data now available on almost the whole hista and phyoical envirunment presents a nearly unique opportunity for ecological studies in an arctic region. I hope that this paper will lay a foundation for further studies of sea birds by others. 
SCHEDULE OF FIELD RESEARCH

Field work on the current studies began in 1959 and extended from 15 June to 9 September, 1959; from 2 April to 21 October, 1960; and from 27 April to 3 October, 1961. One winter visit was made from 27 February to I Marci, 1959. The size of the field party varied from year to year with a maximum of three in 1959 (from I July to 12 August, only one), a maximum of seven during a short period of intense census effort in 1960, and a maximum of three in 1961. Early and late season observations on the establishment and breakup of the colonies were made by a single man. No early season observations were possible in 1959.

\section{ACKNOWLEDGEMENTS}

I am deeply indebted to the following persons who, along with myself, conducted the field work during parts of the investigations: Dr. B. Kessel, Dr. G. W. Cox, Dr. J. F. Opsahl, Dr. G. C. West, D. O. Hill, I. M. Belson, E. L. Schene, E. J. Willoughby, K. M. Jones, W. T. VanVelzen, and my wife, M. M. Swartz. I owe a particular debt of gratitude to $\mathrm{Dr}$. Cox who directed the field party during much of the 1960 field season and who contributed greatly to analysis and preparation of data during the winter of 1960-1961. I wish also to acknowledge the cooperation of Mr. Francis S. L. Williamson who has been most generous in sharing data on sea birds obtained by his research group. Many other investigators contributed in significant measure, large and small, by an enthusiastic, cooperative interest in these studies, resulting in many useful field observations which would not otherwise have been possible to gather.

Vertebrate and invertebrate food samples taken in 1959 were identified by Dr. N. J. Uilimovsky. Dr. James E. Morrow identified fishes from subsequent years. Invertebrates after 1959 were identified by $\operatorname{Ian}$ Ellis and W. T. Pereyra of the University of Washington. 
I am also indebted to Dr. W. Z. Lidiker, Dr. A. H. Miller, and the staff of the Museum of Vertebrate Zoology, University of California, Berkeley, for the use of their facilities during two visits.

I also owe thanks to Dr. Brina Kessel for critical review of the manuscript.

These studies were supported by contract No. AT(04-3)-310

between the University of Alaska and the U. S. Átomic Energy Commission. 
THE PHYSICAL ENVIRONMENT

Geological and climatological features of the sea cliff area are presented in detail in reports of other Project Chariot investigations. Discussion below will concern only those factors which directly impinge on the biology of the colonial sea birds, the functioning of the ecosystem, or on the conduct of the investigation. Data cited below are summarized largely from Wolfe (1960), who reports on data gathered by the United States Weather Bureau beginning on I September 1959.

The climate is severe. High winds are prevalent in the Cape Thompson-Ogotoruk Creek region. From October 1959 to September 1960, average winds over 30 knots occurred on 47 days, 21-30 knots on 78 days, 11-20 knots on 163 days; and 10 knots or less on only 88 days. only four of 1,096 observations in 1959 reported calm. Winds may present serious problems to the birds and to the investigators, especially when blowing onshore. Sea storms are common in the summer months, particularly in late summer, according to our own experience and the testimony of Eskimo inhabitants of the region.

Cloudy days are the rule during the breeding season. In 1960 there were a total of only 19 clear days during June through september. Annual precipitation probably averages about 8 inches, a large proportion of this falling during the summer. In $1960,6.34$ inches fell in the months June through September. Total precipitation October 1959 through september 1960 was 8.63 inches.

Formation, dissoluliun, and dissipation of sea ice depends on a complex of factors, including wind, water currents, and temperature. As a result, ice conditions may vary greatly from day to day. Delimiting the average date of "final freezup" is not possible, although open water available to sea birds near the cliffs is ordinarily greatly restricted beginning in February when a large body of stable ice becornes established in the embayment south of Point Hope and extends south of the cliffs. A zone of grounded ice here may extend two or more miles offshore. This zone is the last to disappear in the summer and during 1959, 1960, and 1961 broke up by the end of the first week in July. 
Breeding sea birds occur in five concentrated groups on the higher, more stable, cliffs. The colonies are scattered from Point Crowbill, just northwest of the mouth of Ogotoruk Creek, to the end of the cliffs about 1.5 miles west-northwest of Cape Thompson. The groups of breeding birds are here referred to as "colonies," each colony separated from the next by topographic discontinuities of low relief and softer rock which vary from a few hundred yards up to 1.5 miles in length. Each colony has been designated by a number beginning with Colony 1 at Point Crowbill and extending to Colony 5 west-northwest of Cape Thompson (see Fig. 1). Cliffs supporting bird colonies range from 30 feet to more than 600 feet in height. Most of the rock is soft and extensively fractured, and, except for a few places, nesting ledges are not safely accessible by man. Small or large rock falls are common, and a more or less continuous shower of stones falls from many of the cliff faces. A narrow gravel beach separates most of the cliffs from the ocean, but in only one colony (Colony 5) is it continuous. In Colonies 1 through 4, one to several headlands project into the ocean, rendering much of the study area inaccessible except by boat. Storms and movement of the sea ice often work considerable change in shoreline topography from year to year. 

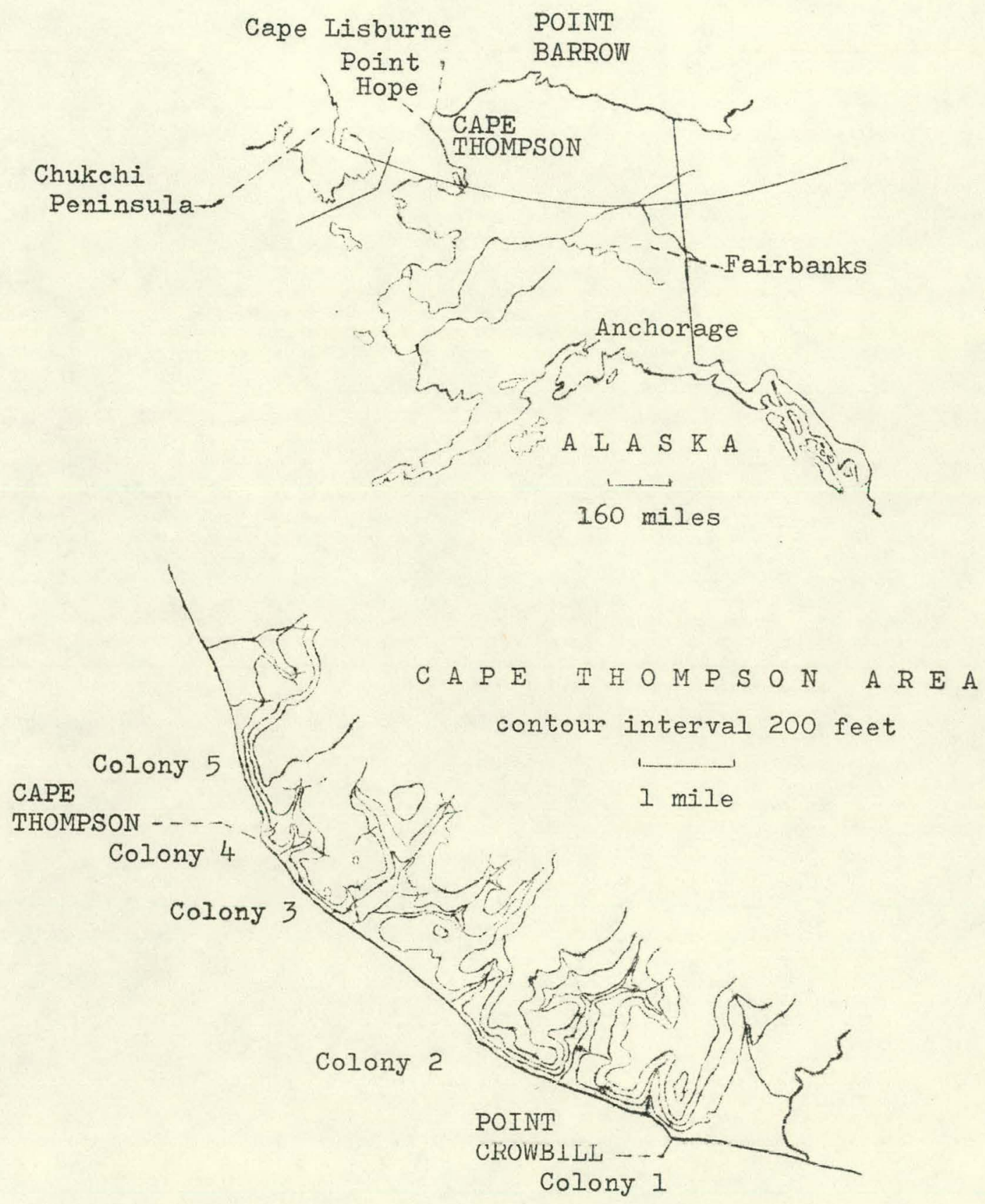

Figure 1. Location of sea bird colonies 
SPECIES BREEDING ON THE SEA CLIFFS

Nine species of sea birds regularly breed on the sea cliffs: pelagic cormorant (Phalacrocorax pelagicus Pallas), glaucous gull (Larus hyperboreus Gunnerus), black-legged kittiwake (Rissa tridactyla Linnaeus), common murre (Uria aalge Pontoppidan), thickbilled murre (U. Iomvia Linnaeus), black guiliemot (Cepphus grylle Iinnaeus), pigeon guillemot (‥ columba Pallas), horned puffin (Fratercula corniculata Naumann), and tufted puffin (Lunda cirrhata Pallas). Nesting records were secured for all species except the tufted puffin, which undoubtedly breeds here, but it was not possible to reach the nest sites. Four terrestrial species breed regularly on the sea cliffs: gyrfalcon (Falco rusticolis Linnaeus), peregrine falcon (‥ peregrinus Tunstall), Say's phoebe (Sayornis saya Bonaparte), and the common raven (Corvus corax Linnaeus). The gray-crowned rosy finch (Leucosticte tephrocotis Swainson) and the snow bunting (Plectrophenax nivalis Linnaeus) were seen breeding on the cliffs in 1959. Of these terrestrial species, only the gyrfalcon, peregrine, and raven are significantly involved in the sea bird ecosystem.

Specimens have been taken of all species of sea birds and have been placed in the University of Alaska Museum.

Data pertaining to morphometry and breeding biology were gathered during all three summers but data dependent on collected specimens are largely confined to 1960. Specimens of both species of murres, kittiwakes, and horned puffins were killed with shotguns: at weekly or biweekly intervals, primarily from the nesting ledges of Colony 5 (see Frontispiece). This colony was selected as a collecting site because of its relative isolation from the primary study colonies and because it is physiographically unfavorable for studies of nesting birds. Collectlons of other species were less intensive, since populations were small and less able to withstand decimation. Numerical data on nest establishment, egg-laying, hatching, and departure of chicks were obtained by observation of nesting areas chosen for accessibility and visibility to the investigators. 
Murres

Both common murres and thick-billed murres nest on the cliffs, though the latter are more numerous; in general, the geographic distribution of the thick-billed murres is more northerly than that of the common, which is reaching its northern limit in northwest Alaska. The phenology and ecological niches of the two species are similar, though there are some evident differences (see pages 34 , 99, and 106-108.

Comparisons of Measurements and Weights

Measurements of culmen length, distance between nostril and bill tip, wing length (flattened), and tarsal length were taken on adult birds. Measurements are summarized for both species of murres in Table 1. In the thick-billed murre, measurements for nostril to bill tip and for tarsal length were significantly greater in the male than in the female ( 0.05 and 0.01 levels, respectively). Storer (1952) noted significant differences between sexes in tarsal length, culmen length, and bill depth, with males showing greater values in all cases. No significant differences were found in wing length in either study.

In the common murre, wing length was found to be significantly greater in males as compared with females ( 0.01 level). Other comparisons between sexes were not significantly different. Storer (1952) found significant differences in culmen length and bill depth, but not in wing length or tarsal length.

When compared, average measurements of the two species showed significant differences in all cases. Common murres had significantly longer culmen, nostril to bill tip, and tarsal lengths, and significantly shorter wing lengths than thick-billed murres $(0.01$ level in all cases).

These differences between species, especially in bill length and wing length, may be related to differences in feeding niche (see pages 106-108. 
TABLE 1. External measurements (in millimeters) of adult tijick-billed and common murres collected at Cape Thompson colonies during 1960

\begin{tabular}{|c|c|c|c|c|c|c|c|}
\hline \multirow[b]{2}{*}{ Measurement } & \multirow[b]{2}{*}{ Sex } & \multicolumn{3}{|c|}{ Thick-billed Murre } & \multicolumn{3}{|c|}{ Common liurre } \\
\hline & & No. & Mean $\pm S t$. Error & Range & No. & Mean $\pm s t$. Error & Range \\
\hline \multirow{3}{*}{ Culmen } & $\pi$ & 79 & $38.3 \pm 0.23$ & $33.4-42.7$ & 39 & $44.9 \pm 0.29$ & $41 \cdot 6-49 \cdot 4$ \\
\hline & $\subsetneq$ & 58 & $37.6 \pm 0.26$ & $33.1-43.5$ & 37 & $44.2 \pm 0.33$ & $40 \cdot 6-49 \cdot 3$ \\
\hline & $8+4$ & 137 & $38.0 \pm 0.18$ & $33.1-43.5$ & 76 & $44.6 \pm 0.22$ & $40 \cdot 6-49 \cdot 4$ \\
\hline \multirow{3}{*}{$\begin{array}{l}\text { Nostril } \\
\text { to } \\
\text { bill-tip }\end{array}$} & $d x$ & 80 & $31.3+0.18$ & $28 \cdot 3-34.8$ & 39 & $38.8 \pm 0.27$ & $35.6-42.0$ \\
\hline & $q$ & 59 & $30.7 \mp 0.19$ & $28.0-34.6$ & 37 & $38: 2 \pm 0.24$ & $35.9-41.0$ \\
\hline & $3+9$ & 139 & $31.0 \pm 0.14$ & $28.0-34.8$ & 76 & $38.5 \pm 0.18$ & $35 \cdot 6-42.0$ \\
\hline \multirow{3}{*}{ ving } & 0 & 80 & $223.6 \pm 0.72$ & $208-256$ & 41 & $216.7 \pm 0.88$ & $202-229$ \\
\hline & 0 & 59 & $223.2 \pm 0.85$ & $201-235$ & 38 & $215 \cdot z+1.02$ & $201-228$ \\
\hline & $c^{2}+9$ & 139 & $223.4 \pm 0.55$ & $201-236$ & 79 & $216.0+0.67$ & $201-229$ \\
\hline \multirow{3}{*}{ Tarsus } & 8 & 80 & $37.2 \pm 0.20$ & $33.5-4 \check{2} .1$ & 41 & $38.5 \pm 0.24$ & $35.3-42.1$ \\
\hline & $\underline{0}$ & 59 & $36.4 \pm 0.20$ & $32.8-39.8$ & 38 & $38.0 \pm 0.29$ & $34.0-41.1$ \\
\hline & $c^{-1}+q$ & 139 & $36.9 \pm 0.15$ & $32.8-42.1$ & 79 & $38.3 \pm 0.19$ & $34.0-42.1$ \\
\hline
\end{tabular}


Weights were taken of all adult murres collected at Cape Thompson. The amount of subcutaneous and abdominal cavity fat was recorded on a scale of five classes (class 1 - no visible fat; class 5 - excessive amount of fat).

Weights of adult thick-billed and common murres are summarized for bi-weekly periods and for the summer of 1960 as a whole in Table 2 . Weight differences between sexes of these species were not apparent. Common murres, however, averaged significantly heavier than thickbilled murres. Since the weights of males of the two species were only slightly different (not significant), the overall species difference is related to a large difference between the weights of females of the two species.

Weights of both males and females summarized over two-week periods fluctuated markedly (Figures 2 and 3 ). Comparisons between, weights during different periods were in most cases not statistically significant. The drop in weight of female thick-billed murres between May and the first half of June was significant (0.05 level). This drop was also shown by male thick-billed murres but not by common murres, possibly because of the small numbers of this latter species examined during this part of the summer. The drop shown by female common murres between the first and second halves of August was also significant $(0.05$ level). This general drop was present in male common murres and in male and female thick-billed murres. The fact that in the thick-billed murre changes during the summer are similar in both sexes suggests that these changes are not entirely random fluctuations. Determination of the cause of these changes in weight is difficult. The decrease in weight between May and early June, corresponding to the pre-nesting period of cliff occupation, may indicate a weak development of daily feeding patterns at this time, or possibly that sea ice conditions limited favorable feeding areas in the vicinity of the cliffs.

A second marked decrease in weight occurred between the last half of July and the end of August, corresponding to the period when most adults were feeding chicks. This decrease may indicate that 
TABLE 2. Average weights in grams of adult male and female thick-billed and common murres throughout the summer of 1960 at Cape Thompson colonies

\begin{tabular}{|c|c|c|c|c|c|}
\hline \multirow{2}{*}{ Sex } & \multirow{2}{*}{ Period } & \multicolumn{2}{|c|}{ Thick-billed Murre } & \multicolumn{2}{|r|}{ Common Murre } \\
\hline & & No. & Av. Wt. \pm st. Error & No. & Av. Wt. \pm St. Error \\
\hline \multirow{8}{*}{ 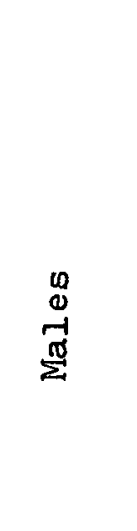 } & May & 8 & $1001.0 \pm 16.70$ & 0 & - \\
\hline & June $1-15$ & 6 & $966.8 \pm 26.60$ & 0 & - \\
\hline & June $15-30$ & 24 & $1000.5 \pm 14.74$ & 14 & $971.6 \pm 20.04$ \\
\hline & July $1-15$ & 14 & $955.1 \pm 15.56$ & 14 & $977.2 \pm 8.38$ \\
\hline & July 15-31 & 17 & $1003.7 \pm 26.39$ & 2 & $966.5 \pm 39.50$ \\
\hline & Aug. 1-15 & 7 & $967.0 \pm 28.03$ & 5 & $1051.6 \pm 37.48$ \\
\hline & Aug - 15-31 & 10 & $925.5 \pm 20.87$ & 2 & $904.5 \pm 2.54$ \\
\hline & Sept.1-15 & 3 & $940.7 \pm 55.25$. & 4 & $981.8 \pm 26.10$ \\
\hline Total & Summer & 79 & $975.5 \pm 7.87$ & 41 & $980.8 \pm 10.28$ \\
\hline \multirow{8}{*}{ 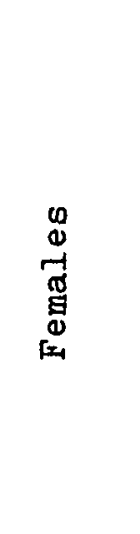 } & May & 10 & $972.3 \pm 9.08$ & 3 & $995.3 \pm 8.18$ \\
\hline & June $1-15$ & 7 & $895.7 \pm 20.29$ & 1 & 1017 \\
\hline & June $15-30$ & 011 & $1001.0 \pm 29.04$ & 8 & $1021.5 \pm 45.43$ \\
\hline & July $1-15$ & 14 & $950.1 \pm 19.98$ & 6 & $1009.3 \pm 14.75$ \\
\hline & July $15-31$ & 14 & $981.2 \pm 25.09$ & 2 & $983.0 \pm 6.00$ \\
\hline & Aug. 1-15 & 2 & $974.5 \pm 17.51$ & 7 & $984.6 \pm 13.68$ \\
\hline & Aug $\cdot 15-31$ & 14 & $886.8 \pm 19.50$ & 8 & $940.0 \pm 15.39$ \\
\hline & Sept.1-15 & 8 & $908.0 \pm 19.39$ & 2 & $987.5 \pm 53.51$ \\
\hline Total & Summer & 60 & $949.8 \pm 9.41$ & 37 & $988.9 \pm 11.62$ \\
\hline $\begin{array}{l}\text { All } \\
\text { birds }\end{array}$ & Summer $r$ & 139 & $964.4 \pm 6.12$ & 78 & $984.6 \pm 7.68$ \\
\hline
\end{tabular}




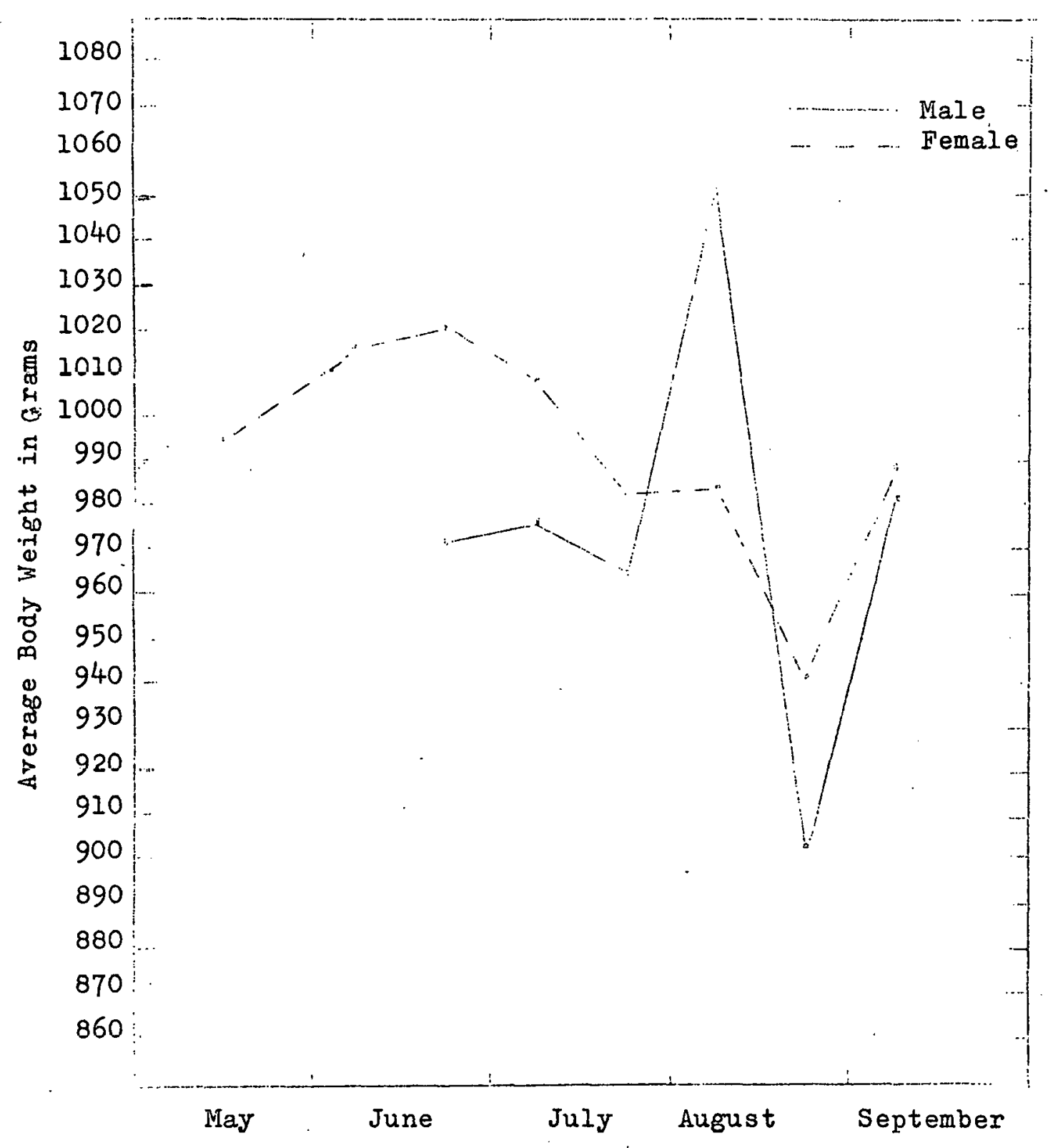

Figure 2. Average weights of adult male and female common murres at Cape Thompson colonies during summer of 1960. 


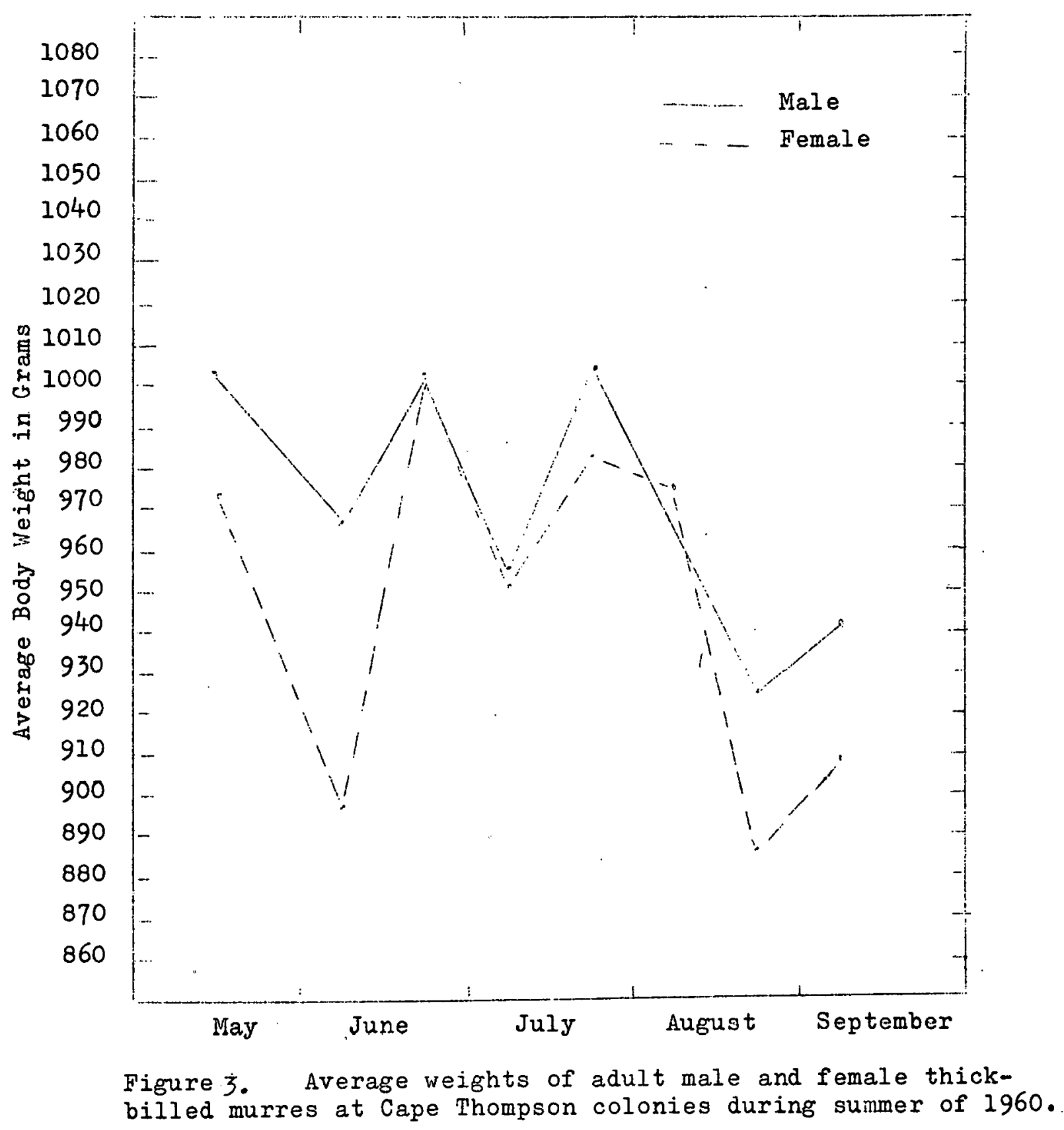


during this period much of the food obtained by adults is diverted to the chicks, resulting in a less favorable energy balance for the adults. Adults of both species showed this decrease clearly.

Plumage and Molt

Birds at the cliffs were almost all in complete breeding plumage during all three breeding seasons.

During the summer of 1959, a thick-billed murre in winter plumage was collected on $14 \mathrm{July}$. In 1960, individuals in almost complete winter plumage were seen in the water at the base of the cliffs on $29 \mathrm{July}$ and 16 August. One thick-billed murre in winter plumage was collected on 3 August by D. Johnston about two miles south of Ogotoruk Creek. This bird showed slight development of gonads and a weak development of the brood patch. It is probable that these birds in complete winter plumage are young, non-breeding birds.

From 20 July through the first week of September, 1960, occasional thick-billed murres had traces of white feathers on the throat (typical of winter plumage). Whether these were non-breeding adults or simply early-molting breeders is not certain. On 20 August, E. J. Willoughby, aboard the Motor Vessel BROWN BEAR, collected two individuals about 40 miles from shore, one with white feathers on the throat, and one apparently in the process of molting the primary feathers. The former possessed a well-developed brood patch which was in the process of regressing, suggesting that it was a breeding bird. The latter showed no trace of a brood patch and only a slight degree of gonadal development.

On 12 July 1960, a male common murre was collected on which the feathers of the ventral side of the post-ocular groove were whitetipped. There were no white feathers around the eye itself, as in the typical "bridled" form of the common murre, which has been recorded only in populations in the Atlantic Ocean. It is possible that this may represent a weak development of this character, however. A skin 
was made of this specimen and is in the University of Alaska Museum (L. G. S. 60-2I6).

On 30 August 1960, a completely albino thick-billed murre chick was found dead on the beach of one of the colonies. Development of the chick was equivalent to that of other chicks which were entering the water and it is probable that this individual had attempted to do so. The skin of this :ndividual has been placed in the University of Alaska Museum (L. G. S, 60-530). Storer (1952) does not list any completely albino specimens of the thick-bilied murre, although partial albinism has been recorded several times in the species.

\section{Winter and Early Spring Activities}

Little is known of the wintering grounds of murres nesting in Alaska. The bulk of murre populations apparently winter south of Bering Strait (Gabrielson and Lincoln, 1959). Shuntov (1961) states that large populations of both thick-billed and common murres spend the winter jin Bristol Bay, and it is possible that Cape Thompson birds are represented in these fiocks. Scattered observations; mostly from Point Hope, indicate that small numbers may regularly be present in the Cape Thompson region throughout the winter in open leads in the ice. During the winter of 1959-60, observations by D. C. Foote at Point Hope indicated that over 100 birds remained in the area in places where open water was available. Rev. Lawton of Point Hope states that if open water is present, murres are likely to be present. The relative status of the two species of murres in vinter at Point Hope is not known, but it is probable that the bulk of records, if not all, are of the thick-billed murre.

Shuntov (op. cit.) observed northward flights of murres in Bristol Bay in early April. An increase in numbers of murres in leads and open water areas in the vicinity of Cape Thompson took place during the last half of April in 1960 and preceded the arrival of birds at the nesting cliffs. Between 20 and 25 April, L. M. Belson observed flocks of 
murres, ranging from 25 to 75 birds each, flying north in the vicinity of Point Hope. These flocks totaled about 1,300 birds. On 25 April, W. O. Pruitt noted several flocks of murres and eiders, totaling about 500 birds, between Point Hope and the mouth of Angahyoukuk Creek. The first murres were reported at Kivalina by a whaling crew on 26 April (fide D. J. Saario). Many of these observations may have represented birds moving nors to the vicinity of other colonies, but their presence indicates that extensive movements and an increase of numbers took place during this period in 1960.

\section{Pre-nesting Period of Cliff Occupation}

In 1960 thick-billed murres first arrived at the Cape Thompson cliffs on 2 May. Large numbers were present on the cliffs at the initial observation, though this did not represent a large fraction of the total breeding population. Since no open water of any significance is normally available at the base of the Cape Thompson cliffs until about another month has passed, the phase of land-coming described by Tuck (1960), of temporary residence in the water before actual occupation of the leciges, is not found at Cape Thompson. Common murres were first observed on 10 May. In 1961 thick-billed murres arrived in large numbers on 1 May. Common murres were first observed on 7 May. About two months elapsed in both 1960 and 1961 before egg-laying began.

As Tuck (1960) observes, the nesting phenologies of colonies in which both species of murres are found have been little studied. Observations at Cape Thompson, however, do not seem to agree with the few that have been made elsewhere. Tuck (op. cit.) shows clearly that in colonies he has studied on the east coast, thick-billed murres arrive later and nest later than do common murres.

It is possible that many of the murres were paired on arrival at the cliffs or that pairing took place shortly after arrival. Copulation was observed on the date of arrival in both 1960 and 1961, long before egg-laying. In any event, pairing probably occurs on the 
water, and at Cape Thompson it was not possible to investigate pairing where it probably occurred several miles at sea beyond the firmly anchored zone of inshore ice. Tuck (op. cit.) takes issue with several authors who contend that pairing takes place before arrival. It should be noted that Tuck uses the word "arrival" in a different sense than I have at Cape Thompson, since birds in most other colonies investigated "arrive" in the water immediately adjacent to the nesting cliffs some time before actual occupation of the ledges. In the absence of evidence drawn from observations at sea, copulation on the day of arrival would seem to indicate that at least some pairing has occurred by the time the ledges are occupied.

The early part of the pre-nesting period at Cape Thompson was characterized by alternating periods in which birds were present in large numbers or almost totally absent. The controlining factors in these periods of presence and absence are not clear. Uspenski (1956) has suggested that arrival at the nesting cliffs is related to ice conditions. It is therefore possible that sea ice movements, resulting in changes in location of open water feeding areas may influence numbers at the cliffs. Weather at Cape Thompson influences the birds in some respects but does not seem to be basic in controling the presence-absence pattern. Probably the dominating factor in this pattern which repeats year after year is a complex of physiological and behavioral factors operating in the recrudescence of the breeding condition.

Superimposed upon this pattern of presence and absence at the cliffs was a daily activity pattern. This diurnal pattern will be discussed in more detail later, but in general it involved a build-up of numbers during the afternoon and evening hours and a decrease in numbers during the morning hours. During June, fluctuations in numbers of several days' duration continued but became reduced in magnitude. During this same period the diurnal pattern, probably related to feeding, became more prominent. During this period a strong attachment for the nesting ledges developed and a regular daily feeding rhythm centered at the cliffs was established.

The nature of territorial behavior in murres is not clear, 
although it is obvious that territories, if present, must consist of a very limited area. Aggressive behavior on the nesting ledges is common, though it diminishes as nest site selection is completed. This behavior often leads to active fighting in which the individuals may leave the ledges and continue fighting in the water for long periods. Pairs of these fighting birds captured in the water are usually males. Five pairs captured in 1960 were all males. Tuck (1960), on the other hand, captured six fighting thick-billed murres, all of which were females. Tuck (op. cit.) discusses conflict in some detail as does Pennycuick (1956): Their observations are nearly identical with those made at Cape Thompson. Observations by Johnson (1941) indicate that when eggs are moved some distance from their original location, the adults tend to move them back, indicating an attachment not only to the egg, but to a specific section of the ledge. It is probable that a minimum defended area does occur, and that it is related to both a specific ledge area and to the location of the egg or chick, since these are subject to some movement due to the absence of a definite nest.

During the latter part of the pre-nesting period, open water areas along the shore at the base of the Cape Thompson cliffs and pools in the ice close to shore were intensively utilized by the birds (see Fig. 4). Murres were occasionally noted on the ice along the shore, in most cases as a result of inability to gain sufficient flying speed on departing from the cliffs. On areas of smooth ice many of these birds were able to take off. In some cases, especially where the ice was uneven, they were apparently unable to do so. Murres injured in rock falls on the cliffs or in striking the ice were frequently noted on the ice near the cliffs. 


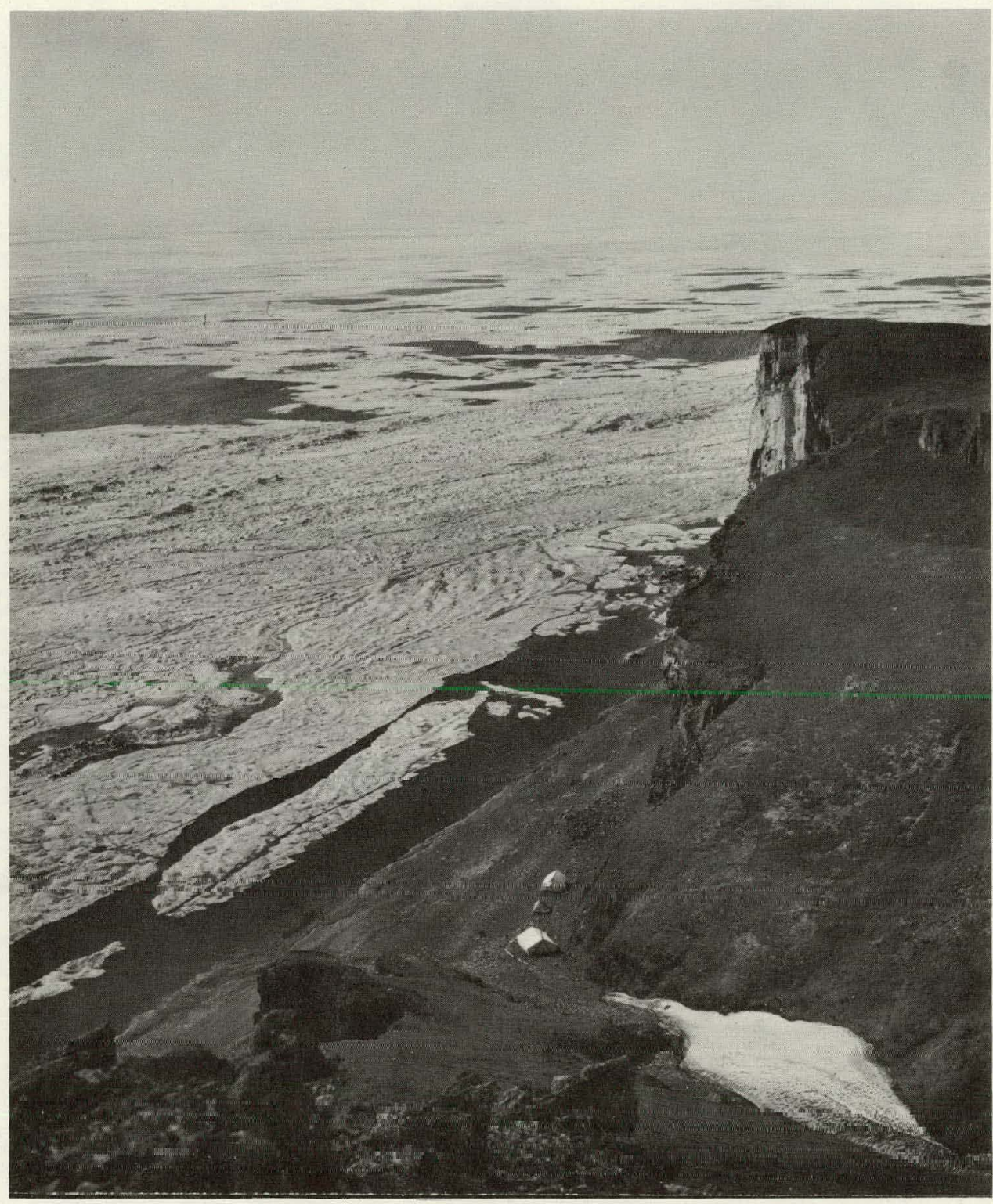

Figure 4. View of Colony 4 showing offshore leads developing as the ice melts. Approximately 12,000 sea birds were occupying these patches of open water on 16 June 1960. 
Esg-laying and Incubation

The first eggs of both thick-billed and common murres were observed on 9 July 1959. In 1960 eggs of both species were found on 27 June. On 26 June, however, two female thickbilled murres were collected, each containing a recently ovulated follicle, indicating that some laying occurred in thick-billed murres before 27 June. In 1961, a common murre egg was seen on 23 June. Thick-billed murre eggs were observed on 24 June. Uspenski (1956) has reported that egg-laying in murres is closely associated with sunshine. Data from Cape Thompson support his conclusions in that bursts of laying occurred in all three years during sunny days following rainy, overcase periods.

Egg-laying continued through the end of July in all years, although many of the late layings represented replacement of eggs by birds which had lost them through falls or predation. The peak of initial laying lasted about 10 days (Fig. 5).

Tuck (1961) has thoroughly discussed the egg and phenomena associated with laying and incubation. No significant departures from what is already known were observed at Cape Thompson. The details need not be repeated here. Both thick-billed and common murres lay a single egg. No nest is constructed, and the eggs are therefore laid on bare ledges, usually in level or depressed areas where the chance of rolling off is reduced. Both adults incubate, and the egg is not normally left unattended by the parents. The close approach of an observer, however, will cause the departure of many incubating birds. The level of disturbance necessary to frighten an incubating adult from the egg is least at the beginning of the incubation period.

Data on the stage of development of the reproductive organs and brood patches throughout the course of the summer were obtained from birds collected at regular intervals in 1960 . At the time of autopsy, testes of males were removed and lengths of the major and minor axes measured. Ovaries were removed 


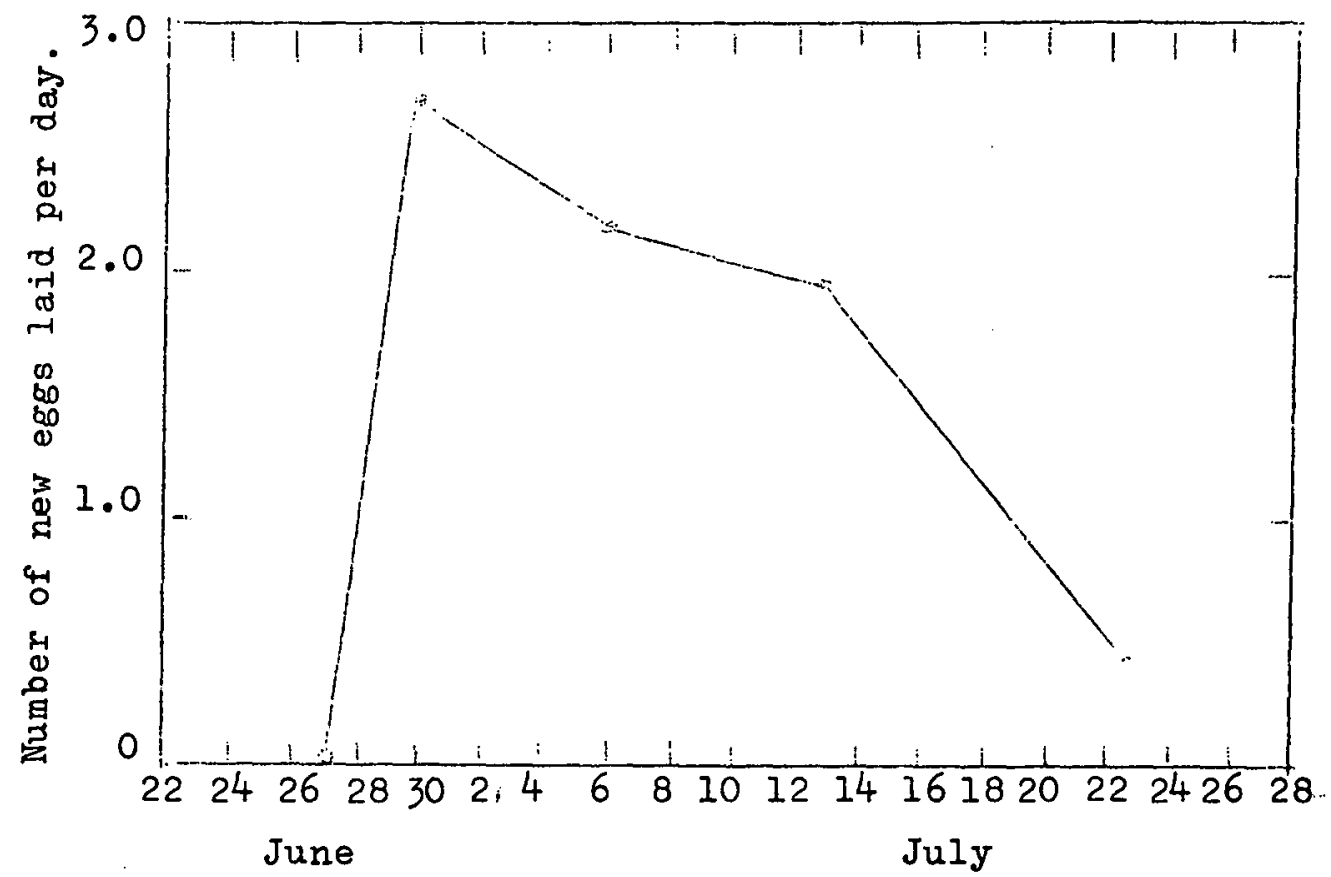

Figure 5. Average number of eggs laid per day on mapped plots by murres at Cape Thompson during the summer of 1960 . 
from females, and the diameter of the largest follicle was measured.

From measurements taken on testes at the time of autopsy, the approximate volume of these organs could be calculated using the formula for a prolate spheriod $\left(V=4 / 3 \pi a b^{2}\right)$. Data on volume of testes of thick-billed murres were summarized for bi-weekly periods over the entire summer (Table 3, Fig. 6)... Maximum development was attained during the first half of June, about two weeks before the first eggs were laid. The volume then declined gradually until in the first part of september values were below those obtained in May. Data for common murres were summarized in the same manner (Table 3, Fig. 7). Data on common murre males are lacking for the early part of the summer, but testes volumes from late June through early September were similar to those of thick-billed murres.

It is interesting that Tuck (1960) observed the earliest copulations at Cape Hay in the Canadian arctic only five days before the first egg was laid. At Cape Thompson, almost two months regularly seems to elapse; and further, copulation at Cape Thompson has been observed occasionally almost until departure of the chicks. This contrasts with the three week "copulation period" of Tuck. "On the grounds that, although copulation virtually ceased in his observations after this three-week period, lost eggs could be replaced with fertile egys for some time, he hypothesized that spermatozoa might live in the female for some time. The decline in testis volume at Cape Thompson, beginning about two weeks before the first laying, is consistent with his hypothesis in that it is likely that copulations after regression of testes had begun would result in transfer of fewer or less vigorous sperms.

Data for diameter of largest ovarian follicles of females was also summarized by bi-weekly periods over the entire summer for both species of murres (Table 4, Fig. 6 and 7). Maximum follicle size occurred in both species during the 
TABLE 3. Volume of testes (in cu. cm.) of male thick-billed and common murres throughout the summer of 1960 at Cape Thompson.

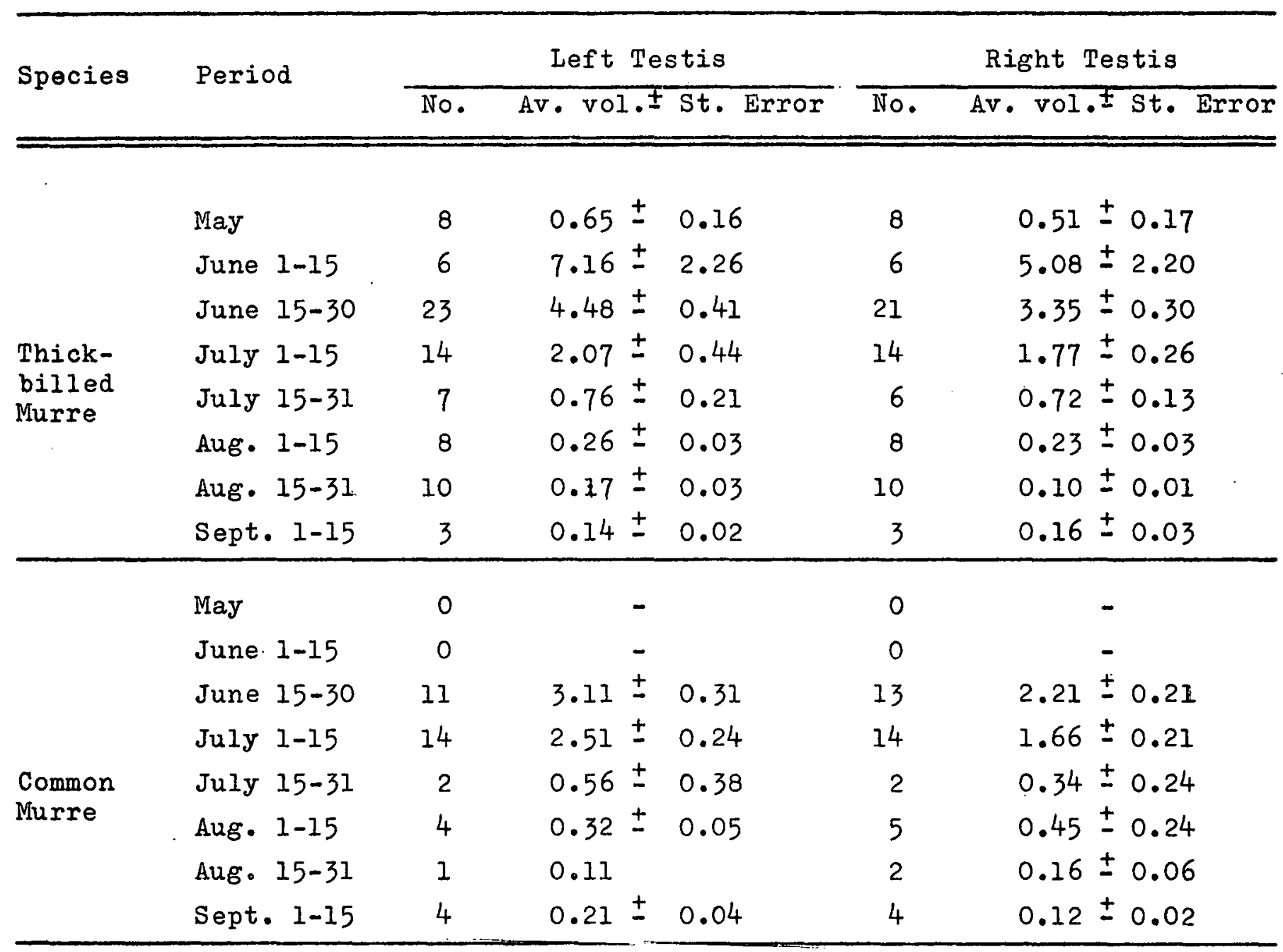




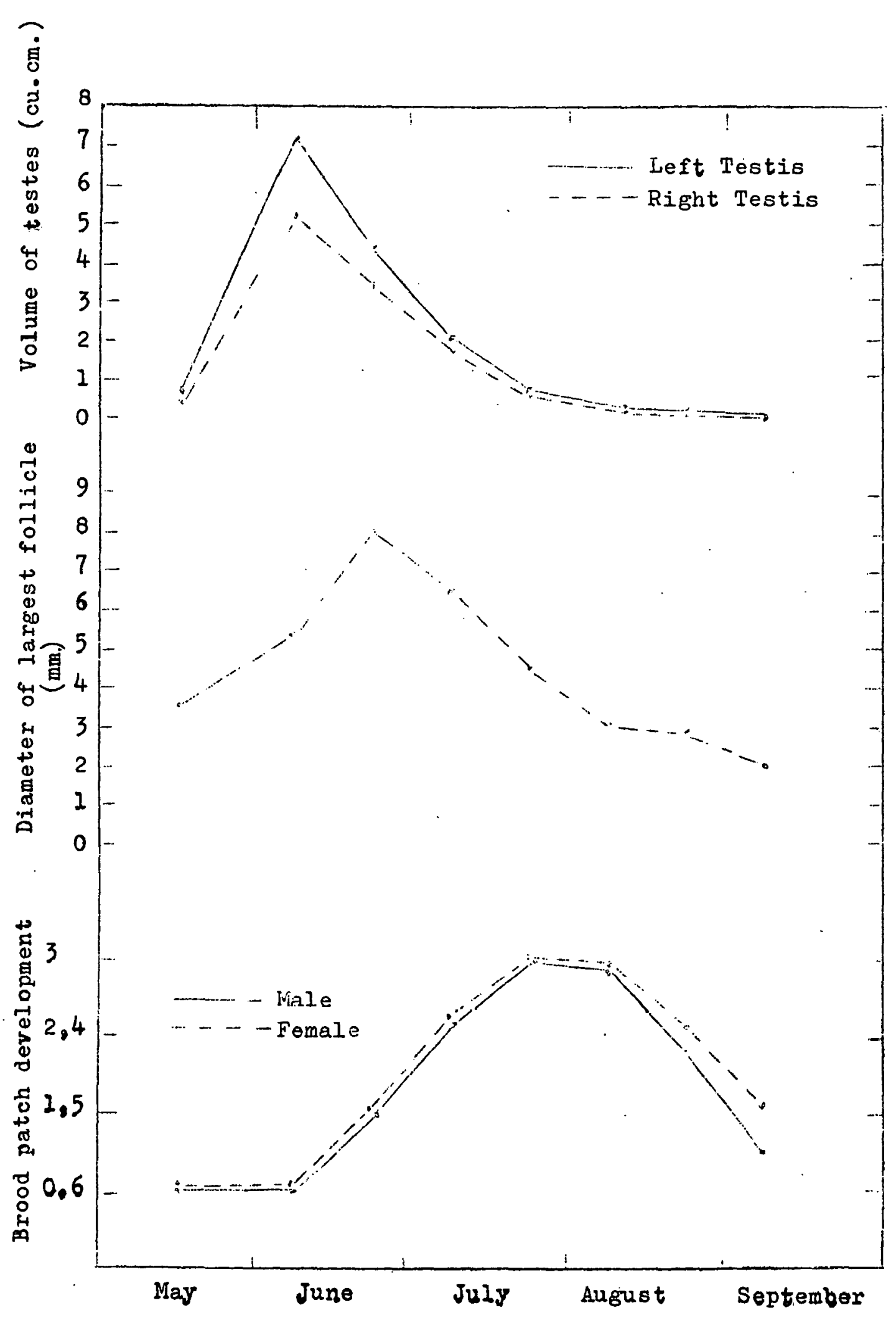

Figure 6. Volume of testes, diameter of largest ovarian follicle and development of brood patch of thick-billed mirres at Cape Thompoon during summer of 1960 


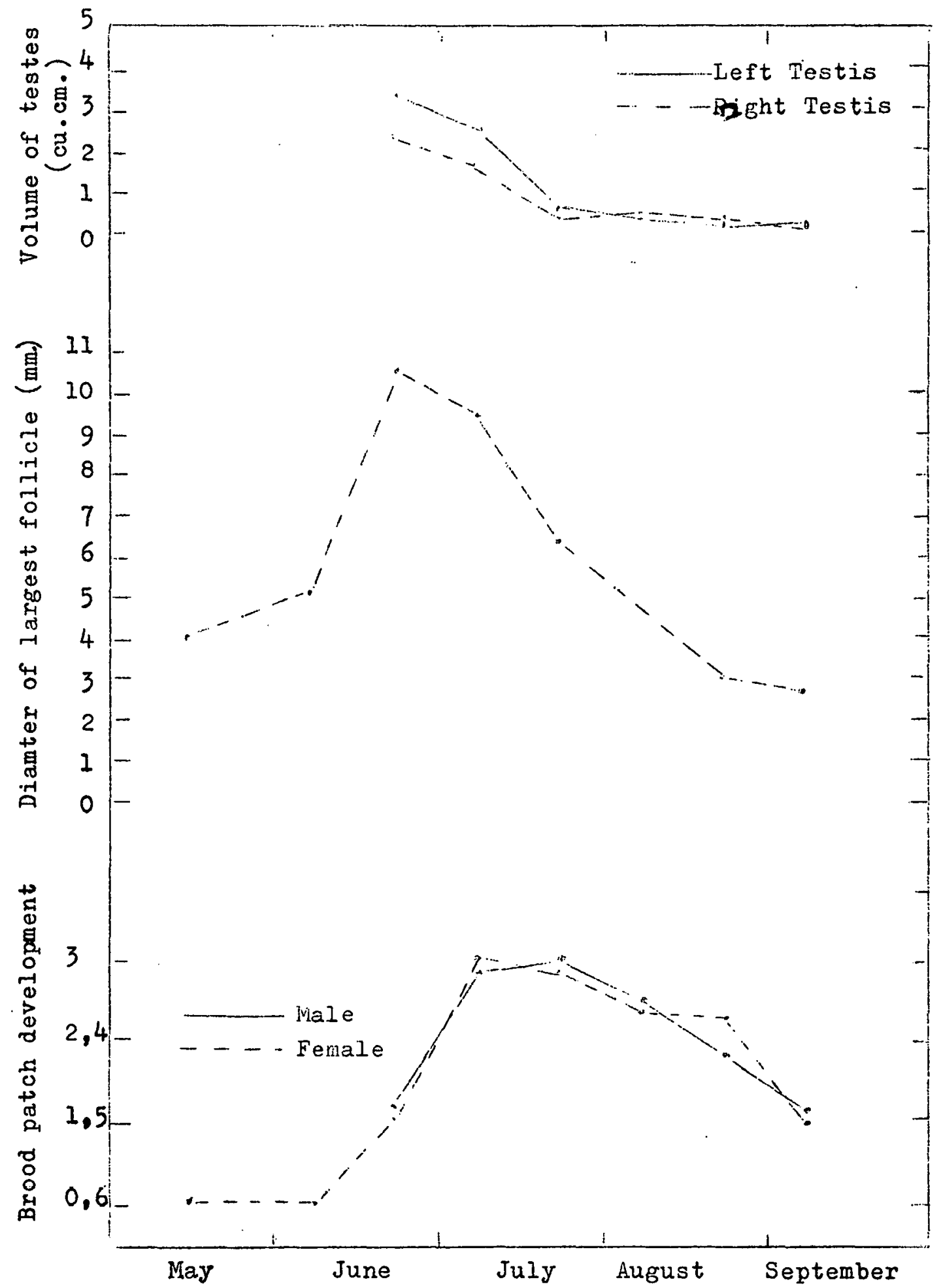

Figure 7. Volume of testes, diameter of largest ovarian folliche and development of brood patch in common murres at Cape Thompson during summer of 1960 
TABLE 4. Average diameter (in millimeters) of largest ovarian follicle of female thick-billed and common murres throughout the summer of 1960 at Cape Thompson

\begin{tabular}{|c|c|c|c|c|}
\hline \multirow{2}{*}{ Period } & \multicolumn{2}{|r|}{ Thick-Billed Murre } & \multicolumn{2}{|r|}{ Common Murre } \\
\hline & No. & Av. diameter $\overline{\text { St. Error }}$ & No. & Av. diameter \pm St.Erro \\
\hline May. & 10 & $3.67 \pm 0.46$ & 3. & $4.13 \pm 0.19$ \\
\hline June $1-15$ & 7 & $5.43 \pm 0.68$ & 1 & 5.1 \\
\hline June $15-30$ & 11 & $8.06 \pm 1.37$ & 8 & $10.54 \pm 1.22$ \\
\hline July $1-15$ & 14 & $6.57 \pm 0.61$ & 6 & $9.47 \pm 1.50$ \\
\hline July 15-31 & 4 & $4.52 \pm 0.45$ & 2 & $6.25 \pm 1.10$ \\
\hline Aug. $1-15$ & 2 & $3.10 \pm 0.40$ & 8 & $4.82 \pm 0.27$ \\
\hline Aug. 15.31 & 4 & $2.88 \pm 0.24$ & 8 & $3.00 \pm 0.19$ \\
\hline Sept. $1-15$ & 7 & $1.99 \pm 0.25$ & 2 & $2.60 \pm 0.00$ \\
\hline
\end{tabular}


last half of June, corresponding to the period when laying began. Follicle size declined after this period. Maximum development of gonads of the two sexes did not occur at the same time.

The stage of development of the brood patches of all adult murres collected was recorded. Measurements of size and drawings of location and appearance were made.

Development began with the loss of feathers on separate, oval areas on either side of the mid-ventral line of the posterior part of the abdomen. As development proceeded, these areas united and formed a single, large brood patch. Brood patches were similar in size and location in males and females and in both species of murres. In thick-billed murres the maximum width, measured along the body curvature, averaged $60.1 \mathrm{~mm}$; and the length, measured along the midline, averaged $34.4 \mathrm{~mm}$. In the common murre the maximum width averaged $57.7 \mathrm{~mm}$ and length $33.4 \mathrm{~mm}$. These measurements are from birds showing maximum development of the brood patch.

Development and regression of brood patches was divided into arbitrary stages and each bird classified on this basis. This scale was based on the following criteria:

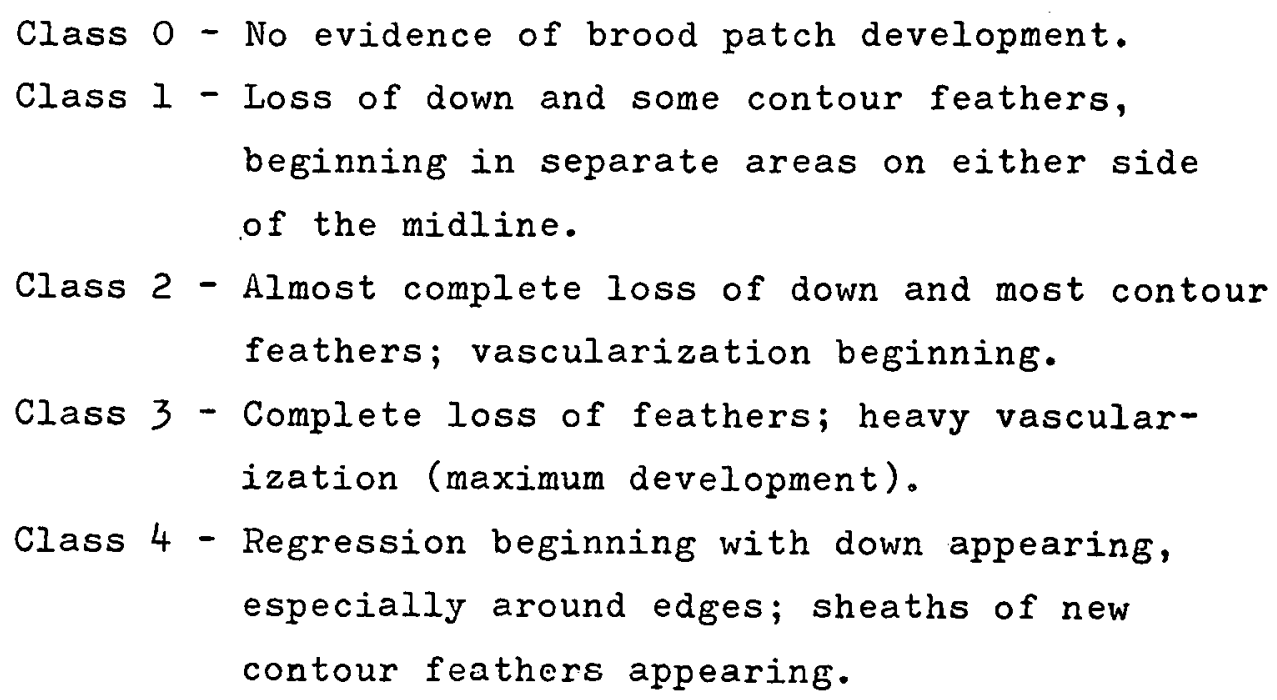


Class 5 - Most of area down-covered, contour feathers beginning to break out of sheaths.

Class 6 - Complete regression, appearance as in class 0 . Stages in development of brood patches of common and thickbilled murres, based on the above classification, were summarized over bi-weekly periods for the entire summer (Table 5, Fig. 6 and 7). Brood patches were absent in males and females of both species during May and the first half of June. Development began in late June and was maximum in most birds throughout July. Development in common murres appeared to be somewhat later, but this difference is probably not significant. Regression began during August, but was not complete by the first week in september when collecting of large numbers of birds was discontinued.

The length of the incubation period was not determined precisely, but observations on marked plots allowed approximate periods to be determined. The period between first observed laying, on 27 June 1960, and first observed hatching, $30 \mathrm{July,}$ was 34 days in the thick-billed murre. The first laying of common murres was 27 June 1960 and the first hatching on 1 August, giving a period of 36 days. Individual incubation periods for birds on mapped plots were determined to within several days. These incubation periods are summarized in Table 6.

Tuck (1960) summarizes incubation times as given by several authors and no doubt rightly, points out that the variable incubation times seen in murres probably are due to both varying assiduity among the parents and differing microclimate between nest sites.

Loss of eggs at Cape Thompson during incubation was heavy in 1959 and 1960, and less so in 1961. The most common cause of egg loss was falling from ledges. Disturbance of birds by approach of observers, and especially by close approach to the cliffs by aircraft, often resulted in loss of 
TABLE 5. Brood patch development of adult thick-billed and common murres of both sexes throughout the summer of 1960 at Cape Thompson (See page 28-29 for description of class values.)

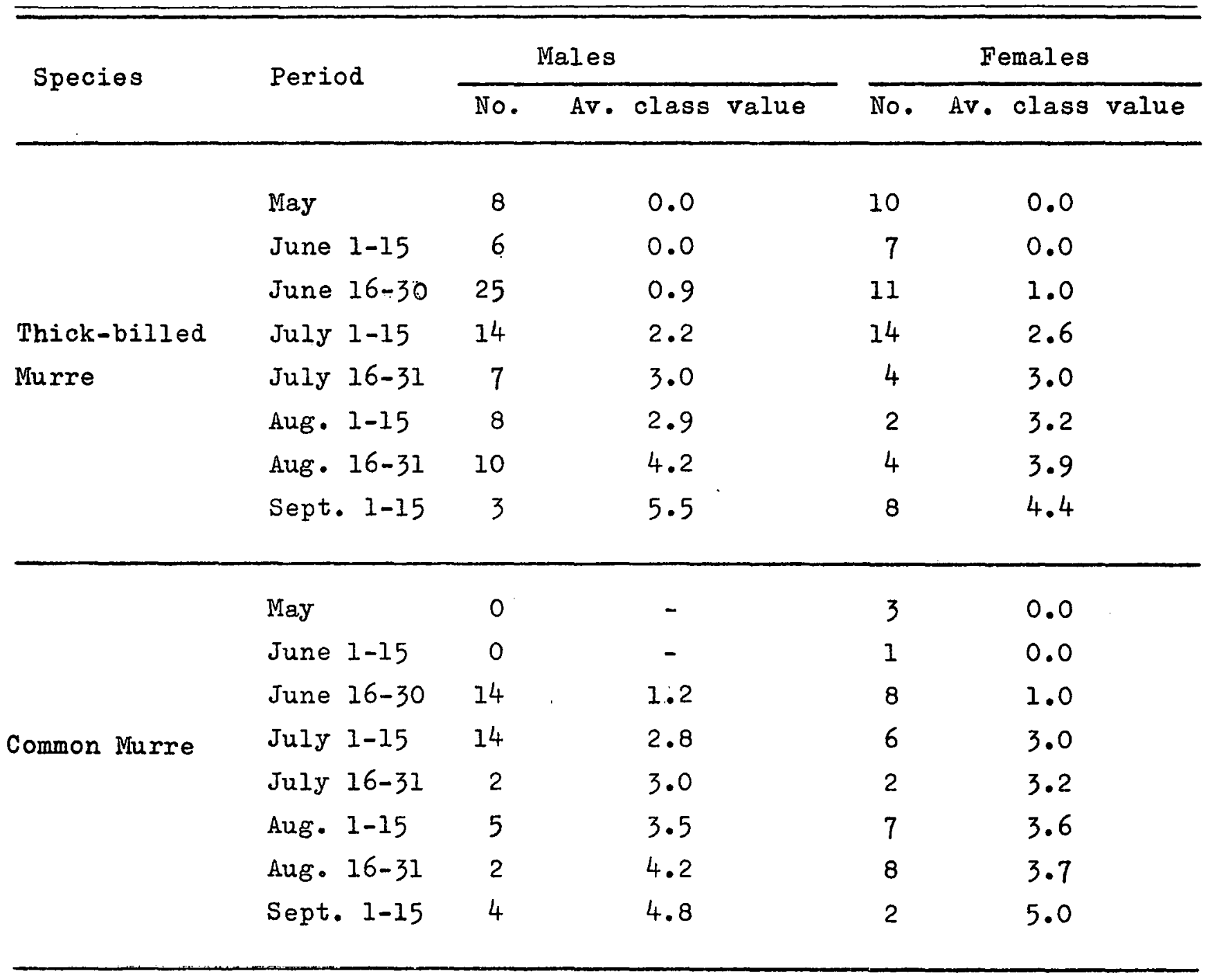


TABLE 6. Individual incubation periods of murres (both species) on mapped plots at Cape Thompson during the summer of 1960

\begin{tabular}{cc} 
Length of period & $\frac{\text { Number of cases }}{6}$ \\
\hline $31-39$ days & 5 \\
$28-37$ days & 3 \\
$28-33$ days & 1 \\
$31-36$ days & \\
\hline
\end{tabular}


large numbers of eggs. Predation by other birds, mostly glaucous gulls and ravens, was a second major cause of egg loss. A number of minor factors were also responsible for some mortality, including predation by foxes and possibly weasels, high winds, falling of eggs into crevices resulting in damage to the egg or inability of the adult to incubate them. High waves during storms washed eggs from low ledges in certain localized areas, but since most murres do not nest below 30 feet, this loss was probably small. The diminished loss in 1961 was probably due to less airplane traffic near the cliffs early in the incubation period.

Eggs lost through falls or predation, or by removal by humans, were often replaced by the birds, especially if the loss occurred soon after the initial laying. Fig. 8 diagrams egg replacement on a ledge from which eggs were removed by Eskimo hunters. On $6 \mathrm{July}$ all eggs present, approximately 87, were taken. New eggs were found on the ledge during the succeeding few days, although these probably represented some initial layings. The rate of replacement was greatest between 19 July and 5 August, indicating that replacement in most cases does not occur until about two weeks after loss. Similar observations were made by Uspenski (1956) and Tuck (1960).

\section{Hatching and Ledge-life of the Chicks}

The first hatching of thick-billed murres was recorded on 11 August in 1959, on $30 \mathrm{July}$ in 1960, and on $27 \mathrm{July}$ in 1961. Common murre chicks were first observed on 11 August in 1959 and on 1 August in 1960. In 1961 a severe storm prevented certain determination of the first common murre hatching but it probably occurred on 31 July. Pipping of the eggs was noted 1-2 days before final emergence in several cases. 


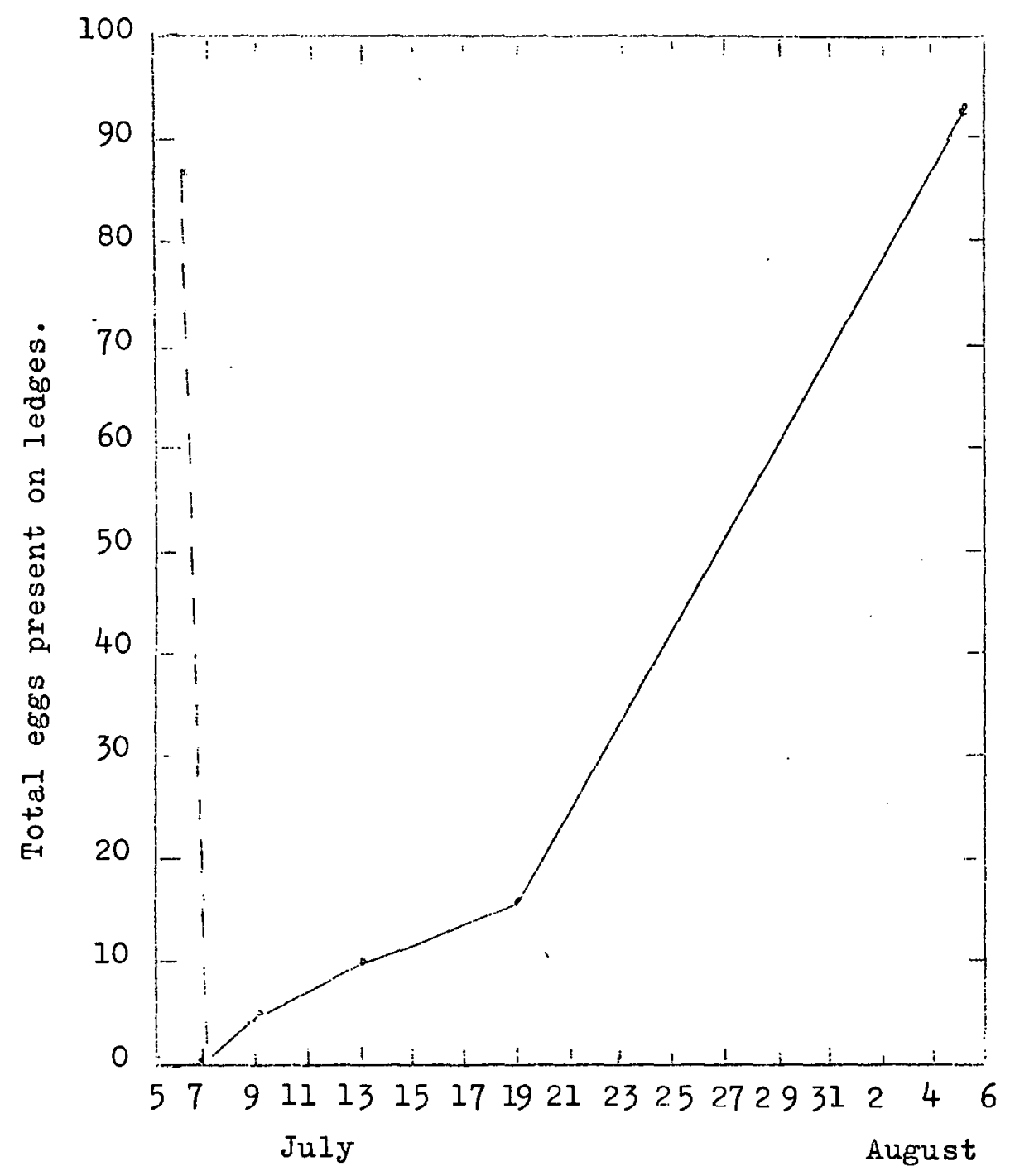

Figure 8. Replacement by murres of eggs removed by Eskimo hunters from ledges at Cape Thompson on 6 July, 1960 
Hatching continued in all three years through the first week of September. Many of these late hatchings were the result of replacement layings by adults which had lost eggs. The peak of hatching occurred during about 10 days (Fig. 9).

At hatching the chick is covered with a thick coat of down, and it is able to move short distances soon after hatching. Mortality is high during the first few days after hatching due to falling of chicks from the nest ledges.

Both parents. feed and brood the chick. The chick is not normally left unattended except for brief periods when the chick is nearing the age of departure from the ledges. Whole fish were fed to the chicks, and, in all cases observed, only a single fish was brought to the chick at one time.

Chicks remained on the ledges approximately three weeks. The length of this period was determined for a number of marked chicks, and was between 19 and 25 days for the thick-billed murre. Two common murre chicks remained on the ledges for at least four weeks, suggesting a somewhat longer period of occupation for this species. Data from these marked chicks are summarized in Table 7 .

Departure of Chicks from the Cliffs

Murre chicks leave the ledges at a relatively early stage of development. The down feathers have not been completely replaced by contour feathers, and the primary feathers of the wing are still incompletely developed. Although no attempt was made to follow the development of the chicks in detail, measurements and weights were obtained from a number of chicks collected in the process of leaving the ledges (Table 8 ). Common murre chicks showed heavier average weights and greater development of the primary feathers at the time of fledging. 


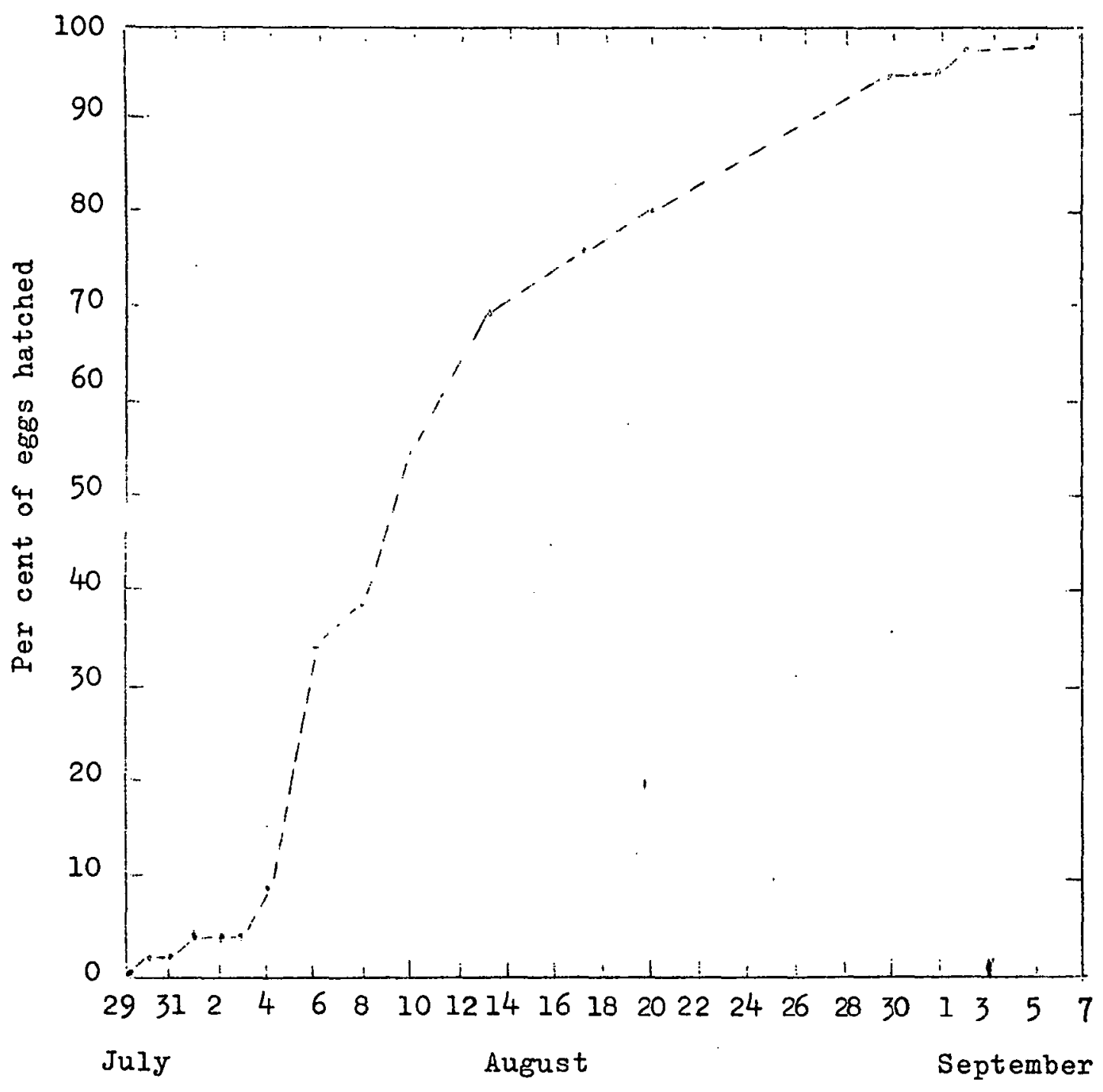

Figure 9. Percentage of eggs of thick-billed and common murres hatched on mapped plot from late July to early September, 1960, at Cape Thompson 
TABLE 7. Duration of ledge occupation by marked murre chicks at Cape Thompson during the summer of 1960

\begin{tabular}{lcc}
\hline \hline \multicolumn{1}{c}{ Species } & Length of occupation & Number of cases \\
\cline { 2 - 3 } & $20-23$ days & 4 \\
Thick-billed & $22-23$ days & 1 \\
murre & $22-24$ days & 1 \\
& $22-25$ days & 1 \\
& $19-24$ days & 1 \\
Common murre & $20-23$ days & 1 \\
& $28+$ days & 2 \\
\hline
\end{tabular}


TABLE 8. Average weights and measurements of thick-billed and common murre chicks collected while leaving ledges at Cape Thompson during the late summer of 1960

\begin{tabular}{lcccccc}
\hline \hline Species & No. $\begin{array}{r}\text { Weight } \\
\text { (grams) }\end{array}$ & $\begin{array}{c}\text { Culmen } \\
(\mathrm{mm})\end{array}$ & $\begin{array}{c}\text { Nostril } \\
\text { to bill- } \\
\text { tip (mm) }\end{array}$ & $\begin{array}{c}\text { Tarsus } \\
\text { (mm) }\end{array}$ & $\begin{array}{c}\text { Length of } \\
\text { (mm) }\end{array}$ \\
\hline $\begin{array}{l}\text { Thick-billed } \\
\text { murre }\end{array}$ & 6 & 121.5 & 18.4 & 13.5 & 31.1 & 27.7 \\
$\begin{array}{l}\text { Common } \\
\text { murre }\end{array}$ & 4 & 179.9 & 19.5 & 14.6 & 32.9 & 34.6 \\
* length out of sheath & & & & & \\
\hline
\end{tabular}


The greater weight of common murres when entering the water may be related to the longer period of cliff occupation of chicks of this species (see previous section). Uspenski (1956) has noted similar differences in weights of chicks of the two species, and he states that considerable variation in weight at departure is shown in different localities. Tuck (1960) comments similarly on the latter point and believes that differences in climate and resulting variation in diversion of energy to thermoregulation may be the cause. Both authors indicate that chicks tend to lose weight during the few days preceding departure. Although detailed data were not obtained on this point at Cape Thompson, it should be noted that a thickbilled murre chick collected from a ledge on 19 August 1960, weighed 183.1 grams, which was well above the average for departing chicks of the species (see Table 8). Pennycuick (1956) did not observe any decrease in feeding rate of thickbilled murre chicks preceding departure.

In 1959 departure of thick-billed murre chicks was first noted on 25 August, in 1960 on 18 August, and in 1961 on 19 August. The first common murre chick departure was noted on 26 August in 1960 and on 24 August in 1961, though it is probable that some departures took place before these dates. Departure of murres continued at least through 7 September in 1959 when the field party left. In 1960 the last chicks were seen on 17 September. Adults of both species were observed as late as 23 September 1960 and it is probable that these birds were tending chicks until this date. Though detailed late-season data could not be gathered in 1961, counts of adult murres on the cliffs indicated that at least some chicks were probably still present on 17 September. (See Fig. 10 for the pattern of chick departure in 1960.)

Departures took place in greatest numbers in the evening hours, typically between about 1800 and 2300 hours Bering Standard Time, reaching a peak at about 2100 to 2200 hours. It seemed possible that the plunge of the chicks from the ledges 


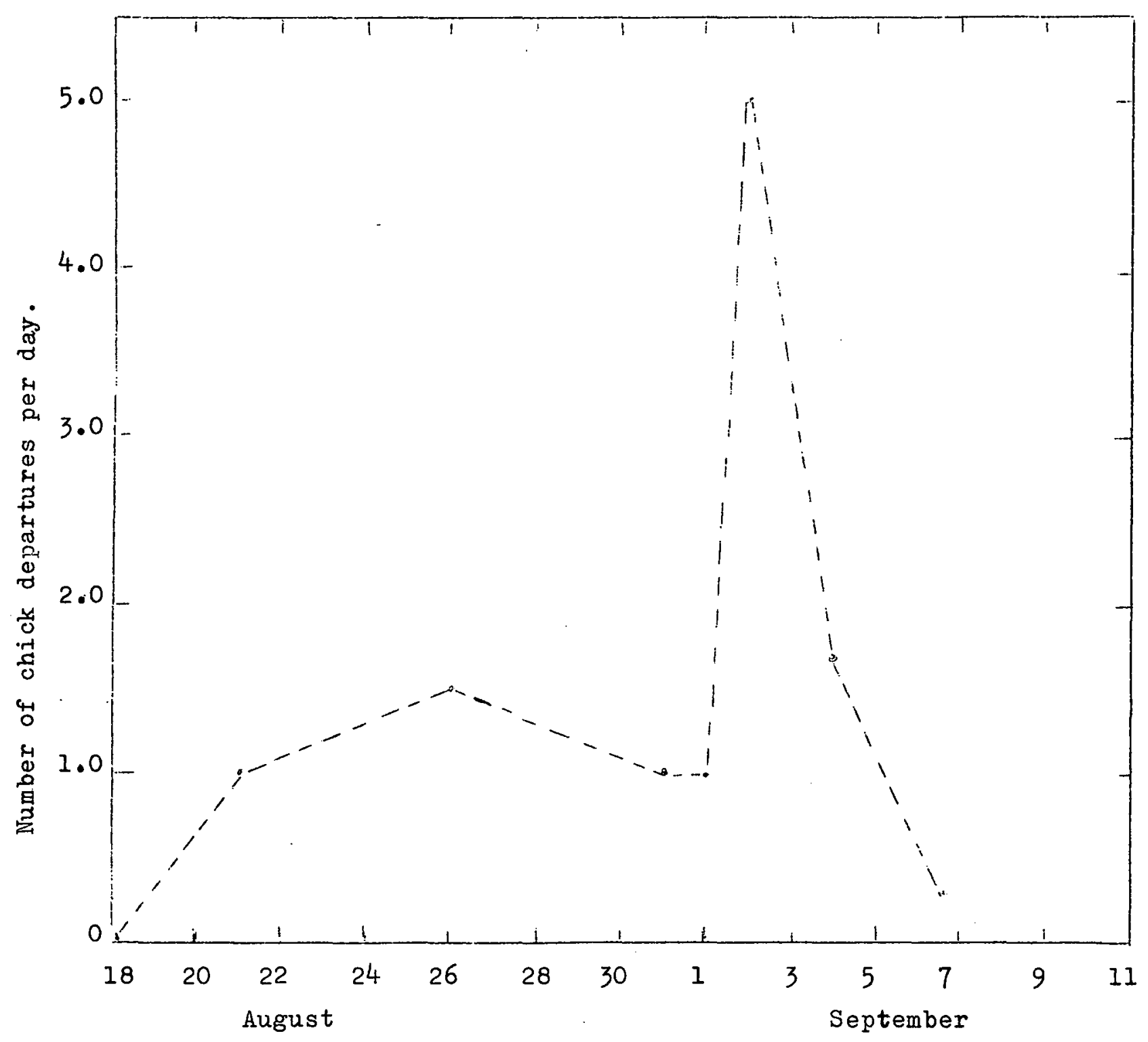

Figure 10. Average number of murre chick departures per day on mapped plots during late August and early September, 1960, at Cape Thompson 
might be correlated with diminishing light intensity. Chicks were captured, banded, and counted as they departed on 21 and 23 August 1960, and on 25, 26, and 30 August 1961. These data were plotted against readings of light intensity taken with a Weston Master III light meter (see Fig. 11). The aggregate of these observations, however, do not clearly demonstrate that diminishing light intensity triggers departure, since departure on cloudy days begins at about the same clock hour and follows essentially the same pattern as it does on clear days. Further, departure seems to occur in greater numbers on clear evenings. The advent of dawn does not produce a significant increase in departures.

The actual departure of chicks has been discussed by a number of observers (Perry, 1940; Kay, 1947; Keighly and Lockley, 1948; Pennycuick, 1956; Uspenski, 1956; Tschantz, 1959; Tuck, 1960) and will not be described here.

Mortality of chicks during departure from ledges was high. The chicks are protected by a heavy pad of feathers on the breast, and although most birds landing on the beach were uninjured, some chicks died of injuries sustained when they struck the beach in areas of loose, angular rock. Probably the greatest cause of mortality, however, was failure of the chicks to become reunited with adults. This was most noticeable in cliff areas where many of the chicks were unable to fly directly into the water, and thus became separated from adults. These chicks frequently returned to shore in a weakened condition or died in the water and were washed ashore. Some mortality was apparently due to premature departure from the cliffs. 

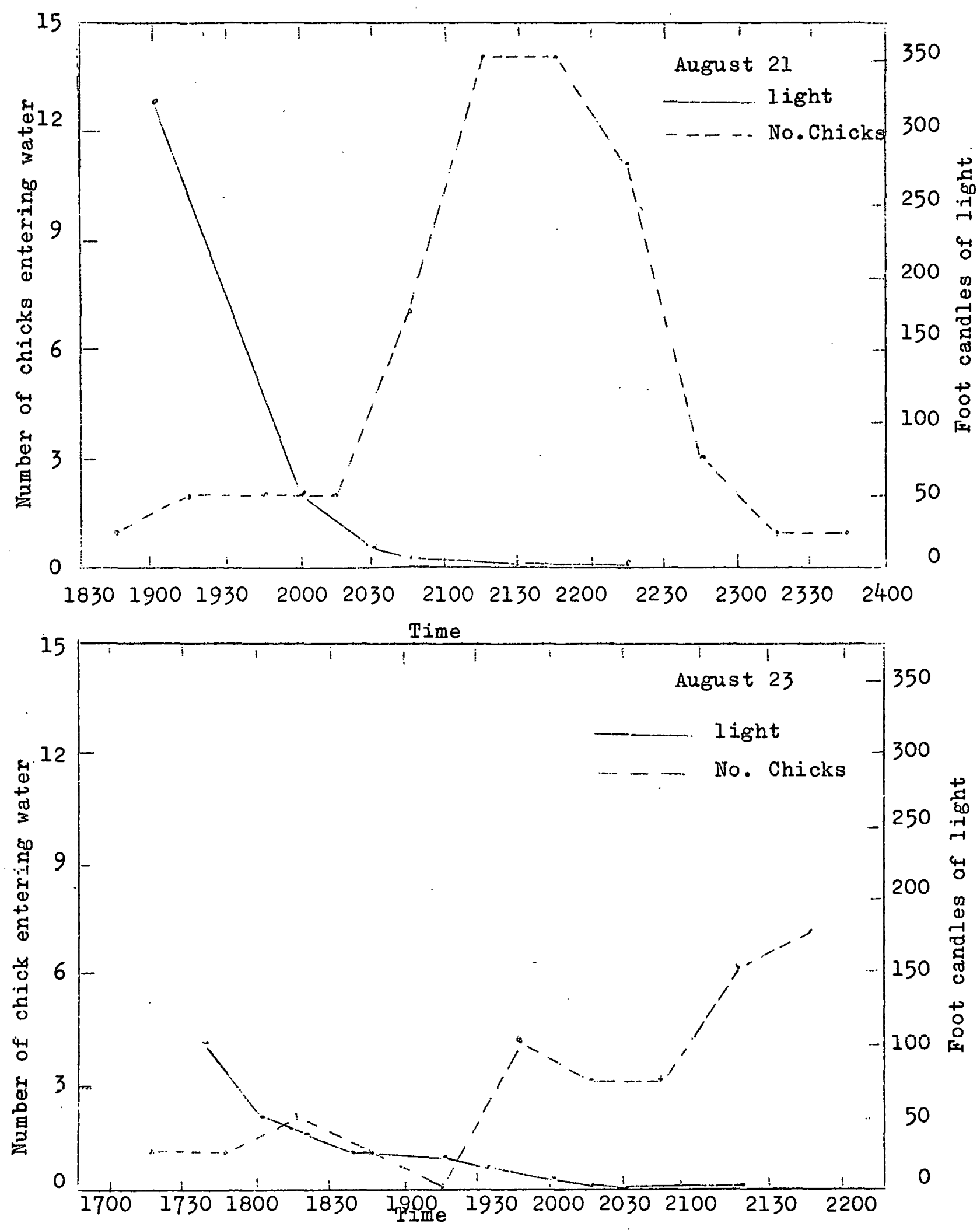

Figure 11. Numbers of murre chicks entering water in relation to time of day and light intensity on August 21 and 23, 1960, along a limited section of beach at Cape Thompson 
Breeding Success

No completely reliable data were obtained on breeding success of murres since human interference, primarily by Eskimo egging parties, occurred on the murre plots every year. Egg mortality (destruction or loss of the original egg) in 1961 was 36.9 per cent of 83 eggs on one plot in Colony 3 and 26.8 per cent of 100 eggs on one plot in Colony 4. On eight plots which were egged, mortality of the replacement eggs was 51.4 per cent of 29 eggs on one plot in Colony 4 and 28.7 per cent of seven plots in Colony 3. No good data were obtained on hatching success or fledging success.

\section{Mortality}

Mortality of adult murres was primarily traceable to rock falls. Because of the varying stability of the rocks, mortality varied from colony to colony. In 1960 all dead or injured murres along the beach below Colony 5 were counted and removed at intervals from 12 June to 7 september. Due to scavenging by glaucous gulls, heads were frequently separated from the bodies, so separate tallies were made. In 1960 a total of 439 identifiable individual thick-billed murres and 36 common murres were found on the beach of Colony 5. The contributing population according to the 1960 census was 208,000. These mortality data do not represent the total rock-fall mortality, since many, perhaps most, injured birds succeed in reaching the water and swim out to sea to die later. Some of these ultimately are blown back to land but to widely scattered locations. Also, many birds died earlier than 12 June; prior to this date, many widely scattered carcasses which could not be counted were seen on the ice. These carcasses mostly went to sea wilh the ice in early July. It should be noted that Colony 5 is situated on the most unstabie cliffs, and mortality as judged by carcasses on the 
beach was much higher here than in the other colonies.

Although the Colony 5 beach was not patrolled regularly in 1961, it was clear that mortality from rock falls was considerably lower than in the previous year, probably due to less wind and rain on the cliffs which in turn directly influence rock falls.

Mortality of chicks was judged in the same way and in 1960 2,962 were counted until 7 September. Chicks of the two species of murres were not differentiated. Most of these deaths represented birds which were apparently old enough to have successfully gone to sea but which died in the attempt.

Mortality of both adults and young is also caused by factors other than rock falls. Eagles, gyrfalcons, and peregrine falcons prey on adult murres. The young as well as the eggs of murres furnish the primary items in the diet of glaucous gulls during the egg and chick soason. Ravens prey on eggs and young. It is likely that foxes and weasels prey. on eggs and young, though this was not directly observed.

Black-legged Kittiwake

Weights and Measurements

Measurements of culmen length, distance between nostril and bill tip, wing length (flattened), and tarsus length were taken on all adult birds collected. These are summarized in Table 9. Average values for these measurements were in all cases significantly greater $(0.01$ level) in males than in females. These differences, along with the greater average weight of males (see below) indicate a slight sexual dimorphism in body size in kittiwakes. Ranges of all of these measurements, however, showed a high degree of overlap, and it was therefore not possible to use them in sexing live birds.

Coulson and White (1958a) have noted a similar difference 
TABLE 9. External measurements (in millimeters) of black-legged kittiwakes collected at Cape Thompson colonies during 1960

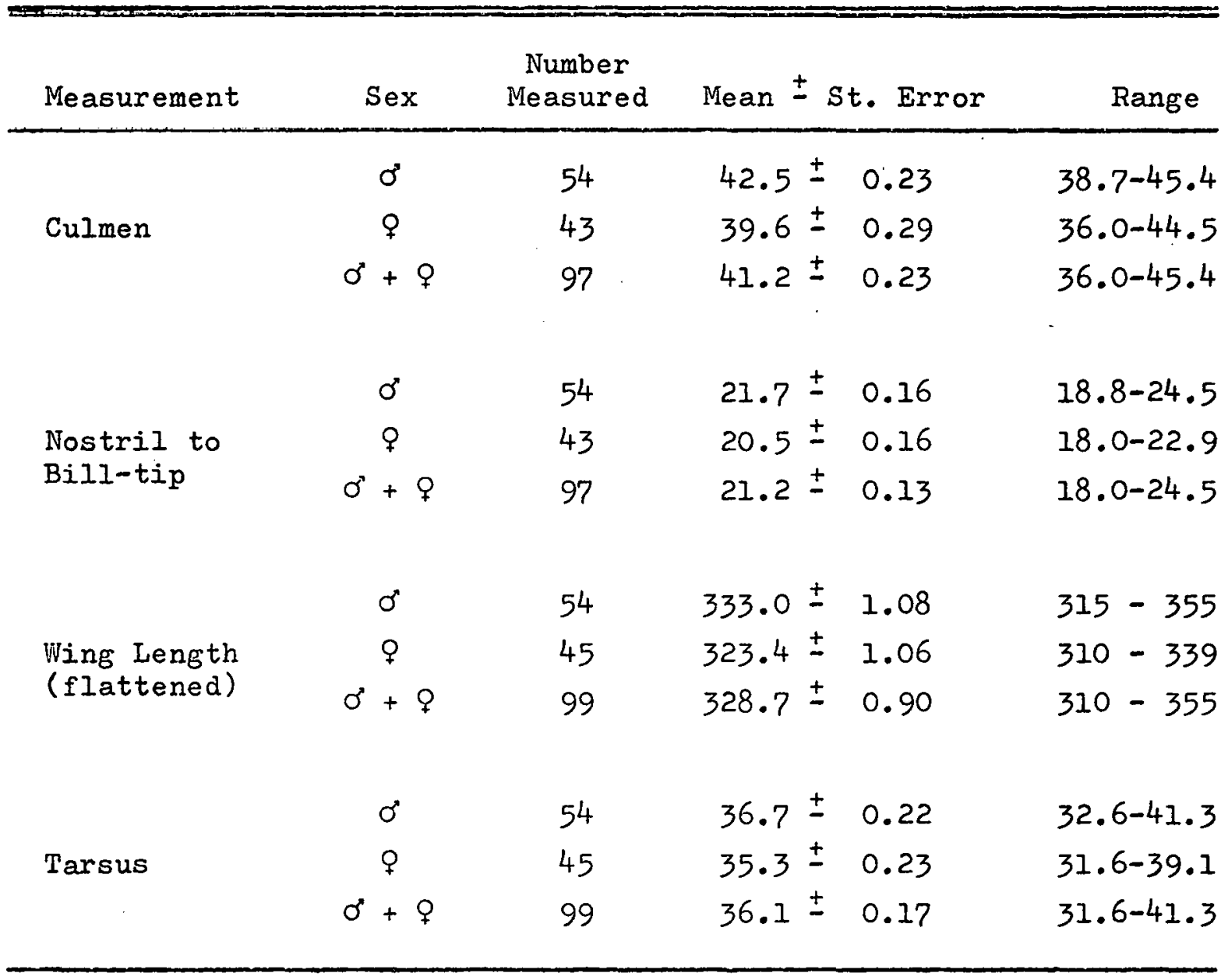


in wing length of birds in Great Britain. A total of 26 males and 20 females gave average wing lengths of 305.5 and $296.9 \mathrm{~mm}$, respectively. These workers also report that measurements of wing length of ten birds of each sex in the British Museum gave values of $307 \mathrm{~mm}$ for males and $298 \mathrm{~mm}$ for females. The difference in magnitude between the measurements of these workers and those in the presint study may in part be due to differences in the technique of taking the measurement.

Weights were taken on all adult kittiwakes collected. These are summarized by sexes for bi-weekly periods and for the summer as a whole in Table 10, and are shown graphically in Fig. 12.

In males the lowest average weight was recorded in late May, shortly after the birds first arrived at the cliffs (441.2 grams for three birds). Weights of males then increased to near 500 grams and remained high through the summer and at least into September (Fig. 12)。 The pattern was somewhat different in females, During May and early June weights averaged about 420 grams, well below the average for the entire summer. During late June weights increased to about 474 grams. After this period they declined and remained below average for most of the rest of the summer period. In October two females taken averaged 376.6 grams as compared to the weight of 532.8 grams for one male taken at the same time. Part of the loss in weight during early July may well have represented losses connected with egg-laying. The continued low weight may be correlated with the observation that females spend more time in incubation than do males (see below).

For the summer as a whole, males averaged 489.1 grams while females averaged only 442.9 grams. This difference is significant ( 0.01 level) and further emphasizes the difference in size of the sexes. 
TABLE 10. Average weights in grams of adult male and female black-legged kittiwakes throughout the summer of 1960 at Cape Thompson colonies

\begin{tabular}{|c|c|c|c|c|}
\hline Sex & Period & $\begin{array}{l}\text { Number } \\
\text { Weighed }\end{array}$ & Av. Wt. $\pm s t$. Error & Range \\
\hline Males & $\begin{array}{l}\text { May } \\
\text { June } 1-15 \\
\text { June } 16-30 \\
\text { July } 1-15 \\
\text { July } 16-31 \\
\text { Aug. } 1-15 \\
\text { Aug. } 16-31 \\
\text { Sept. } 1-15 \\
\text { Sept. } 16-30 \\
\text { Oct. } 1-15\end{array}$ & $\begin{array}{r}3 \\
6 \\
10 \\
11 \\
4 \\
4 \\
6 \\
8 \\
0 \\
1\end{array}$ & $\begin{array}{l}441.2 \pm 10.4 \\
478.9 \pm 10.8 \\
490.8 \pm 12.7 \\
486.6 \pm 8.2 \\
493.5 \pm 29.5 \\
526.9 \pm 22.7 \\
479.7 \pm 18.2 \\
496.6 \pm 14.8 \\
532.8\end{array}$ & $\begin{array}{l}425.2-460.7 \\
431.5-506.0 \\
428.0-558.0 \\
440.7-518.7 \\
438.0-572.0 \\
474.8-585.0 \\
423.0-556.0 \\
449.0-567.0 \\
- \\
-\end{array}$ \\
\hline Total & Summer & 53 & $489.1 \pm 5.4$ & $423.0-585.0$ \\
\hline Females & $\begin{array}{l}\text { May } \\
\text { June } 1-15 \\
\text { June } 16-30 \\
\text { July } 1-15 \\
\text { July } 16-31 \\
\text { Aug. } 1-15 \\
\text { Aug. } 16-31 \\
\text { Sept. } 1-15 \\
\text { Sept. } 16-30 \\
\text { Oct. } 1-15\end{array}$ & $\begin{array}{r}1 \\
4 \\
14 \\
10 \\
4 \\
1 \\
4 \\
4 \\
0 \\
2\end{array}$ & $\begin{array}{l}421.7 \pm \\
415.6 \pm 16.3 \\
473.7 \pm 9.1 \\
449.9 \pm 9.7 \\
429.5 \pm 23.3 \\
455.5 \pm 10.2 \\
406.3 \pm 13.2 \\
429.7 \pm 13 \\
=-5=5.1 \\
376.6 \pm 5\end{array}$ & $\begin{array}{l}383.0-448.0 \\
410.0-540.0 \\
418.0-501.5 \\
385.0-489.0 \\
-379.0-428.0 \\
403.0-548.0 \\
371.5-381.7\end{array}$ \\
\hline Total & Summer & 44 & $442.9 \pm 6.1$ & $371.5-540.0$ \\
\hline $\mathrm{All} \mathrm{Bi}$ & Summer & $9 ?$ & $468.1 \pm 4.7$ & $371.5-585.0$ \\
\hline
\end{tabular}




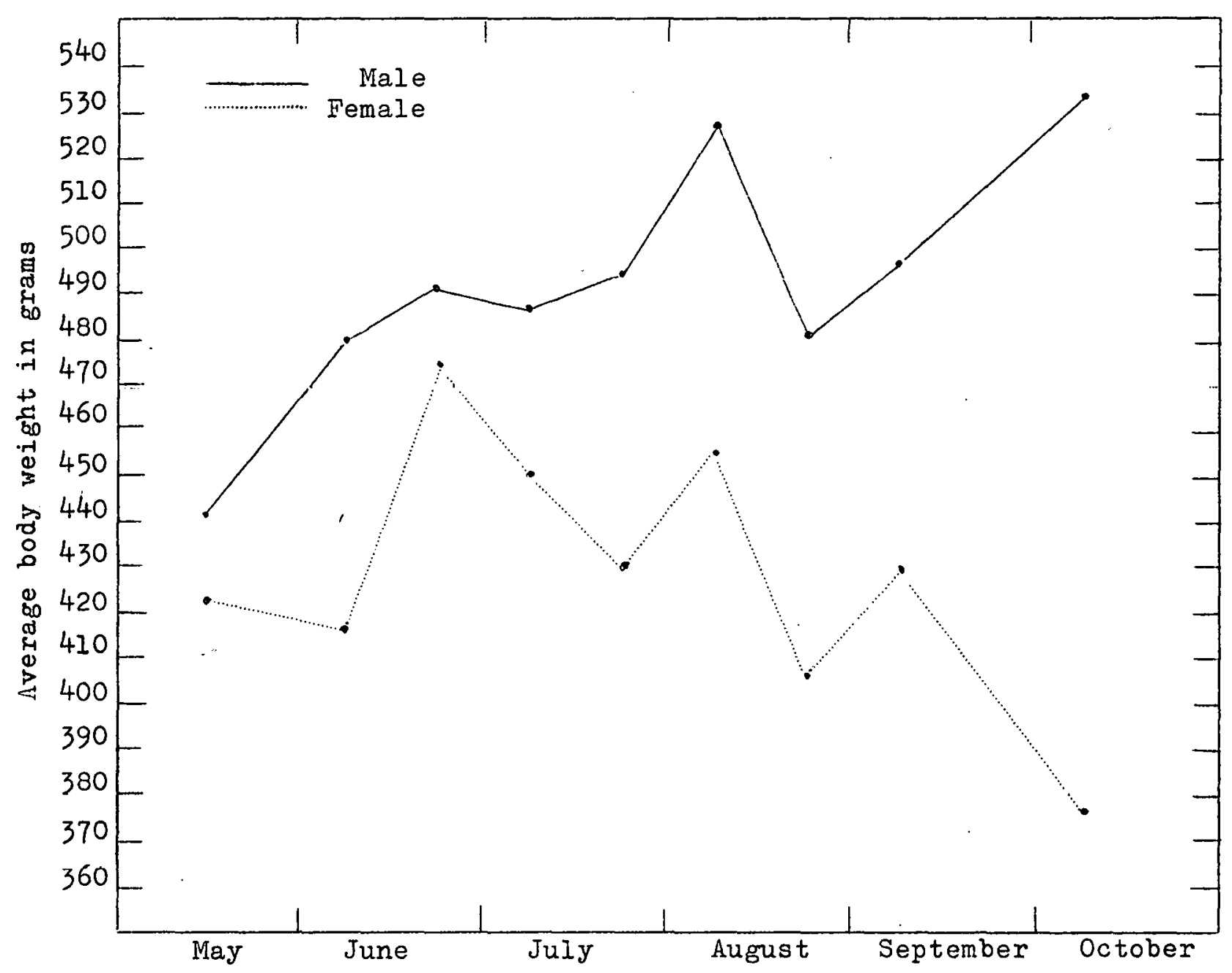

Figure 12. Average weights of adult male and female black-legged kittiwakes at Cape Thompson colonies during summer of 1960 
Plumage and Molt

For a complete description of the sequence of molts and plumages of the black-legged kittiwake, the reader is referred to Gabrielson and Lincoln (1959) or Witherby, et al. (1941).

All adult birds were in full breeding plumage upon arrival at the cliffs in late May. This plumage was retained throughout the summer. The post-nuptial molt apparently began in Cape Thompson birds about 25 August 1960 or shortly before. On this date four males and three females were found to be in various stages of feather replacement. All showed some replacement of contour feathers, and two of them were in the process of replacing one or two of the primary wing feathers. Three individuals collected on 26 August also showed contour feather replacement. The post-nuptial molt apparently continued into October in at least some individuals. On 2 october one was noted to be in the process of replacing the primary wing feathers, while a second had apparently completed this replacement. A male collected on 7 October showed evidence of molt, but was probably a non-breeding bird (second summer bird).

\section{Winter Range and Spring Migration}

The winter range of this species is poorly known since the birds are primarily pelagic during the non-breeding season. Scattered winter records suggest that Alaskan birds winter at sea from the Aleutians southward (Gabrielson and Lincoln, 1959). It is apparently a common winter visitor off the coasts of Washington and Oregon, and more rarely, off California (ibid.). Shuntov (1961) observed large numbers of black-legged kittiwakes in Bristol Bay and describes the distribution and movements of these birds. As in the case of murres, it is possible that Cape Thompson birds are represented, though none of the large flights 
described by Shuntov seem likely to have been headed north of the Bering Strait.

Kittiwakes were first seen at the cliffs on 18 June in 1959, but may have been present in the area on my arrival on 16 June. In 1960 they arrived on 25 May and in 1961 on 22 May.

\section{Pre-Nesting Period of Cliff Occupation}

In 1960 a good opportunity for offshore observation occurred. On 21 May two large flocks of kittiwakes were seen from a plane on an area of open water close to the cliffs. Other large flocks were seen on the same day in an open lead about 15 miles offshore from the cliffs. Apparently few, if any, of the individuals noted on 21 May were actually occupying the cliff ledges. No kittiwakes were seen from 22 to 24 May but on 25 May large numbers were noted occupying the nesting ledges. Thus, in 1960 large numbers of individuals apparently arrived in the area on $2 I$ May or shortly before, and within a few days began occupying the cliff ledges.

This pattern of arrival apparently differs with geography and in different years in the same area. Uspenski (1956) states that kittiwakes appear along the coasts of Novaya Zemlya in flocks long before they occupy the actual colonies. Between 1948 and 1950 he found that arrival on the coasts occurred about two months before laying began. It was also noted that on Novaya Zemlya the ledges are often covered with snow at the time of the arrival of the birds, and that ledge occupation does not occur until these areas melt free. Witherby, et al. (1941) state that nesting cliffs in the British Isles are visited beginning in late February to the second week in March, but that the birds do not "settle in" until late March or midApril. Cullen (1957), working in the Farne Islands in England, states that males occupy the nesting ledges immediately after 
arrival from their winter quarters, an observation similar to that in the present study.

At Cape Thompson the stable zone of sea ice immediately off the cliffs may discourage close approach to shore until open holes appear. Hence, variability in sea ice conditions may be the dominant factor here.

The pre-nesting period of cliff occupation lasted until 25 June in 1959, 13 June in 1960, and 18 June in 1961 when vigorous nestbuilding began. From arrival to initiation of nest-building the birds were occupied with pairing and nest site selection. Uspenski (1956), however, states that in Novaya Zemlya the birds begin to build or repair nests immediately after the first occupation of the nest sites.

A strong development of colony and nest-site tenacity has been shown for this species by other workers. In the British Isles, Coulson and White (1958a) have shown that breeding birds almost always return to the same colony to breed in subsequent years. Birds marked as non-breeders (chicks and second summer birds) showed a lower degree of colony tenacity, but even with these individuals the majority returned to the natal colony to breed.

Nest-site tenacity is well-developed among breeding individuals. Out of 66 breeding birds banded in one year, Coulson and White (ibid.) found that only 23 changed the nest location in the following breeding season. They also found that this nest-site tenacity increased with the number of seasons that an individual had bred.

Pairing is accomplished during the pre-nesting period chiefly through an advertising display of the male (Cullen, 1957). Males occupy the ledges first and advertise with the "choking" display, a behavior pattern found in many gulls. In the kittiwakes this display is unique in serving the function of advertisement. A complete discussion of the nature, function, and origin of this display is given by Cullen (1957). 
While the males are occupying the ledges, females which are unpaired congregate in groups near the nesting areas (Cullen, ibid.). At Cape Thompson individuals (presumably unpaired females) utilized pools of water near the cliffs and the narrow strip of open water along the shore at the base of the cliffs.

At Cape Thompson the formation of the pair bond occurred in most individuals soon after arrival. Copulations were first noted in 1960 on 2 June and in 1961 on 12 June. Copulations were observed frequently from these dates on. Initial copulations were not observed in 1959. Coulson and White (1958a) have noted that over 50 per cent of the adults breeding for at least the second time retained the same mate as during the previous season.

It should be noted that there is a large variation both in arrival of individuals of different age groups during the same season and in the time of arrival of the first individuals at a colony in different seasons. In Northumberland, England, Coulson and White (1958a) found that birds with previous breeding experience. arrived on the average on 9 March, those breeding for the first time on 14 April, and non-breeding birds not until 4 July. Thus, there may be a spread of over a month in the time of arrival of all the breeding individuals in a given season.

Variation in time of arrival in different years is also great. Belopolski (1957) has summarized dates of arrival over periods of years in colonies located in the Barents Sea. At the Seven Islands Preserve on the eastern Murmansk coast over a five-year period, the first arrival varied from $5 \mathrm{March}$ to $22 \mathrm{March}$. In Franz-Joseph Land the variation over six years was from 11 April to 6 May, and over seven years at one location on Novaya Zemlya from 12 April to 10 May. Annual variations in arrival may therefore vary as much as a month in a given locality.

Phenology of Nesting Activities

The phenology of nesting activities at Cape Thompson is summarized in Table 11. Changes i.n the reproductive organs and brood patches were correlated with this phenological pattern. Size of testes, largest ovarian follicle, and measurements and descriptions of the 


\begin{tabular}{l} 
TABLE 11. $\begin{array}{l}\text { Phenology of nesting activities of black-legged } \\
\text { kittiwakes at Cape Thompson, Alaska, 1959-196I }\end{array}$ \\
$\begin{array}{lllll}1959 & \text { First Building } & \text { First Egg } & \text { First Hatching First Fledging } \\
1960 & \text { not observed } & 22 \text { June } & 20 \text { July } & 30 \text { August } \\
1961 & 13 \text { June } & 21 \text { June } & 17 \text { July } & 20 \text { August } \\
18 \text { June } & 25 \text { June } & 22 \text { July } & 27 \text { August }\end{array}$ \\
\hline
\end{tabular}


brood patches were taken on all birds collected.

Data for testis volume in 1960 is presented in Table 12 and

Fig. 13. Development of testes had begun in birds collected in late May, and maximum size was achieved during the period from 16 to 30 June. This maximum development was coincident with the time of initiation of laying by females: Following this period the testes began regressing, and by 16 to 31 July they were below the May level. Regression to the non-breeding condition was complete by (at least) late September.

Maximum follicle size was observed in females during the period between 16 and 30 June, corresponding to the time of initiation of laying (Table 13, Fig. 13).

Brood patches are developed by both sexes. There are three separate patches, two on the anterior lateral parts of the abdomen and one on the posterior median part of the abdomen.

Development begins with the loss of down on the apterial portions of the anterior patches. Following this, loss of contour feathers occurs. The posterior patch develops somewhat more slowly than the anterior ones. Vascularization of the patches completes development.

Regression begins with the appearance of down and sheaths of new contour feathers on the pterlae and around the edges of the patches. Down then completely covers the patch and new contour feathers begin to break out of their sheaths. The contour feathers are the last to develop completely.

A scale of six developmental and regressional stages was developed, similar to that for murres, to enable quantitative evaluation of changes through the season:

Class 0. - No evidence of feather loss.

Class 1. - Partial loss of down and contour feathers from anterior patches.

Class 2. - Complete loss of feathers from anterior patches, partial loss from posterior patch.

Class 3. - Maximum development. 
TABLE 12. Volume of testes (in cc.) of male black-legged kittiwakes throughout the summer of 1960 at Cape Thompson colonies

\begin{tabular}{|c|c|c|c|c|c|c|}
\hline \multirow[b]{2}{*}{ Period } & \multicolumn{3}{|c|}{ Left Testis } & \multicolumn{3}{|c|}{ Right Testis } \\
\hline & No. & Av. & Vol. Ist. Error & No. & Av. & Vol. $\pm s t$. Error \\
\hline May & 3 & & $0.20 \pm 0.02$ & 3 & & $0.12 \pm 0.03$ \\
\hline June $1-15$ & 5 & & $0.41 \pm 0.03$ & 5 & & $0.17 \pm 0.03$ \\
\hline June $16-30$ & 9 & & $0.65 \pm 0.10$ & 8 & & $0.28 \pm 0.04$ \\
\hline July $1-15$ & 11 & & $0.33 \pm 0.05$ & 10 & & $0.17 \pm 0.02$ \\
\hline July $16-31$ & 4 & & $0.05 \pm 0.01$ & 4 & & $0.04 \pm 0.01$ \\
\hline Aug. 1-15 & 4 & & $0.08 \pm 0.03$ & 3 & & $0.05 \pm 0.02$ \\
\hline Aug. 16-31 & 6 & & $0.05 \pm 0.01$ & 6 & & $0.03 \pm 0.01$ \\
\hline Sept. $1-15$ & 8 & & $0.03 \pm 0.01$ & 7 & & $0.02 \pm 0.00$ \\
\hline Sept. $16-30$ & 1 & & 0.01 & 1 & & 0.01 \\
\hline Oct. $1-15$ & 1 & & 0.01 & 1 & & 0.01 \\
\hline
\end{tabular}




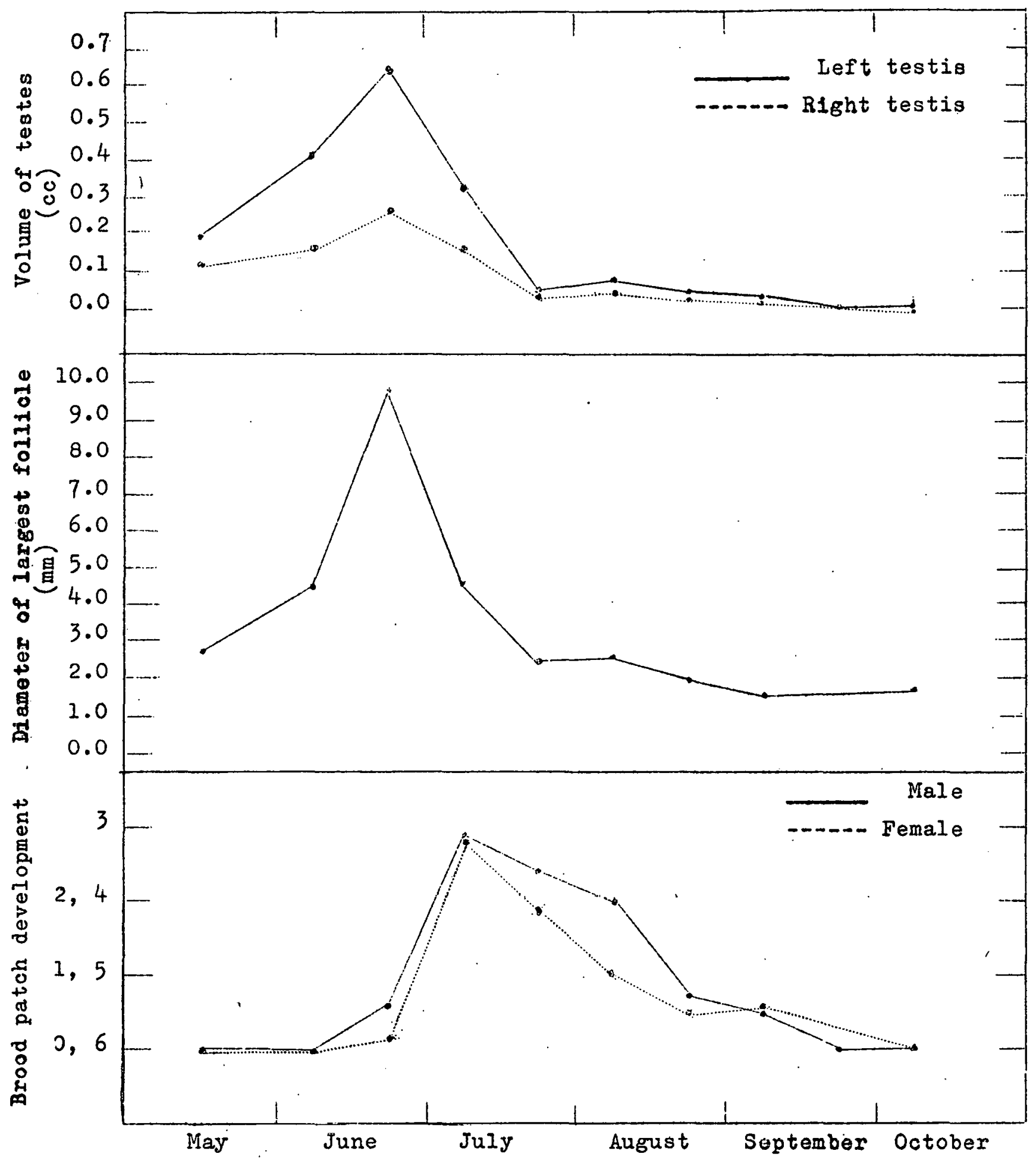

Figure 13. Volume of testes, diameter of largest ovarian follicle, and development of brood patch of black-legged kittiwakes at Cape Thompson colonies during summer of 1960 
56

TABLE 13. Average diameter (in millimeters) of largest ovarian follicle of female black-legged kittiwakes throughout the summer of 1960 at Cape Thompson colonies

\begin{tabular}{|c|c|c|c|}
\hline Period & No. & Av. Diameter \pm St. Error & Range \\
\hline May & 1 & 2.9 & - \\
\hline June $1-15$ & 4 & $4.6 \pm 1.5$ & $3.2-7.8$ \\
\hline June $16-30$ & 15 & $9.8 \pm 1.5$ & $2.8-19.2$ \\
\hline July $1-15$ & 9 & $4.7 \pm 0.5$ & $3.1-8.0$ \\
\hline July 16-31 & 4 & $2.6 \pm 0.5$ & $2.0-4.0$ \\
\hline Aug. $1-15$ & 1 & 2.7 & - \\
\hline Aug. $16-31$ & 4 & $2.0 \pm 0.1$ & $1.8-2.3$ \\
\hline Sept. $1-15$ & 4 & $1.7 \pm 0.2$ & $1.0-2.1$ \\
\hline Sept. $16-30$ & 0 & - & . \\
\hline Oct. 1-15 & 2 & $1.8 \pm 0.1$ & $1.7-1.9$ \\
\hline
\end{tabular}




$$
\begin{aligned}
& \text { Class 4. - Down and sheathed feathers appearing in } \\
& \text { pterylae and around margins of patches. } \\
& \text { Class 5. - } \begin{aligned}
\text { Patches completely down covered; contour } \\
\text { feathers breaking out of sheaths. }
\end{aligned} \\
& \text { Class } 6 . \text { - No evidence of brood patch. }
\end{aligned}
$$

Average values obtained from birds collected throughout the summer are given in Table 14 and Fig. 13. Patches were absent on birds taken through mid-June. Patch development began in late June, and was maximal during most of July. Regression began in late July, and was probably completed during the last half of September or early october.

$$
\text { Nest-building }
$$

Nest-building activity was typically greatest during about a ten-day period, beginning in the third week of June, during Which time flocks of birds were frequently seen flying in definite flight lines up the ravines or along the coast collecting mud or vegetation. Material was gathered in a restricted area, varying in size with the number of birds involved. These areas gradually shifted, possibly as available material became exhausted and as progress in construction demanded different materials. The location of these gathering areas varied from near the edge of the cliff-top to approximately a half mile inland. Scattered individuals were engaged in nest-buiJ.ding as late as two weeks after the main construction period.

Two major types of material were used in nest construction. Mud, mixed with moss and rootlets, was used in forming the base of the nest. Plant materials, such as grasses, sedges, and herbaceous stems, were added later.

The mud is deposited on the nest site, using a lateral and downward jerking motion of the head (Cullen, 1957). This motion 
TABLE 14. Brood patch development of adult male and female blacklegged kittiwakes throughout the summer of 1960 at Cape Thompson colonies (see page 12 for description of class values)

\begin{tabular}{l|c|c|c|c}
\hline \multirow{2}{*}{ Period } & \multicolumn{2}{|c|}{ Males } & \multicolumn{2}{c}{ Females } \\
\cline { 2 - 5 } Nay & No. & Av. Class Value & No. & Av. Class Value \\
June 1-15 & 3 & 0.0 & 1 & 0.0 \\
June 16-30 & 10 & 0.0 & 4 & 0.0 \\
July 1-15 & 11 & 0.6 & 15 & 0.2 \\
July 16-31 & 4 & 2.9 & 10 & 2.8 \\
Aug. 1-15 & 4 & 3.6 & 4 & 4.2 \\
Aug. 16-31 & 6 & 4.0 & 1 & 5.0 \\
Sept. 1-15 & 8 & 5.3 & 4 & 5.5 \\
Sept. 16-30 & 1 & 5.5 & 4 & 5.4 \\
Oct. 1-15 & 1 & 6.0 & 0 & 2 \\
\hline
\end{tabular}


serves to expel the sticky material from the mouth. The mud is then trampled into place with the feet. Trampling may continue for long periods of time (up to an hour or more). Following the construction of a mud platform, the plant material is added. This material is deposited using a motion similar to that employed in mud deposition, and is also trampled into place.

The completed nest is approximately $40-50 \mathrm{~cm}$ in outside diameter and $20-30 \mathrm{~cm}$ in inside diameter. Nests are frequently built on top of older nests so that the total height of a nest may be $50 \mathrm{~cm}$ or more. The depth of the cup, which is well-developed, is about $5-10 \mathrm{~cm}$.

The nest and nest-building behavior of this species shows a high degree of adaptation to the cliff-nesting habit (Cullen, 1957). The well-constructed nest with its mud and deep cup is apparently a response to prevent loss of eggs and young through falls. Correlated with the use of mud, and the more complex nest, are the elaboration of the head jerking and trampling behavior patterns, which are only weakly shown in other gulls:

\section{Laying and Clutch Size}

The clutch size of kittiwakes at Cape Thompson during 1960 averaged 1.9 egg's (60 nests). Moot olutches contained ?. e.gs (88 per cent); a few contained only 1 egg ( 10 per cent); and one nest was found in 1960 with three eggs. Although no quantitative data on clutch size were obtained during 1959, no 3-egg clutches were noted. In 1961, clutch size averaged 1.76 (29 nests) with 79 per cent two-egg clutches, 21 per cent one-egg clutches. It appears that 2 eggs is the normal clutch size for kittiwakes at Cape Thompson.

Table 15 summarizes clutch sizes obtained by the present vorkers and by other workers on nesting colonies in the North 
TABLE 15. Clutch size of black-legged kittiwakes in various geographical areas

\begin{tabular}{|c|c|c|c|c|c|c|c|}
\hline Location & $\begin{array}{l}\text { Number } \\
\text { of } \\
\text { nests }\end{array}$ & $\begin{array}{c}\text { Per } \\
\text { Cent } \\
1-e g g \\
\text { nests }\end{array}$ & \begin{tabular}{|c|} 
Per \\
Cent \\
2 -egg \\
nests
\end{tabular} & $\begin{array}{c}\text { Per } \\
\text { Cent } \\
3 \text {-egg } \\
\text { nests }\end{array}$ & $\begin{array}{l}\text { Per } \\
\text { Cent } \\
4-\text { egg } \\
\text { nests }\end{array}$ & $\begin{array}{l}\text { Ave. } \\
\text { size }\end{array}$ & Authority \\
\hline $\begin{array}{c}\text { Cape Thompson, } \\
\text { Alaska }\end{array}$ & 89 & 13.5 & 85.4 & 1.1 & 0 & 1.84 & Present Study \\
\hline $\begin{array}{c}\text { Northumberland, } \\
\text { England }\end{array}$ & 149 & 10.1 & 74.5 & 15.4 & 0 & 2.05 & $\begin{array}{l}\text { Coulson and } \\
\text { White, } 19.58 \mathrm{~b}\end{array}$ \\
\hline $\begin{array}{c}\text { Novaya Zemlya, } \\
\text { U.S.S.R. }\end{array}$ & 100 & 12.0 & 87.0 & 1.0 & 0 & 1.89 & Uspenski, 1958 \\
\hline $\begin{array}{c}\text { Kharlov Is., } \\
\text { U.S.S.R. }\end{array}$ & 577 & 22.5 & 58.8 & 18.4 & 0.4 & 1.96 & $\begin{array}{l}\text { Belopolski, } \\
1957\end{array}$ \\
\hline $\begin{array}{l}\text { Farne Islands, } \\
\text { England }\end{array}$ & 138 & 15.2 & 75.4 & 13.4 & 0 & 1.94 & Cullen, 1957 \\
\hline
\end{tabular}


Atlantic and Barents Sea. Data from Novaya Zemiga colonies are most similar to those of Cape Thompson. In eastern Murmansk and in the British Isles, 3-egg clutches are more common.

Eggs are apparently not laid on successive days. In several cases, at least a two-day interval separated the laying of the first and second eggs, and in one instance this interval was at least three days. Incubation begins with the laying of the first egg but may not be continuous until the clutch is completed.

Uspenski (1956) states that re-laying may occur if the first clutch is lost. The interval between loss and re-laying in four instances was 16 to 26 days. No re-laying was observed at Cape Thompson.

Clutch size, according to Coulson and White (1958a, 1958b), may vary with the age and previous breeding experience of the bird, and with the time of year the clutch is laid. They found that females breeding for the first, second, and third times had average clutches of $1.83,2.06$, and 2.33 eggs, respectively. In relation to time of laying, the average size of the clutch was largest during the early part of the breeding season and smallest in the latter part. These two factors are related in that older birds tend to breed earlier.

\section{Inculation}

Both sexes incubate and both have a well-developed brood patch. The nest is not normally left unattended, though unusual disturbances may result in both parents being absent simultaneously. Coulson and White (1958a) report that although both adults incubate, the female spends more time on the nest than does the male.

The incubation period of the eggs of 15 nests at Cape Thompson was determined with a maximum possible error of 3 days. These determinations averaged 28.0 days, and the maximum possible variation 
in length of incubation was between 25 and 31 days. These values agree closely with those of Coulson and White (1958b) who found an average length of 27.3 days (range of 25-32 days) in 119 nests in Northumberland, England. These values are summarized in Table 16 along with those of other workers. The low values of 24 days and less are probably in error.

\section{Nestling Period}

The hatching of young in two-egg clutches at Cape Thompson generally occurred within two days of each other. In one case an interval. of five days elapsed and in another case apparently ten days elapsed between the hatching of the two chicks.

The nestlings are conspicuously colored, being predominantly white, rather than cryptically colored as with most other gulls. In addition, they show a number of behavioral adaptations to cliffnesting (Culien, 1957). The young birds tend to face the cliff wall most of the time and do not engage in vigorous flight movements as do other gulls.

Both parents feed the young. The food given is regurgitated, partly digested material. The young kittiwakes usually take the food directly from the throat of the parent, instead of picking up food deposited on the ground nearby as in most other gulls. Feeding is probably done about equally by both parents since their frequency at the nest during this period is about the same (Coulson and White, 1958a).

Cullen (1957) has also shown that adults do not discriminate between individual chicks or even between number and age of chicks until they are nearly ready to leave the nest. In the Cape Thompson study, chicks were occasionally noted to move to different nests, especially when very young. Several of these chicks remained 
TABLE 16. Incubation period of the black-legged kittiwake as determined by various workers

\begin{tabular}{|c|c|c|c|c|}
\hline Location & $\begin{array}{c}\text { Number of } \\
\text { observations }\end{array}$ & $\begin{array}{l}\text { Average } \\
\text { length } \\
\text { (days) }\end{array}$ & $\begin{array}{c}\text { Range of } \\
\text { determinations } \\
\text { (days) }\end{array}$ & Authority \\
\hline $\begin{array}{l}\text { Nor thumberland, } \\
\text { Engl and }\end{array}$ & 119 & $27 \cdot 3$ & $25-32$ & $\begin{array}{l}\text { Coulson and } \\
\text { White, } 1958 \mathrm{~b}\end{array}$ \\
\hline $\begin{array}{c}\text { Novaya Zemlya, } \\
\text { U. S. S. R. }\end{array}$ & 6 & - & $24-26$ & $\begin{array}{l}\text { Uspenski, } \\
1956\end{array}$ \\
\hline Not known & - & - & $21-24$ & $\begin{array}{l}\text { Witherby, et } \\
\text { al., } 1941\end{array}$ \\
\hline $\begin{array}{c}\text { Cape Thompson, } \\
\text { Alaska }\end{array}$ & 15 & 28.0 & $25-31$ & Present study \\
\hline
\end{tabular}


in the new nest and apparently fledged successfully. No evidence was noted of hostile behavior by adult birds to these foreign chicks. A rigorous peck order is, however, established among the chicks in a nest, and the movement of a chick to a new nest did result in hostile behavior among the chicks during the rearrangement of the peck order.

The duration of the nestling period is somewhat indefinite, since even after the young are able to fly they will return to the nest and be fed by the adults. Coulson and White (1958b) have defined the fledgling period as the time between hatching and the final vacating of the nest by the young. The length of this period, as determined by these workers in a British colony, was 42.7 days. Some young fledged as early as 32 to 34 days after hatching and some as late as 53 to 55 days after hatching.

Although this fledgling period may have biological significance in being related to the time that the young are actually cared for by the parents (jbid.), both these workers' observations and observations at Cape Thompson indicate that there is a great deal of variability in the length of this period. The length of time necessary for the young to fly successfully may be a satisfactory, and more uniform, measurement. In the present study the nestling period was determined as the time between hatching and the first departure of the fledgling from the nest. In 22 nests at Cape Thompson where the time of first departure was noted (with a maximum error of 4 days) the duration of this period averaged 44.0 days. Coulson and lihite $(1958 \mathrm{~b})$ indicate that very few chicks are able to fly well before the 36 th day after hatching. Witherby, et . (1941) state that young are fed by the parents for a month or five weeks after hatching. Uspenski (1956) states that, based on two observations, the entire period of development in the nest 
does not exceed 30 to 32 days. Ho also notes that in the seven Islands, U.S.S. R., the duration of nest occupation is 33 to 37 days.

At Cape Thompson in 1960, observations were made of adults and chicks occupying nest sites as late as 14 October, which was the last date that adult birds were seen at the cliffs.

A total of 16 final departures of chicks from nests were noted (with a maximum error of 4 days) at Cape Thompson in 1960. These averaged 53.2 days after hatching. In 1961, four such cases were observed which averaged 49.5 days. At the time observations of breeding biology were discontinued in early September 1960, however, nine nests were still under observation in which the chicks had not departed after at least 56.8 days in the nest. In 1961, 5 chicks had not departed on 23 september after an average of 59 days in the nest. The length of these times for final departure of the young is much greater than the value obtained by Coulson and White (1958b) and by other workers. Thus, it appears that at Cape Thompson the young birds do not leave the nest or the nesting area as early as in other areas where they have been studied.

\section{Breeding Success}

Breeding success in 1960 and 1961 is tabilated in Table 17.

The differences evident in clutch size, hatching success, and fledging success between the two years are of unknown origin, though increased predation of eggs by glaucous gulls in 1961 may account for the differences in hatching success and fledging success. No causes for the smaller average clutch size in 1961 were observed. Coulson and lihite $(1958 \mathrm{~b})$ have shown increases in clutch size and breeding success correlated with breeding experience in kittiwakes. 
TABLE 17. Breeding success of black-legged kittiwakes at Cape Thompson, Alaska, 1960 and 196]

\begin{tabular}{lcc}
\hline & 1960 & 1961 \\
\hline Total active nests & 60 & 29 \\
Total eggs laid (original) & 113 & 51 \\
Average clutch size & 1.92 & 1.876 \\
Eggs lost before hatching & 28 & 16 \\
Eggs replaced & 1 & 1 \\
Hatching success (per cent) & 75 & 69 \\
Total fledged & 73 & 21 \\
Breeding success (per cent) & 65 & 41 \\
\end{tabular}


It is possible that changes in the age structure of the study area occurred to influence these changes, but no data were obtained.

\section{Late Summer Activity}

After about the middle of July, adult birds gathered in increasing numbers in groups on beach areas or on the water near the nesting cliffs. The first of these groups, composed of about 40 adults, was noted on $12 \mathrm{July} 1960$. By the end of July the average size of these groups had increased to 100-150 birds. By 13 August these groups frequently contained several hundred birds. As increasing numbers of kittiwake chicks fledged during late August and September, flocks of these young birds began to develop. These groups of juveniles were noted on the vater near the cliffs and on deserted ledge areas. On 13 september 1960, a total of six flocks, ranging in size from 50 to about 1,000 birds, were seen along the cliffs. On 25 september a flock of about 1,000 fledged young was seen. Although many young were seen after this date, no other large flocks were seen. Apparently the bulk of the young birds left the area during the fourth week of September. The same pattern prevailed in 1961.

In late september flocks composed mainly of adults predominated. Adults and young, however, were seen resting on the cliffs after this date, and some of the adults appeared to be still tending young.

A period of stormy weather prevailed between 25 september and 5 October, 1960, and during this period the flocks of adults disappeared from the vicinity of the cliffs. Immediately after the storm, however, at least some of these large flocks returned to the cliff area and were present until 14 october.

After 14 October 1960 the only kittiwakes seen in the area were a small number of young. The number of these birds gradually 
decreased until, on 21 October 1960 when observations were discontinued, only 31 individuals were seen along the entire length of the cliffs. Departure of the last birds was not observed in 1961.

Glaucous Gull

\section{Weights and Measurements}

Weights and measurements were obtained for nine fully adult birds (eight males and one female). Weights for the males ranged from 1,466 to 1,824 grams and averaged 1,617 grams. The one female collected was a crippled bird and weighed only 1,033 grams. Two sub-adult (third summer) birds, one of each sex, were collected. The weight of the female was not obtained; that of the male was 1,553 grams. A total of seven flying young of the year was collected. Weights taken on six of these varied between 1,156 and 1,597 grams, and averaged 1,307 grams.

Measurements of external features and of the size of the reproductive organs were taken on most of these individuals in a manner similar to those for other species (Table 18). External. measurements summarized by other workers (Witherby, et al., 1941; Ridgeway, 191.9) indicate that males are markedly larger in slze than females.

\section{Winter Range and Arrival at Cliffs}

This gull is an uncommon wintering species in the Aleutian Islands and a regular winter visitor along the coasts of Washington, Oregon, and California (Gabrielson and Lincoln, 1959). A few birds apparently winter as far north as open vater is available, as indicated by scattered observations of gulls in open leads at 
TABLE 18. Weights and measurements of adult, sub-adult, and juvenile glaucous gulls at Cape Thompson colonies during 1960 and 1961

\begin{tabular}{|c|c|c|c|c|c|c|}
\hline & Number & $\begin{array}{l}\text { Average } \\
\text { Weight } \\
\text { (grams) }\end{array}$ & $\begin{array}{l}\text { Average } \\
\text { Culmen } \\
(\mathrm{mm})\end{array}$ & $\begin{array}{l}\text { Average } \\
\text { Nostril } \\
\text { to bill- } \\
\text { tip (mm) }\end{array}$ & $\begin{array}{c}\text { Average } \\
\text { Wing } \\
(\mathrm{mm})\end{array}$ & $\begin{array}{l}\text { Average } \\
\text { Tarsus } \\
\text { (mm) }\end{array}$ \\
\hline $\begin{array}{l}\text { Adult } \\
\text { males }\end{array}$ & $8^{d}$ & $1,617.4$ & 60.0 & 27.0 & 458 & 74.3 \\
\hline $\begin{array}{l}\text { Adult } \\
\text { females }\end{array}$ & 1 & $1,033^{a}$ & 51.9 & 23.1 & 423 & 68.0 \\
\hline $\begin{array}{l}\text { Sub-adult } \\
\text { male }\end{array}$ & 1 & 1,553 & 69.8 & 26.8 & 438 & 71.0 \\
\hline $\begin{array}{l}\text { Sub-adult } \\
\text { female }\end{array}$ & 1 & $\mathrm{~b}$ & 53.9 & 25.3 & 433 & 64.0 \\
\hline $\begin{array}{l}\text { Juvenile } \\
\text { males }\end{array}$ & 3 & 1,402 & 57.4 & 24.8 & 461 & 70.2 \\
\hline $\begin{array}{l}\text { Juvenile } \\
\text { females }\end{array}$ & 3 & 1,212 & 51.1 & 19.9 & 404 & 66.5 \\
\hline $\begin{array}{ll}\text { a } & \text { Crippl } \\
\text { b Fresh } \\
\text { c Follic } \\
\text { d Testis } \\
\text { testis } \\
\text { males } \\
\text { was: } \\
\text { were n }\end{array}$ & $\begin{array}{l}\text { ed bird } \\
\text { but dama } \\
\text { le size } \\
\text { volume } \\
\text { l.56; r } \\
\text { taken fr } \\
\text { left tes } \\
\text { lot obtai }\end{array}$ & $\begin{array}{l}\text { found alive } \\
\text { aged carcass } \\
\text { less than } 1 \\
\text { in ce of on } \\
\text { right testis } \\
\text { rom } 21 \text { Augus } \\
\text { stis } 0.66 ; \\
\text { ined. }\end{array}$ & $\begin{array}{l}\text { on beach; } \\
\text { mm } \\
\text { male take } \\
\text { l.13. Ave } \\
\text { ight testis }\end{array}$ & $\begin{array}{l}\text { follicle } \\
\text { en } 1 \text { June } \\
\text { erage volu } \\
\text { tember (bo } \\
s 0.32 \text {. }\end{array}$ & $\begin{array}{l}\text { size } 2.1 \\
1960 \text { was: } \\
\text { ume in cc } \\
\text { oth } 1960 \text { ar } \\
\text { Measuremen }\end{array}$ & $\begin{array}{l}\text { mm. } \\
\text { left } \\
\text { for six } \\
\text { and } 1961 \text { ) } \\
\text { ats of one }\end{array}$ \\
\hline
\end{tabular}


Point Hope during the winter of 1959-60.

The spring migration and arrival of glaucous gulls at the nesting colonies occurs earlier than for other cliff-nesting species. In 1360 the first influx of gulls (probably of this species) in the Cape Thompson vicinity was noted by D. C. Foote at Point Hope on 19 April (June 1960 Sea-Cliff Birds Report).

L. M. Belson observed four at Point Hope on 20 April 1960. The first Glaucous gulls in 1960 were seen at the nesting cliffs on 26 April when 20 were noted on the ice near Point Crowbill. From this date on, birds were seen daily at this location in increasing numbers. In 196I, they first arrived on 27 April and again gradually increased in numbers to the maximum. No marked alternation of periods of presence and absence of birds at the cliffs similar to that shown by murres was noted.

\author{
Nest and Nest Site
}

Glaucous gulls usually nest in loose colonies varying in size from a few to many pairs. In the present study individual pairs were occasionally noted nesting in isolated situations, but most pairs nested in loose groups of from three to four pairs to thirty to forty pairs.

Nests may be located in a variety of situations, including slopes above cliff areas, low rocky or sandy islands, and at times, areas at the base of cliffs or isolated rocky pinnacles (Witherby, et al., 1941). At Cape Thompson all nests were located on ledges near the top of the cliffs or on the slopes above the cliffs. Nests were most commonly located in grassy areas (chiefly Elymus sp.). The presence of this grass in the vicinity of the nest was a significant factor in the concealinent of the young.

The nest of the glaucous gull is quite variable, but it is usually bulky. It is constructed of available plant materials, the exact composition being variahle. The nest has a moderately well- 
developed cup. In the Cape Thompson area, the nests were constructed mostly of Elymus stems and leaves.

\section{Phenology of Nesting Activity}

Little variation was observed in nesting phenology among the three years of study. The dates of initiation of nest-building and egf-laying were not obtained in 1959 or 1960. Examination of three eggs taken at Point Crowbill on 5 June 1960, however, indicated that these eggs had been incubated approximately 11 to 14 days. Thus, these eggs were probably laid about 25-28 May. If the incubation period of Cape Thompson birds is similar to that of North Atlantic birds, in which the duration is 27-28 days (Witherby, et al., 1941), the fact that the first hatching occurred on 16 June suggests that laying began on 20 or 21 :May. In 1961, nest-building began on 9 May and egg-laying on about 16 May.

The first hatching in 1959 occurred on 19 June, and in both 1960 and 1961 the first hatching was observed on 16 June. In ail years most of the young hatched during the last half of June and fledged toward the end of July. Fledging was complete by mid-August.

\section{Clutch Size and Incubation}

Clutch size was determined in 50 glaucous gull nests. In these nests clutch size ranged from 1 to 5 eggs and averaged 2.86 eggs (Table 19). Nests with three-egg clutches were most common.

Re-nesting following loss of the first clutch occurs at least occasionally. Ke-nesting was observed during 1959 (December 1959 Sca-Cliff Report). In 1960, one pair constructed a second nest a few feet from the first after their chicks had been removed by Eskimo hunters on 6-7 July; they did not re-lay, however. 
TABLE 19: Clutch size of glaucous gulls nesting at Cape Thompson during 1960

\begin{tabular}{ccccccc}
\hline $\begin{array}{c}\text { No. } \\
\text { 1-egg } \\
\text { nests }\end{array}$ & $\begin{array}{c}\text { No. } \\
\text { 2-egg } \\
\text { nests }\end{array}$ & $\begin{array}{c}\text { No. } \\
\text { nests }\end{array}$ & $\begin{array}{c}\text { No. } \\
\text { n-egg } \\
\text { nests }\end{array}$ & $\begin{array}{c}\text { No. } \\
\text { nests }\end{array}$ & $\begin{array}{c}\text { Total number } \\
\text { of nests }\end{array}$ & $\begin{array}{c}\text { Average } \\
\text { clutch size }\end{array}$ \\
\hline 2 & 6 & 40 & 1 & 1 & 50 & 2.86 \\
\hline
\end{tabular}


Nestling Life and Fledging

In contrast to the young of the kittiwake, chicks of the glaucous gulls are protectively colored, with a plumage of grayish to brownish barred feathers. The young also exhibit concealing behavior by crouching and remaining motionless at the approach of an observer.

During the first few days after hatching, the young tend to remain in or very close to the nest. Later they leave the nest, remaining, however, within the territory and in the immediate vicinity of the nest.

During the nestling period the young are fed partially digested food which is regurgitated by the adults onto the ground in the presence of the chicks.

The duration of the nestling period in 1960 in two nests on Colony 3 was, in both cases, between 42 and 53 days. In 1961 the nestling period for six nests ranged from about 44 days to over 57 days, averaging about 50 days.

\section{Late Summer Activities}

Throughout the early part of the summer, glaucous gulls were seen regularly feeding individually or in small groups on murre carcasses and other carrion along the beaches near the cliffs. After late July, larger loafing and feeding aggregations, developed. Loafing flocks of 50 to 100 birds were noted during August on the water below the cliffs and on various beach areas. In late August and early September, concentrations of up to 200 birds were seen on the beach at Colony 5, where the birds were feeding almost exclusively on dead, or in many cases, living murre chicks.

From 10 september to 27 September, 1960, the number of glaucous gulls in the vicinity of the cliffs decreased. During this period 
almost all of the adult birds disappeared. After about 19 september, fledglings constituted the bulk of the glaucous gull population in the area. The decrease in numbers during this period was correlated with observations of many individual gulls flying south along the coast. On 27 September only ten fledglings were counted along the entire cliff area.

From 27 September to 21 October 1960, the number of birds present fluctuated greatly. These fluctuations appeared to be correlated with alternate periods of fair and stormy weather. Between 26 September and 5. October, a period of stormy weather with high south winds prevailed along the coast; by 3 october the number of glaucous gulls on the beach at Ogotoruk Creek had increased to approximately 100. These individuals were feeding largely on quantities of invertebrates and plant material washed upon the beach. From 6 october to 14 october, after the storm had diminished, the number of gulls again fell to less than ten. From 15 october to 20 October, a second period of stormy weather prevailed, and by 21 October the number of birds had again increased and about 180 were present in the vicinity of Ogotoruk Creek. During these periods of increase in numbers, the proportion of adult birds increased slightly, but adults were at all times outnumbered by immature birds. Observations were discontinued on 21 October 1960 while large numbers of glaucous gulls were still present. Some birds probably remain in the area as long as open water is present along the shore. In 1959 gulls (probably glaucous gulls) were present in the area on 15 November and on 2 December. In 1961 the same general pattern of dimunition in numbers in late september prevailed. Observations were terminated on 3 October 1961 when glaucous gulls were still in the area. 
Breeding Success

Data on breeding success are meager. A glaucous gull nesting area on Point Crowbill was regularly preyed upon by foxes. In all years this area supported an average of 55 to 60 nests. Not a single chick fledged from most of this area in any of the three years and at most only one or two from the whole of Point Crowbill. Breeding success on part of a better protected area on Colony 3 was 50 per cent ( 18 nests) in 1961. Essentially all of the production of young in 1961 occurred from Colony 3 (52 nests in all), Colony 2 (20 nests), and Colony 5 ( 16 nests). Nests on Point Crowbill (60 nests) and Colony 4 (2 nests) failed. If the figure 50 per cent is taken as typical of nests on Colonies 2, 3, and 5, and 0 per cent for those on Point Crovbill and Colony 4, out of a total of 150 nests in 1961 , overall breeding success was 29 per cent, with an approximate yield of 126 fledglings.

Horned Puffin

Weights and Measurements

Seven male and ten female horned puffins, all adults in breeding plumage, were collected during the summer of 1960. Body weights, external measurements, and measurements of reproductive organs vere taken on all birds in a manner similar to that for other species (Table 20). Weights and all external measurements averaged somewhat greater in males than in females, but these differences were not statistically significant. It was not possible to sex the adults using external measurements. 
TABLE 20. Weights and measurements of horned puffins collected at Cape Thompson colonies during 1960

\begin{tabular}{|c|c|c|c|c|c|c|c|c|c|}
\hline Sex & Date & $\begin{array}{l}\text { Wei ght } \\
\text { (grams) }\end{array}$ & $\begin{array}{l}\text { Culmen } \\
(\mathrm{mm})\end{array}$ & $\begin{array}{l}\text { Nostril- } \\
\text { Bill tip } \\
\quad(\mathrm{mm})\end{array}$ & $\begin{array}{l}\text { Wing } \\
(\mathrm{mm})\end{array}$ & $\underset{(\mathrm{mm})}{\operatorname{Tarsus}}$ & $\begin{array}{c}\text { Largest } \\
\text { Follicle } \\
(\mathrm{mm})\end{array}$ & $\begin{array}{r}\text { Test } \\
\text { ( } \\
\text { Left }\end{array}$ & $\begin{array}{l}\text { sol. } \\
\text { Right }\end{array}$ \\
\hline 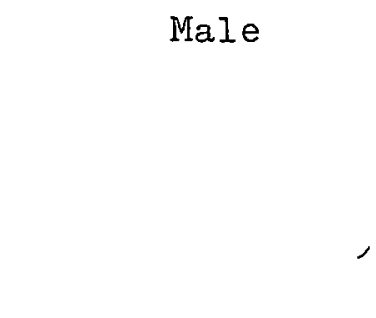 & $\begin{array}{r}25 \text { June } \\
8 \text { July } \\
12 \text { July } \\
27 \text { July } \\
29 \text { Aug. } \\
29 \text { Aug. } \\
6 \text { Sept. }\end{array}$ & $\begin{array}{l}656 \\
635 \\
669 \\
679 \\
666 \\
610 \\
621\end{array}$ & $\begin{array}{l}51.8 \\
51.0 \\
49.7 \\
51.8 \\
52.7 \\
46.0 \\
50.8\end{array}$ & $\begin{array}{l}18.9 \\
20.8 \\
19.7 \\
20.4 \\
19.1 \\
16.5 \\
18.1\end{array}$ & $\begin{array}{l}196 \\
203 \\
195 \\
202 \\
205 \\
202 \\
194\end{array}$ & $\begin{array}{l}30.8 \\
33.5 \\
35.6 \\
35.5 \\
31.1 \\
27.5 \\
32.5\end{array}$ & r & $\begin{array}{l}0.93 \\
1.91 \\
0.44 \\
0.69 \\
0.10 \\
0.32 \\
0.06\end{array}$ & $\begin{array}{l}0.58 \\
1.59 \\
0.30 \\
0.46 \\
0.06 \\
0.25 \\
0.05\end{array}$ \\
\hline Mean & & 648.0 & 50.5 & 19.1 & 199.6 & 32.4 & & & ${ }^{\circ}$ \\
\hline St. Error & & 24.3 & 2.0 & 1.4 & 4.1 & 2.6 & & & \\
\hline Female & $\begin{array}{l}1 \epsilon \text { June } \\
1 \epsilon \text { June } \\
1 \epsilon . \text { June } \\
25 . \text { June } \\
2 \bar{\epsilon} \text { June } \\
1 \hat{c} \text { July } \\
1 \hat{z} \text { July } \\
2 L \text { July } \\
6 \text { Sept. } \\
12 \text { Sept. }\end{array}$ & $\begin{array}{l}646 \\
623 \\
638 \\
643 \\
674 \\
616 \\
507 \\
\\
593\end{array}$ & $\begin{array}{l}50.8 \\
47.9 \\
50.8 \\
47.8 \\
49.4 \\
46.1 \\
45.2 \\
45.9 \\
50.6 \\
50.0\end{array}$ & $\begin{array}{l}18.2 \\
17.1 \\
18.5 \\
19.3 \\
18.5 \\
18.4 \\
16.1 \\
18.2 \\
17.3\end{array}$ & $\begin{array}{l}202 \\
199 \\
189 \\
199 \\
222 \\
197 \\
188 \\
182 \\
205 \\
190\end{array}$ & $\begin{array}{l}31.7 \\
30.7 \\
29.0 \\
30.5 \\
33.4 \\
32.7 \\
30.9 \\
31.0 \\
34.1 \\
30.4\end{array}$ & $\begin{array}{l}5.1 \\
5.7 \\
6.7 \\
7.1 \\
7.0 \\
4.3 \\
5.4 \\
3.6 \\
2.6\end{array}$ & & \\
\hline Nean & & $617 \cdot 5$ & 48.4 & 18.0 & 197.0 & 31.4 & & & \\
\hline St. Error & & $47 \cdot 3$ & 2.1 & 0.9 & 11 & 1.5 & & & \\
\hline Mean both sexes & & 631.7 & $49 \cdot 3$ & 18.4 & 198.2 & 31.8 & & & \\
\hline St. Brror & & 41.2 & $2 \cdot 3$ & 1.2 & 8.7 & 2.1 & & & 2 \\
\hline
\end{tabular}


Winter Range and Arrival at the Cliffs

Gabrielson and Iincoln (1959) state that horned puffins apparently winter at sea from the limit of open water south. Shuntov (1961), however, states from his work in the southeastern Bering sea that horned puffins are found in the open sea only in May and June. Occasional individuals are recorded off the coasts of Washington, Oregon, and California (Peterson, 1961). No reports of the species wintering in the vicinity of Cape Thompson have been received.

In 1960 the first horned puffins of the spring in the vicinity of Cape Thompson were seen on 6 June, and in 1961, on 8 June. From arrival through the end of June, varying numbers were seen along the cliffs. Occupation of ledges near nesting crevices apparently occurred soon after arrival. In England, occupation of the nesting area by common puffins, Fratercula arctica, is frequently preceded by alternate periods of presence and absence of the birds on the water near the nesting area. Such a pattern of presence and absense, if present at all, was not conspicuous at Cape Thompson.

Nest and Nest Site

The nest sites at the Cape Thompson cliffs were exclusively natural crevices in the cliffs. Some of these crevices showed evidences of having been enlarged or modified by digging but no true burrows were noted. Burrows are at times constructed by horned puffins, but are apparently less commonly used than are natural crevices (Gabrielson and Lincoln, 1959). Burrow nesting appears to be more common on islands in the southern parts of the breeding range. Perhaps the absence of significant populations of other crevice or 
burrow nesting species at Cape Thompson, along with the relative abundance of crevices, may account for the absence of burrow nesting in this area.

No elaborate nest is constructed in the crevice, but all nesting crevices examined contained a thin scattering of plant materials over the actual nest area.

\section{Egg-laying and Incubation}

Although by the end of the study nearly all of the horned puffin nests had been located $(1,062)$, few of them were accessible for observation of the eggs and young. Thirteen nests, each containing a single egg, were accessible for observation, eight in 1960 and five in 1961. In 1960 egg-laying apparently began about 25 June; at this time a female with one ovulated follicle was collected. The first nests with eggs, however, were not located until $6 \mathrm{July.} \mathrm{In} 1961$, two nests with one egg each were located on $8 \mathrm{July}$. One of these had been empty on $4 \mathrm{July}$. A replacement egg was laid in another nest between 23 and $26 \mathrm{July}$.

The duration of incubation was not determined exactly, but in one nest it was at least 38 days (egg first noted on 6 July; chick hatched on 12 August). The incubation period of the common puffin in England is about 40 to 43 days (Lockley, 1953), and it is likely that the duration is similar in the horned puffin.

\section{Nestling Perind}

Only two of the eggs under observation in each year hatched, perhaps because of their relative accessibility and consequent frequent disturbance. In all but one of the cases of failure to hatch, the egg disappeared with no indication of ite fate. 
The first hatching in 1960 was noted on 12 August. The duration of the nestling period was determined to be between 36 and 42 days in one case (chick hatched between 17 and 20 August; chick departed between 24 and 27 September). This is somewhat shorter than the period of 47 to 51 days recorded by Lockley (1953) for the common puffin. Observations did not reveal whether the chick was deserted before leaving the nest, as is the case in the common puffin. No chicks fledged from the nests under observation in 1961.

\section{Departure of Adults}

In 1960 adults appeared to be present in maximum numbers through 20 to 27 September. During this period many individuals were noted sitting on deserted murre ledges or near crevice entrances, suggesting that less time was being spent in care of the young.

In 1960 the adults apparently left between 27 September and 2 October, on which date the last individuals were seen. In 1961, the last observations of horned puffins were made on 24 September.

\section{Pelagic Cormorant}

In 1960 the first individuals of this species were seen on 8 May, when a flock of 18 was seen flying along the coast near the cliffs. Cormorants were first noted occupying the nesting ledges on 26 May. In 1961 the first cormorants were seen on 21 May. On 20 July 1959 a cormorant nest was found with a clutch of two eggs. On 11 August the nest was found to be empty, but on 28 August a single egg was present, indicating that re-laying had occurred in the same nest after loss of the first clutch. 
By 13 June 1960 nest-building activity was being carried on by most pairs. A single nest on Colony 4 was completed about 15 June. In this nest, which was the only nest accessible for close observation in 1960, the first egg was laid on 18 June. A second was present on 20 June, and a third was laid on 22 or 23 June. A pipped egg was noted in this nest on $18 \mathrm{July}$. On $19 \mathrm{July}$ two young had hatched, and by $20 \mathrm{July}$ all three had hatched. The incubation period was therefore 27 or 28 days. Fledging occurred between 10 and 13 September for one young and between 13 and 17 september for the remaining two. The duration of the fledgling period was therefore between 52 and 60 days.

In 1960 fledged young from other cormorant nests were observed in the water below nests on 29 August. In 1959 a nest with nearly fledged young was seen on 17 August; these young were seen on the water a few days later.

In 1961, a completed nest was located on 11 June and on 21 June, two eggs were present. On 7 July an egg was observed in a nest on Colony 4. A second egg was found in this nest on 8 July. None of the accessible nests of Colony 4 produced chicks or fledglings, though observations of a concentration of 15 active nests about 250 feet up an overhanging cliff on Colony 2 indicated that fledging began on Colony 2 on 28 August. A single juvenile was seen on 24 August on the rater at Colony 3.

Throughout the late part of the summer of 1960 , but beginning on $19 \mathrm{July}$, immature cormorants (second year birds) were observed at several locations, mainly at the extreme northwest end of Colony 2. This area did not support nesting cormorants but is close to the largest nesting concentration on the Cape Thompson cliffs (about 300 yards). These birds presumably represented mostly non-breeding immatures visiting the cliffs for the first time. An estimated 15 to 25 immatures were present at the cliffs in 1960 . In 1961 
a few immature cormorants appeared in late June and were occasionally seen in small numbers during July and August.

In 1960 adults and fledged young were present in near maximum numbers at least until 27 September. Many apparently departed during a period of stormy weather between 28 september and 5 October. The latest observation was of a single individual at Point Crowbill on 17 October. In 1961, adults and young were still present on 3 October when the last observer departed.

Data for two individuals of this species collected in 1960 are given in Table 21 .

Rough-legged Hawk

In 1959 a pair was seen occupying a nest on the cliffs on 19 June. The nest was empty and no actual breeding activity was noted. These individuals were seen frequently along the cliffs during the early summer and less frequently after mid-July. In 1960 a single individual was seen over Point Crowbill on 5 May. None were observed later than this date, and none was seen during 1961 .

\section{Golden Eagle}

In 1959 two adults and one immature golden eagle were present along the cliffs. On 24 June the adults vere flushed from a large stick nest, but no evidence of actual breeding at this location was noted. In 1960 and 1961 at least one pair frequented the area of the clifts. No nesting activity was noted. These birds were frequently observed near the north end of Colony 2 where we regularly collected the food remains. Golden eagles were frequently observed feeding on murres during all three summers. Golden eagles nested on the nearby 
TABLE 21. Other sea birds collected at Cape Thompson cliffs, 1960

\begin{tabular}{|c|c|c|c|c|c|c|c|c|c|c|c|c|}
\hline Species & & Date & Sex & Age & Plumage & $\begin{array}{l}\text { Weight } \\
\text { (grams: }\end{array}$ & $\begin{array}{l}\text { Culmen } \\
\text { (mm) }\end{array}$ & $\begin{array}{l}\text { Nostril- } \\
\text { Bill tip } \\
(\mathrm{mm})\end{array}$ & $\begin{array}{l}\text { Wing } \\
(\mathrm{mm})\end{array}$ & $\begin{array}{l}\text { Tarsus } \\
\text { (mm) }\end{array}$ & $\begin{array}{l}\text { Test } \\
\text { Left }\end{array}$ & $\begin{array}{l}\text { Vol. } \\
\text { Right }\end{array}$ \\
\hline Pelagic & 20 & Sent. & 0 & $T \mathrm{~mm}$ & דעור & 724 & 497 & & 265 & 557 & & \\
\hline $\begin{array}{l}\text { Pelagic } \\
\text { Cormorant }\end{array}$ & 7 & Oct. & $\sigma$ & Imm. & Juv. & 2,126 & 52.5 & & 283 & 58.2 & & \\
\hline $\begin{array}{l}\text { Glaucous- } \\
\text { Blaucous- } \\
\text { winged Gull }\end{array}$ & 20 & sept. & $\sigma$ & Ad. & Winter & 1,595 & 62.1 & 26.1 & 399 & 68.7 & 0.04 & 0.04 \\
\hline $\begin{array}{l}\text { Herring } \\
\text { Gull }\end{array}$ & 26 & July & 9 & Imm. & First Year & 928 & 57.3 & 24.2 & 410 & 70.6 & & \\
\hline $\begin{array}{l}\text { Black } \\
\text { Guillemot }\end{array}$ & & June & 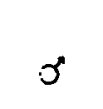 & Ad. & Breeding & 399 & 31.9 & 24.2 & 170 & 33.5 & 0.26 & 0.64 \\
\hline $\begin{array}{l}\text { Pigeon } \\
\text { Grillemot }\end{array}$ & 25 & April & $\sigma$ & $A \dot{c}$. & $\begin{array}{l}\text { Pre-nup. } \\
\text { molt }\end{array}$ & 426 & 30.5 & 22.9 & 168 & 31.9 & 0.03 & 0.0 .1 \\
\hline $\begin{array}{c}\text { Common } \\
\text { Raven }\end{array}$ & 15 & May & $\sigma$ & Ad. & Breeding & & 35.2 & 48.2 & 462 & 69.8 & $2 . c 6$ & 1.96 \\
\hline
\end{tabular}

$\because$ See page 84 
Kukpuk River and it is possible that these birds came from that area to feed at the cliffs.

\section{Gyrfalcon}

In 1959 one pair of gyrfalcons was present along the cliffs, but no evidence of nesting was found. In 1960 individuals were noted near the south end of the cliffs in April and May, and again in late September and October. On 22 August 1960 a pair was seen on the beach near the west-northwest end of the cliffs. None was observed near the cliffs during the middle of the summer. In 1961, gyrfalcons nested on Point Crowbill. Two chicks of undetermined age were visible in the nest on $5 \mathrm{July}$. These, almost fully fledged, were last seen in the nest on 21 July. They were not present on $25 \mathrm{July}$ and were not seen thereafter. It is possible that they did not fledge successfully.

Peregrine Falcon

In 1959 two pairs were regularly observed along the cliffs. One pair nested and fledged at least two young. In 1960 a single pair was seen regularly, and a nest containing four eggs was located on 12 June on the Colony 3 cliffs. On 25 June the adults were still incubating, but on $9 \mathrm{July}$ at least one young had hatched. On 5 August the nest contained two chicks. Observations on 16 August indicated that these two young had fledged successfully.

In 1961 the same nest held four eggs on 26 June. Three of these eggs hatched, and on 8 August, three young left the nest. 
Pomerine Jaeger; Parasitic Jaeger; Iong-tailed Jaeger

During 1959 all three jaegers were observed in the vicinity of the sea cliffs, with the long-tailed jaeger being the most common.

In 1960 only parasitic and long-tailed jaegers were seen. The latter species was present throughout the summer, and nests were located in nearby areas. Parasitic jaegers were most frequently noted during the last half of the summer. Both of these species were occasionally noted harassing kittiwakes and robbing them of. dropped food. Individuals were also occasionally noted feeding on carcasses of dead murres on the beaches along the cliffs. On 2 September 1960 an immature parasitic or pomarine jaeger was observed killing a fledgling kittiwake in the water off colony 3 .

In 1961, all three species were seen, but, again, long-tailed jaegers predominated and were observed feeding on dead murres and kittiwakes.

Glaucous-winged Gull

On 20 September 1960 an adult male gull which appears to be of this species, or possibly a hybrid between this species and I. hyperboreus, was collected at Ogotoruk Creek from a flock of glauoous gulls. The data for this specimen are summarized in Table 21 . The identification of thic specimen has not yet been verified.

\section{Herring Gull}

On $25 \mathrm{July} 1960$ ar immature herring gull (bird of the year) with a broken wing was collected from a group of glaucous gulls on the water near the mouth of Emmikroak Creek. The head and wings of this specimen were saved. Data for this specimen are given in Table $2 l$. 
An adult and an immature were also seen at Ogotoruk Creek on 17 October and two adults on 19 October, 1960. Adults of this species were seen in 1961. On 30 May two were seen at Colony $I$ and were sighted repeatedly at Colony 1 through 21 June. A single bird was seen at Colony 2 on 28 June and a single bird on Colony 5 on 3 July.

Mew Gull

In 1959 individual mew gulls were observed along the cliffs occasionally in early and mid-August.

In 1960 an individual was seen at Cape Thompson on 14 August. Between this date and 21 August, a single bird, probably the same individual, was seen daily.

Occasional individuals were seen in 1961.

Black Guillemot

Black guillemots were seen in small numbers throughout the summer of 1959, although there were probably not more than ten individuals present.

In 1960 the first black guillemot was noted at Colony 2 on 5 June. Observations throughout the summer indicated that a total of about eight pairs probably nested along the cliffs, three pairs along Colony 2, and five pairs on Colony 5. On 3 July a nest with two eggs was located in a crevice in the cliff about 8 feet abuve the top of a sloping talus pile at the base of the cliffs. One egg was removed from this nest and preserved. The nest was later found to be deserted, containing only the broken remnants of the second egg. The last individuals were seen on 29 August during 1960. In 1961 this species was first sighted on 7 June. Only two pairs frequented the cliffs in 1961 and no nests were found. Black guillemots were probably present until 28 August but no definite last-sightings were made.

Data for one specimen collected at Point Crowbill on 5 June 1960 are given in Table 21 . 
Pigeon Guillemot

Pigeon guillemots were regularly noted in small numbers (less than ten individuals) along the cliffs during 1959.

In 1960 the first individuals were seen on 12 June. Based on observations throughout the summer, it is probable that only two pairs nested along the cliffs, one pair at Colony 2 and one pair at Colony 5. On 29 July a nest containing two eggs was located at Colony 2. The nest was placed beneath a large series of boulders at the base of the cliffs. The immediate nest site was a small chamber 10 inches high and about 1 foot in diameter located 5 to 6 feet back underneath a large rock slab. The adult was captured on the nest and identified. On egg was also taken from this nest. The nest was later found deserted with the second egg cold but intact.

In 1960 pigeon guillemots were last seen on 29 August.

Guillemots which probably were this species were first sighted in 1961 on 16 June, but definite identification was not made until 23 June. Three nest sites were found in 1961 but none were accessible for observation. Adults were carrying food to one of these nests on 4 and 7 August. An adult was seen perched on a boulder in the water in front of this nest with a fish in its bill on $18 \mathrm{July}$, and it is possible that young were present on this earlier date. No fledglings were observed, and the last adults were seen on 28 August 1961.

Data fui une specimen collected at Point Hope in 1960 are given in Table 21 .

\section{Tufted Puffin}

Relatively small numbers of tufted puffins were regular members of the Cape Thompson colonies. Nearly all of their presumed nest sites were located by observing the adults, but their nesting crevices were uniformly high on the cliffs and inaccessible to climbers. 
In 1959, the first sighting was made on 18 June, though the birds may have been. present before the field party arrived. They were still in the area when the field party left on 9 september. In 1960, the first arrivals were seen on 16 June and the last sighting was made on 25 September. In 1961 they were first seen on 8 June and were last sighted on 23 september.

\section{Common Raven}

In 1959 ravens were seen throughout the summer in the vicinity of the cliffs. Family groups of up to six individuals were regularly noted. At least some of these individuals probably remained in the area throughout the winter.

In 1960 one pair apparently nested near the south end of the cliffs. Throughout the last half of the summer, a family group of five birds frequented the north end of the cliff area, suggesting the presence of two nesting pairs on the cliff area as a whole. In 1961, a single nest on Point Crowbill produced fledlings in unknown numbers. Eight ravens, possibly a family group, ranged the lengths of the cliffs throughout July and August. Data on one specimen collected in 1960 are given in Table 21. 
ABUNDANCE

The intensity of the census effort during the studies at Cape Thompson varied from year to year and from species to species, but in general the census program was aimed at determination of total populations and assessment of possible change in population levels.

Historically, the problem of accurately determining the abundance of breeding sea birds has been a difficult one which has been attacked by many workers. In developing the methods used at Cape Thompson, I have drawn heavily on Russian works, particularly those of Uspenski (1956) and Belopolski (1958). None of the methods heretofore developed has proved entirely satisfactory in either accuracy or ease of execution. Though still not ideal, I hope that those used at Cape Thompson and reported here represent improvements in both respects.

Census Methods

Census at Cape Thompson was normally conducted during the middle and last half of the incubation period of the species involved; although, in some cases, bad weather caused census activities to extend into later phases of the breeding cycle.

Study plots were set up in 1959. These varied in size, but taken together gave complete coverage of the éxposed strata along the 7 miles of coastline. Plots were marked off on $8 \times 10$-inch photographs, utilizing natural topographic features as plot boundaries. Some of the plots set up in 1959 proved of unwieldy size and were broken into two or more plots in 1960. One hundred thirty-seven plots were used in 1960 and were used unchanged in 1961. Numerous smaller plots for various purposes were selected from within these primary plots. 
Abundance of cormorants, gyrfalcons, peregrines, glaucous gulls, and ravens was determined by making direct counts of all nests or nesting sites on the Cape Thompson colonies. Abundance of kittiwakes in 1960 and 1961 also was determined by nest counts. Techniques used in 1959 for determining kittiwake abundance are described later. Pigeon guillemots, black guillemots, and tufted puffins nest in cavities and were counted by collation of seasonlong observations of the birds and searches for nest sites. Horned puffins also nest in cavities, but they were so numerous that other techniques, $:$ which are described later, were attempted.

Census of murres presented more formidable problems. Both species of murres lay their eggs on bare rock ledges and either or both sexes may attend the nest site. Sometimes, if the nesting ledges are clearly visible, the eggs may be counted. Kaftanovski (1940) and Uspenski (1941) used such techniques successfully in the Seven Islands Sanctuary on the Murman Coast. At Cape Thompson, however, those eggs which can be seen and counted are the exception, and determination of abundance depends on counts of the birds made by observers on the water or occasionally on the beaches or cliff-tops.

Although estimates are sometimes necessary, the preferred method is an individual count of the birds. When plots are clearly delineated and divided into sub-sections by the observers, individual counts of the birds is feasible, though time consuming, even for colonies as large as those at Cape Thompson. Attempts to avoid the task of counting the entire extent of the colony by determining average density of birds per unit area of cliff face (as done by Krasovski, 1937) were discarded in the Cape Thompson studies as insufficiently precise.

Although accurate counts ordinarily can be made, murres roosting on the cliffs in this locality undergo cyclic daily fluctuations in numbers such that, at the moment of counting, the birds counted do not represent the entire population nor a constant fraction of it. Each count must therefore be corrected to determine the true breeding 
population. In 1959 it was not possible to investigate these diurnal cycles in detail, but counts made of marked plots during eight days seemed to indicate that curves of these diurnal patterns of cliff roosting tended to be nearly congruent (see Fig. 14). In 1960 we were able to devote more time to such counts, and, although perturbations were evident, a basic pattern of activity consistent with the assumptions made in 1959, was established.

The correction methods used during all three years depended on determination of the per cent of the total population actually present on the cliffs at the moment of census. After the diurnal activity curves were established, the census counts were made. In 1959 two observers (the total field party during 1959 murre counts) in a small boat drifted along the shore just far enough away from the cliffs to avoid flushing the birds. The anchor was lowered while counts were being made. Wovement along the cliffs was usually possible without the noise and disturbance of oars or motors by ut1lizing longshore currents or winds. The birds were counted through $7 \times 50$ binoculars. No correction was made for birds alighting and departing during the count unless flushing occurred.due to our presence. In this event, the birds were counted as they flew away and added to the total.

A black and white photograph of the plot was taken at the beginning of the count, and the exact time was recorded. The photographs permitted exact and caey recording of nesting and:" roosting ledges and were used to determine the feasibility of using photographs as a substitute for time consuming on-the-spot counts. These photographs were used in a manner similar to that recently employed by Boyd (1961) with gannets, but the technique proved unsatisfactory at Cape Thompson because of generally unfavorable weather and topographic conditions.

Due to pitching of the boat and excessive distance of some 


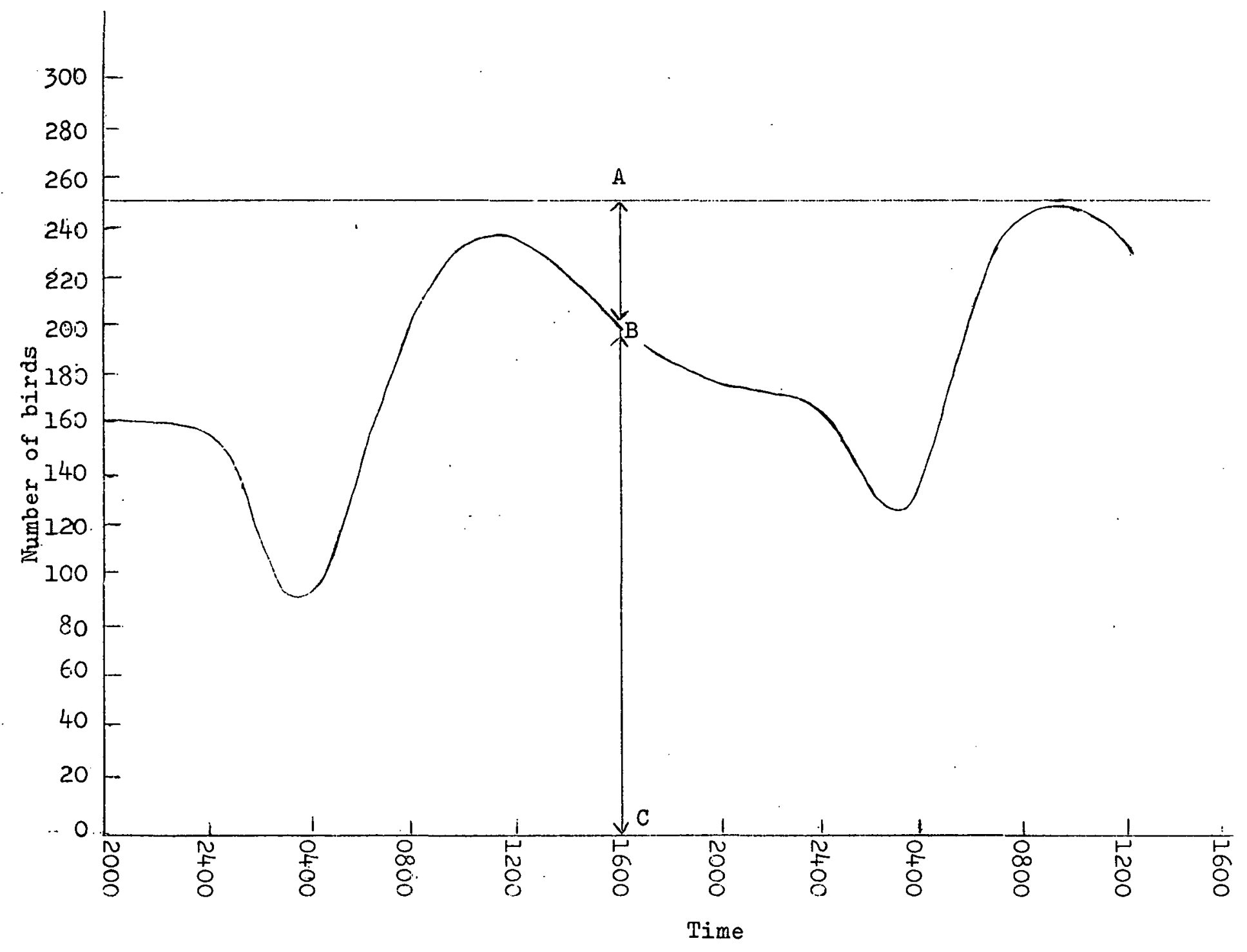

Figure 14. Diurnal cycles of murres, 30 August - 1 September, 1959 
ledges from the observers, it was not possible to count birds individually on all of the plots. In these cases, estimates were made by mentally blocking out groups of 100 birds and summing. Due to bad weather, which hampered counting and restricted the days in which a boat could be used, we were forced by time limitations to make many estimates in 1959. In 1960 and 1961 few estimates were necessary. All estimates were recorded as such.

In all instances counts or estimates were made independently by both observers, recorded, and the two figures averaged later. By referring to the point on the diurnal activity curve corresponding to the time of the count and by determining the distance to the 100 per cent line, $A B$ in Fig. 14, (assumed in 1959 to be equal to the highest total obtained on any day during the incubation period) and to the zero per cent line, BC in Fig. 14, the per cent of the total population represented by the counts was determined. Once this percentage was known, count data could be adjusted to yield the total population of the plot.

In 1959, kittiwake populations were determined using the same techniques as utilized for murres. Diurnal activity curves were less dramatic and less regular than those displayed by murres but were nonetheless definite. During the bad weather prevailing during the census period in 1959, it was more feasible to count or estimate the birds themselves, which contrast well with the cliffs, than to count the nests as was done in 1960 and 1961.

In 1960 a modification of the 1959 census method for murres was developed which may possess advantages in accuracy and which enables easier compensation for diurnal variations in numbers at the cliffs. "Compensation plots" were established in several parts of the cliff area in which the census was to be conducted that day. These plots were scattered widely and were selected only for visibility by observers on shore. A sufficient number of plots were used so as to eliminate distortions caused by the presence or absence of "loitering" birds in the compensation plots. Certain areas on the 
cliffs are used to a greater extent than others by "loitering birds. (This phenomenon of "loitering has been observed by others but its significance is unknown. I suspect many of these birds represent members of a pair "off-duty" at the moment and lacking space to loaf at the nest-site.

The number of birds on the compensation plots was counted by shore observers simultaneously with the complete census counts of the colony by the two other observers in a boat offshore. Counts of compensation plots were made by the shore observers at 15- to 30-minute intervals. Immediately after termination of census for that day, the birds on each of these compensation plots were flushed from their eggs and the eggs were counted. The per cent of breeding individuals at the cliffs during the census period can then be calculated by:

$$
\frac{\text { birds present on plots }}{2 \times \text { number of eggs }} \times 100
$$

It is clear, however, that theoretical breeding populations as computed from egg counts will be low because of egg loss. Further, since extensive re-laying occurs after egg loss, the number of eggs present at a given time is the resultant of two opposing functions, loss and replacement. It was not feasible to investigate egg loss directly at Cape Thompson because of the restricted accessibility of eggs for marking and high mortality of eggs induced by human activity on the breeding ledges. Data from 11 plots on Colony 4 and Colony 5 were analyzed to determine the per cent of the breeding population incubating eggs during the period of census. Murres on these plots were counted at short intervals by five people from 1130 to 2245 hours BST on $22 \mathrm{July}$ 1961. (This is the time of day in which murres were at the cliffs in greatest numbers.) Immediately after completing the counts the 
eggs were counted on all plots; the eggs totalled 1,181. Population peaks did not occur simultaneously on all plots, but except for one plot, all peaks occurred between 1900 and 2230. Peak figures for all plots were summed, yielding 2,808 birds. If it is assumed that birds "off duty" at the moment retain attachment for a given ledge and do not move from plot to plot or go to sea during the hours of counting, the per cent of the population incubating eggs on that day is $\frac{2 \times 1,181}{2,808}=84 \%$. Extensive collecting during the period of incubation and early nestling life did not disclose physiological non-breeders. I have assumed, therefore, that at this season all or nearly all birds resident in the cliff area are attempting to breed.

The figure 84 per cent was used in computing the final correction factors in 1960 and 1961. The per cent of birds present on the ledges at. the moment of census, compensating for both diurnal activity rhythms and egg loss-replacement, was computed as follows:

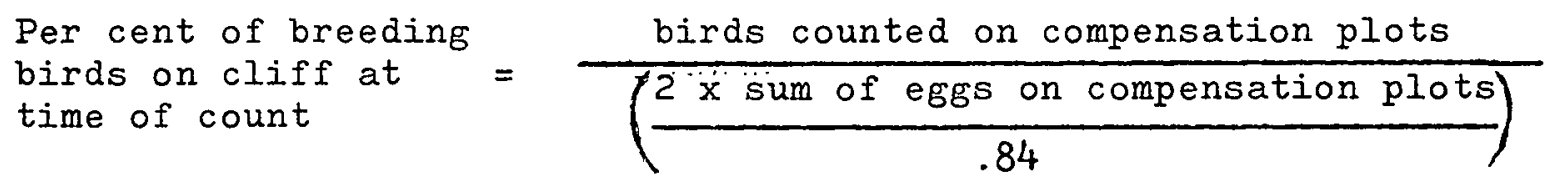

Census methods for murres do not include birds which, even at the daily peaks, are still seen at sea. Attempts to collect birds far at sea were not very successful, but indications exist that at least some of these are young, non-breeders.

Census of horned puffins presents special problems in that the nest sites are hidden in crevices and holes. In 1959 numbers were estimated by slowly cruising by boat past the cliffs in the late evening, when the birds tended to perch on the ledges in greatest abundance. No attempt was made to compensate these figures for birds at sea or hidden in nesting crevices. In 1960 compensation was accomplished utilizing the same principles used for murres. The 
location of the field camp near Colony 4 permitted more or less continuous observation of about half of this colony, and it was possible to locate all or nearly all of the horned puffin nests. At short intervals during the hours of census activity by boat observers, the birds visible on Colony 4 were counted by shore observers. The total number of birds seen by shore observers on Colony 4 divided by twice the number of known nests times 100 then yielded the per cent of the total population represented at a given time by the birds perching on ledges. These percentages were then used to compute the "total" from the data gathered by other observers counting from a boat.

In 1961 an effort was made to locate all nesting pairs of horned puffins for a direct count. All colonies, except Colony 5 which is known to have very few puffins, were counted.

Census Error

As indicated above, several census methods have been used, differing with the species involved. Some of these methods allow relatively little error (e.g.; nest counts of glaucous gulls); in others, e.g., murres, the possible error is larger. In all of these methods the only point at which the data are subject to objective analysis is in the difference between the counts of different observers. With experienced observers this difference tends to be low. In the murre census (perhaps the most challenging in this respect), summing all counts and estimates of two observers in 1960 yields totals of 252,983 versus 255,529, a deviation from the mean $(254,256)$ of only 1,273 or 0.5 per cent. A "T" test yields a value of .0754 . In 1961, sums of similar counts were 22,039 versus 20,204 , a deviation from the mean $(21,121)$ of 917 or 4.3 per cent. Although this seems rather close agreement for field counts, a "T" test yielded a $T$ value of .3907 , indicating that significant differences were present between the two observers. 
The seeming objectivity of such analyses may in some measure be illusory in that subtle adjustments certainly take place through conversations between observers living and working together. It is not possible to assess this adjustment in objective terms and in any event it would seem that the use of multiple observers is an adequate or at least the best practical way to minimize counting errors.

The major source of census error lies in the compensation of alcid figures for diurnal activity patterns and egg loss-replacement. The accuracy of the methods used depends on an adequate number of random samples. Selection of compensation plots was made solely on the basis of whether or not birds and eggs could be counted accurately, and since plots were chosen from various regions on the cliffs, it is unlikely that bias has been introduced. The modifications instituted in 1960 depend, in part, on determination of egg loss and replacement. It is difficult to assess the possible errors introduced by this computation. Direct methods utilizing marked eggs and birds proved unfeasible on the Cape Thompson cliffs. Uspenski (1958) and Tuck (1960) substantiate observations at Cape Thompson that egg mortality is greatly increased by human activity on and near the nesting ledges. It is possible, therefore, that the census methods used during this study provide a more accurate determination of the per cent of the total posstble number of eggs present on a given day than do methods depending on marking techniques. Care was taken to avoid disruptive activity near the study areas.

\section{Results and Discussion}

Census totals from all three years are listed in Table 22. From work subsequent to 1959 it has become clear that large errors 
TABLE 22. Populations of Sea Birds at Cape Thompson, Alaska, 1959 to 1961

\begin{tabular}{|c|c|c|c|c|c|c|c|c|c|}
\hline \multirow[b]{2}{*}{ Colony } & \multicolumn{3}{|c|}{ Murres } & \multicolumn{3}{|c|}{ Kittiwakes } & \multicolumn{3}{|c|}{ Horned Puffins } \\
\hline & y $\quad 1959$ & 1960 & 1961 & 1959 & 1960 & 1961 & 1959 & 1960 & 1961 \\
\hline 1. & 1,900 & 6,300 & $*$ & 0 & 0 & 0 & $\begin{array}{r}60 \\
100\end{array}$ & $\begin{array}{r}418 \\
86\end{array}$ & $\begin{array}{r}140 \\
72\end{array}$ \\
\hline 2 & 79,000 & 123,000 & & 9,200 & 10,400 & $\dagger$ & $\begin{array}{r}330 \\
0\end{array}$ & $\begin{array}{r}470 \\
0\end{array}$ & $\begin{array}{r}490 \\
0\end{array}$ \\
\hline 3 & 19,000 & 44,000 & & 6,100 & 5,900 & $\dot{r}$ & $\begin{array}{r}8 \\
10\end{array}$ & $\begin{array}{r}200 \\
10\end{array}$ & $\begin{array}{r}190 \\
14\end{array}$ \\
\hline 4 & 7,800 & 12,000 & 8,500 & 3,400 & 6,300 & 6,100 & 145 & 178 & 154 \\
\hline 5 & 69,000 & 208,000 & & 5,000 & 3,400 & & 300 & 540 & - \\
\hline tals 1 & 176,000 & 393,000 & & 23,700 & 26,000 & & 953 & 1,902 & \\
\hline
\end{tabular}

\begin{tabular}{|c|c|c|c|c|c|c|c|c|c|}
\hline & Gla & ous Gu & & & gic Cor & orant & & ted $P_{2}$ & fin \\
\hline & 1959 & 1960 & 1961 & 1959 & 1960 & 1961 & 1959 & 1960 & 1961 \\
\hline 1 & 92 & 104 & 120 & 2 & 6 & 8 & 4 & 20 & 6 \\
\hline 2 & 50 & 54 & 40 & 2 & 36 & 36 & 18 & 12 & 34 \\
\hline 3 & $15+$ & 126 & 104 & 0 & 0 & 0 & 0 & 0 & 0 \\
\hline 4 & 8 & 6 & 4 & 8 & 2 & 2 & 0 & 0 & 0 \\
\hline 5 & - & 14 & 32 & 0 & 2 & 0 & 0 & 4 & 0 \\
\hline Totals & & 304 & 300 & 12 & 46 & 46 & 22 & 36 & 40 \\
\hline & & k Guil & mot & & on Guil & emot & & & \\
\hline & 1959 & 1960 & 1961 & 1959 & 1960 & 1961 & & & \\
\hline 1 & 0 & 0 & 0 & 0 & 0 & 0 & & & \\
\hline 2 & & 6 & 2 & & 2 & 4 & & & \\
\hline 3 & & 0 & 0 & & 0 & 0 & & & \\
\hline 4 & $\leqslant 10$ & 0 & 0 & $<10$ & 0 & 0 & & & \\
\hline 5 & & 10 & 2 & & 2 & 10 & & & \\
\hline Totals & $<10$ & $i 6$ & 4 & $<10$ & 4 & 14 & & & \\
\hline
\end{tabular}


are embodied in some of the data taken in that year. Factors causing these errors are discussed below. Species are discussed in order of decreasing abundance.

Murres

In 1959 sufficient personnel were not available for census until late in the season (the first week of September). At that time chicks and adults had begun to leave and the data therefore represent only part of the maximum population. In 1960, close track was kept of population levels and diurnal cycles in two plots on Colony 4. These populations had diminished to about half of their peak by 4 September. Since the breeding phenology of the 1959 season was about two weeks later than that in 1960, it is likely that the 1959 counts represent between one-half and three-quarters of that year's peak population. Colony 1 is unique among the Cape Thompson colonies in that it. is composed to a large extent of non-incubating birds. Counts of this entire colony taken at different times of day or on different days varied greatly. In 1961, uncompensated counts in late July and early August varied from 2,489 to 5,797. The cliffs of Colony 1 differ topographically from the other colonies in that the rock strata are tilted nearly vertically. As a result, ledges which will safely accommodato an egg are rel.atively scarce. The maximum breeding population was probably between 2,000 and 3,000 birds. The large proportion of non-incubating birds frequenting the cliffs during the period of mass incubation may largely have been inexperienced breedere forced to use marginal habitat. Tuck (1960) has shown that egg mortality is high in new breeders. Such high egg mortality coupled with high egg loss from poor habitat may account for many of these unattached birds. The colony is about one mile from any other breeding sites, and it is doubtful, though possible, that these birds represent lo1terers from Colony 2. 
The other colonies, as a whole, do not show such extreme variations as Colony 1 in counts made at different times, though small areas may do so. Such areas seem always to be either marginal habitat or adequate habitat which is obviously not saturated by breeding birds. The latter situation seems rarely to prevail at Cape Thompson, where ordinarily only catastrophe (rock fall, Eskimo egg-gathering, or exceptional storm mortality) produces clearly unsaturated areas. The wide fluctuation in numbers of birds seen in such areas seems due to loitering birds, birds which have not yet laid a first or replacement egg, and, at certain times in the season, new breeders "visiting" the cliffs for the first time.

It was not possible to differentiate the two species of murres in all of the counts at Cape Thompson. Whenever possible, however, the species were differentiated. Uncompensated counts of 244,352 murres counted individually in 1960 for all colonies yielded 40 per cent common murres and 60 per cent thick-billed murres. Distribution among the colonies was not uniform. In Colony 1,19 per cent of 4,118 were common murres; in Colony 2, 51 per cent of 76,828; in Colony 3, 40 per cent of 13,959; in Colony 4, 57 per cent of 8,543 ; and in Colony 5, 19 per cent of 140,904. Differences in distribution are probably due primarily to differences in nest site selection in the two species. Common murres are largely restricted to comparatively wide, deөp, ledees. Thick-billed murres will lay on almost any area, small or large, which will retain an egg. The latter's habitat is more abundant on the Cape Thompson cliffs and is certainly one factor involved in the greater overall abundance of thick-billed murres. In 1961 a complete census was taken only of Colony 1 and Colony 4. Study plots which could be counted most easily and accurately were selected from the ends and center of the other colonies, and the data were compared with those of 1959 and 1960. Due to the peculiarities of Colony 1, census counts alone do not permit firm conclusions as to 
population changes. The number of occupied ledges in Colony 1 did not change, however, and in view of the restricted nesting habitat it is unlikely that significant change occurred. Data from Colony 4 indicate about a one-third reduction in population betwen 1960 and 1961. Population decrease showed itself in the form of reduction in density. The pattern of cliff occupation remained the same, except for one small area the face of which broke away during the 1961 incubation season and was only partially recolonized. Incomplete reoccupation is not surprising in view of the tendency observed by Uspenski (1956) for murres to be tenacious in nest site. Seventeen out of 18 plots in Colony 4 showed reduction in numbers ranging from 3 per cent to 67 per cent. One small area showed an increase from 2 birds to 24 . This small area was a loitering area, not a breeding area, and the apparent increase in population is a sampling artifact.

The reduction in population of Colony 4 in 1961 may partially be due to the more or less constant presence of the investigators in the immediate vicinity during 1960 and 1961. In 1959 our field camp was located about a mile away from the Colony, whereas in 1960 and 1961 it was adjacent to it. In view of our care to avoid undue disturbance at this colony, such an influence upon population would be surprising. It is possible, of course, that the decrease is only apparent, due to census error in one or both years. In the future it would be decirable to sonduct repeated censuses of large areas to examine the consistency of results obtained on different days during the same breeding season. Data taken from census of selected plots in the other colonies showed a small decrease in Colony 2 and a small iricrease in both Colony 3 and Colony 5. Within each colony the change was consistent in direction in all plots sampled. 
Black-legged Kittiwake

Kittiwake data are subject to fewer sources of error than are the alcid data, and perhaps because of this, they show less variation between years. The only clear evidence of population change in kittiwakes is the dramatic increase in the population in Colony 4 between 1959 and 1960. A large part of the increase took place in the northwest half of the Colony where the number of birds increased from 1,560 to 3,930. About three-fourths of this area is unusually susceptible to sea storms, and because of this it is likely that this area fluctuates in its population more than most. Four storms occurred in 1959 with surf sufficiently high to endanger or destroy many kittiwake nests in this area. In 1960 and 1961 such storms were less frequent and less violent during the breeding season. In 1961 a severe sea storm occurred on 21 August after completion of the census and destroyed all of the nests (22) on one of the census plots in this area. Data were not gathered on other plots, but it is likely that proportionate damage occurred.

In spite of the probable role of storm damage in kittiwake breeding in Colony 4, all of the disparity in census figures between 1959 and 1960 cannot be ascribed to this factor, and it is clear that the colony experienced real growth. No significant change in the population of Colony 4 was detected between 1960 and 1961.

In Colonies 1, 2, and 5, kittiwake populations remained essentially stable during the years of study. The differences-in numbers listed are probably within the range of census error. Alternating plots in Colonies 1 through 4 were counted in 1961. Colony 1 was bereft of kittiwakes during all three years, possibly due to lack of favorable nesting sites and/or to saturation by murres. In Colony 2 , counts of 20 plots in 1961 showed a decrease of 5.1 per cent. In Colony 5 counts of 9 plots showed an increase of 1.0 per cent. Colony 3 
appeared to have significantly increased in population; counts of 15 plots showed 20 per cent more birds in 1961.

Colonization of new areas by kittiwakes was not evident during the three years of study, though considerable shifting in population density occurred from plot to plot.

\section{Horned Puffin}

Data for horned puffins showed relatively little variation from year to year except between 1959 and 1960. This variation can certainly be ascribed to the embryonic state of census methods in 1959. The apparent decrease in Colony $I$ between 1960 and 1961 was probably due to census error. The counts in 1961 were made during two days of bad weather, a circumstance we avoided whenever possible because such conditions usually yield low counts. On these two days many nest sites could not be located even when the observers knew from previous experience approximately where they were. All other colonies were counted during good weather.

\section{Glaucous Gull}

Glaucous gull populations probably did not change markedly during the three years of study. Data shown in Table 1 for Colony 3 and Colony 5 in 1959 are misleading because only one man was present at Cape Thompson during the peak of breeding and he was unable to cover the entire extent of the cliffs. The glaucous gull nesting areas which were most thoroughly studied in 1959 (those in Colonies 1, 2, and 4) supported essentially the same population in 1960. In 1960 increased personnel enabled us to reach by rope a large nesting area in Colony 3 which was inaccessible to us in 1959; this nesting 
area accounts for the large difference in numbers cited for this colony between the two years.

\section{Pelagic Cormorant}

Probably pelagic cormorant populations did not change greatly. The greater number listed for 1960 and 1961 results, as in the case of glaucous gulls, from access in 1960 and 1961 to a concentration of nests (in Colony 2) which was not reached in 1959.

\section{Tufted Puffin}

Tufted puffins apparently maintained a stable population during the three years of study, but population levels changed in specific areas. Whether local changes were due to shifting of nest sites or to decimation or recruitment within a given area is not known.

Black Guillemot and Pigeon Guillemot

During 1959 and 1960 the populations of both species probably were essentially the same, but in 1961 black guillemots decreased sharply in number and pigeon guillemots showed a corresponding increase. The factors involved in this shift are unknown.

\section{Peregrine Falcon}

During 1959 two pairs attempted to breed. A pair on Colony 1 brought off two young but another pair on Colony 3 was unsuccessful. In succeeding years peregrines bred successfully on Colony 3 , but no others attempted to breed. 
Gyrfalcon

Gyrfalcons frequented the sea cliffs during all three years but apparently attempted to breed only in 1961. Two chicks, almost fully fledged, were last seen in a nest on Colony 1 on 21 July. These were not present on $25 \mathrm{July}$ and were not seen thereafter. It is possible that they did not fledge successfully. 
TROPHIC RELATIONSHIPS

The sea bird colonies form a highly concentrated segment of an ecosystem involving both marine and terrestrial biospheres, in fact, constituting a link between the two. The trophic aspects of Cape Thompson colonies were under study from the beginning of the investigations, but the most intensive efforts were concentrated in 1960. The basic structure of the food web has been defined and certain of the quantitative relationships have been established.

The physical and biotic characteristics of the portion of the Chukchi sea utilized by feeding sea birds have been discussed by other Project Chariot investigators and will not be considered in detail here.

The feeding radius of murres probably represents the greatest regular flight distance of any of the species breeding at Cape Thompson and extends to about forty statute miles from the colonies, though most of the feeding occurs within about thirty miles. The bottom within the feeding area is composed of small rocks and gravel close inshore, changing to primarily sand and mud at greater depths.

The Chukchi Sea, though obviously productive enough to support the sea bird colonies, is not markedly productive among arctic seas. The invertebrate fauna is fairly rich and abundant, but the fish populations are quite low (Alverson, et. al., 1960). The ten most abundant fish species include only two represented in the food habits studies of these birds: Boreogadus saida (the polar cod) was first in abundance in the ocean (Alverson, op. cit.) and was also the most frequently represented form in the food samples. Mallotus villosus (the capelin) was fifth in abundance but occurred only occasionally in the diet of the sea birds.

Collections of sea birds during the investigations were made roughly in proportion to the population levels of the species concerned. 
Few or no individuals of some species were collected in order to avoid disruption of the population. The food habits of each species, including methods employed in their determination, will be discussed separately. Discussion of community nutrition will follow.

Food Habits

\section{Murres}

Assay of the food habits of murres was accomplished by collecting birds both from the ledges and from the air as they returned to the cliffs from the sea. Early in the study it became apparent that the rapid digestion by murres was going to pose problems in food habit studies, a difficulty also experienced by other workers (Uspenski, 1956; Tuck, 1960). In order that all possible fragments of food be recovered, stomachs of all birds were opened and the lining of the ventriculus was removed along with any food remains. The lining, together with all contained material, was preserved in 70 per cent ethyl alcohol plus 2 per cent glycerine. This procedure prevented damage to fish otoliths and other hard parts. Samples were sorted into vertebrate and invertebrate aliquots and given to specialists for identification (see Acknowledgements). Kesults are tabulated in Table 23.

Tuck (1960) has discussed the state of knowledge of the food habits of murres, pointing out that, in spite of suggestions by Kaftanovski (1938) that differences might exist between the food preferences of the two species, such differences have not, to date, been clearly shown. The present study, conducted in an area frequented by both species, strongly suggests that significant differences do exist. These differences are particularly evident in the relative occurrence of fish and invertebrates in murre stomachs. In stomachs 
TABLE 23. Stomach analyses of murres. Numbers in the per cent column indicate the per cent of "filled" stomachs in which the food item was represented. Figures in parentheses represent frequency in the total number of stomachs examined.

\begin{tabular}{|c|c|c|c|c|c|c|c|c|}
\hline & \multirow{2}{*}{\multicolumn{4}{|c|}{$\frac{\text { Thick-billed Murres }}{\text { Adults }}$}} & \multicolumn{4}{|c|}{ Common Murres } \\
\hline & & & & & \multicolumn{2}{|c|}{ Adults } & \multicolumn{2}{|c|}{ Chicks } \\
\hline & No. & $\%$ & No. & $\%$ & No. & $\%$ & No. & $\%$ \\
\hline Total examined & 176 & & 11 & & 84 & & 2 & \\
\hline Empty & 43 & $(24.4)$ & 4 & $(36.4)$ & 18 & $(21.4)$ & 0 & $(0.0)$ \\
\hline $\begin{array}{l}\text { Containing food } \\
\text { Frequency of }\end{array}$ & 133 & $(75.6)$ & 7 & $(63.6)$ & 66 & $(78.6)$ & 2 & $(100.0)$ \\
\hline invertebrates & 45 & 33.8 & 1 & 25.0 & 4 & 6.1 & 0 & 0.0 \\
\hline Frequency of fish & 85 & 63.9 & 7 & 100.0 & 63 & 95.5 & 2 & 100.0 \\
\hline $\begin{array}{l}\text { Fish: } \\
\text { Gadidae }\end{array}$ & & & & & 7 & 7.5 & & \\
\hline$\frac{\text { Boreogadus }}{\text { Boreogadus }} \frac{\text { saida }}{\text { sp. }}$ & 60 & 45.1 & 4 & 57.1 & $\begin{array}{r}1 \\
51 \\
2\end{array}$ & $\begin{array}{r}77.3 \\
3.0\end{array}$ & 1 & 50.0 \\
\hline Triglidae & 1 & 0.8 & & & & & & \\
\hline Triglops forficata & 1 & 0.8 & & & & & & \\
\hline$\frac{\overline{\text { Triglops }}}{\frac{\text { spoxocephalus }}{\text { Myoxoct }}}$ & & & & & 1 & 1.5 & & \\
\hline quadricornis & 6 & 4.5 & 1 & 14.3 & & & & \\
\hline Myoxocephalus sp. & 3 & 2.3 & & & 1 & 1.5 & & \\
\hline Ammodytes hexapterus & 12 & 9.0 & & & 18 & 27.3 & 1 & 50.0 \\
\hline $\begin{array}{l}\text { Ammodytes sp. } \\
\text { Chirolophus }\end{array}$ & 1 & 0.8 & & & 2 & 3.0 & & \\
\hline polyactocephalus & 1 & 0.8 & 1 & 14.3 & 1 & 1.5 & & \\
\hline Stichaeus punctatus & 1 & 0.8 &. & 14.3 & & & & \\
\hline Lycodes & & & I & 14.3 & & & & \\
\hline Pleuronectidae & 3 & 2.3 & & & 4 & 6.1 & 1 & 50.0 \\
\hline Unidentifiable & 10 & 7.5 & 1 & 14.3 & 5 & 7.6 & & \\
\hline Invertebrates: & & & & & & & & \\
\hline Annelida & & & & & & & & \\
\hline Polynoidea & 2 & 1.5 & & & & & & \\
\hline "Polychaetes" & 12 & 9.0 & & & 4 & 6.1 & & \\
\hline Mollusca & & & & & & & & \\
\hline Pteropods & 1 & 0.8 & & & & & & \\
\hline Trochidae & 2 & 1.5 & & & & & & \\
\hline Naticidae & 7 & 5.3 & & & & & & \\
\hline Natica & 3 & 2.3 & & & & & & \\
\hline Clausa & 1 & 0.8 & & & & & & \\
\hline Arthropoda & & & & & & & & \\
\hline Amphipoda & & & & & 1 & 1.5 & & \\
\hline Gammaridea, species \#1 & 1 & 0.8 & & & & & & \\
\hline Gammaridea, species \#2 & 1 & 0.8 & & & & & & \\
\hline $\begin{array}{l}\text { Gammaridea, species \#3 } \\
\text { Hippolytid }\end{array}$ & & & 1 & 14.3 & & & & \\
\hline $\begin{array}{l}\text { Hippolytid } \\
\text { Notocrangon argig } \\
\text { "shrimp" }\end{array}$ & $\begin{array}{l}2 \\
1\end{array}$ & $\begin{array}{l}1.5 \\
0.8\end{array}$ & & & & & & \\
\hline $\begin{array}{l}\text { "shrimp" } \\
\text { Paguridae }\end{array}$ & $\begin{array}{l}6 \\
3\end{array}$ & $\begin{array}{l}4.5 \\
2.3\end{array}$ & & & 1 & 1.5 & & \\
\hline $\begin{array}{l}\text { Onidentifiable } \\
\text { invertebrate }\end{array}$ & 15. & 2. & & & & & & \\
\hline $\begin{array}{l}\text { Pebbles } \\
\text { Algae }\end{array}$ & 48 & $(27.3)$ & & & 20 & $(23.3)$ & & \\
\hline Algae & 1 & $(0.6)$ & & & 1 & $(1.2)$ & & \\
\hline
\end{tabular}


containing food remnants, 95.5 per cent from adult common murres contained fish as opposed to 63.9 per cent from thick-billed murres. Proportions of invertebrates were reversed, with invertebrates appearing in 6.1 per cent of common murre stomachs and in 33.8 per cent of those of thick-billed murres. Most of the invertebrates represented were bottom-dwelling forms, suggesting more frequent bottom feeding in thick-billed murres. It is possible that the relatively deeper bill of thick-billed murres is adaptive in bottom feeding.

Kaftanovski (1938) specifically suggested a preference for launce (Ammodytes) by common murres. Data from Cape Thompson tend to support his contention. Among stomachs containing fish remains, 26.7 per cent of those of common murres contained launce while 15.3 per cent of thick-billed murres' did so. Calculated on the same basis, 70.6 per cent of thick-billed murre stomachs contained polar cod (Boreogadus saida) and 68 per cent of those of common murres. In this most abundantly occurring food item, no difference in preference is evident between the two species of murres, a fact which tends to support the hypothesis of a preference for launce by the common murres.

No other significant differences in the feeding aspects of the ecological niches of these two very similar species were detected during this otudy.

Seasonal variations in food habits seem simply to reflect availability, in turn reflecting the life cycle or movements of the food species. Polychaetes were taken by thick-billed murres largely between 19 June and $11 \mathrm{July}$. Only one occurrence after $11 \mathrm{July}$ was recorded (on 7 August). Boreogadus saida was eaten abundantly throughout the breeding season by both species. Ammodytes hexapterus was not recovered from:murre stomachs until 10 June, after which time it occurred occasionally in the diet with relatively large numbers being found during August. 


\section{Black-legged Kittiwake}

Collection of food samples of kittiwakes was made in the same way as for murres. Data are tabulated in Table 24.

Belopolski (1957) presents a considerable body of data on kittiwake feeding habits in the Soviet arctic which does not differ greatly from that gathered in the present study. Such differences as do appear can probably be ascribed to differences in the availability of the food items concerned.

Seasonal variations in the diet follow essentially the same pattern as in murres, with Boreogadus saida a frequent item in the diet all summer. Ammodytes hexapterus was abundant in the diet from 24 July until the end of the breeding season. None were found in stomachs taken before $11 \mathrm{July}$.

\section{Glaucous Gulls}

Stomach samples of glaucous gulls were collected and processed in the same manner as with other species. Results are tabulated in Table 25. Additionally, pellets composed of the undigested fraction of ingested material were gathered from the cliff tops and beaches throughout the season. It was not always possible to distinguish pellets cast late in the fall of the previous year from those of the current season, so the seasonal aspects of glaucous gull food habits as determined by this method are somewhat distorted. After all the accumulated pellets had been cleaned up by the field party early in the season, more reliable data could be gathered (see Table 26).

Glaucous gulls are the most omnivorous of the sea birds. Food utilized includes material from the marine environment close to shore, from both brackish and freshwater lagoons, from freshwater ponds and streams, from tundra, and from the beaches and ledges of the sea bird colonies. The sea bird colonies are by far the most important 
TABLE 24. Stomach analyses of kittiwakes. Numbers in the per cent column indicate the per cent of "filled" stomachs in which the food item was represented. Figures in parentheses represent frequency in the total number of stomachs examined.

\begin{tabular}{|c|c|c|c|c|}
\hline & & & & \\
\hline & No." & $\%$ & No. & $\%$ \\
\hline Total examined & 115 & & 48 & \\
\hline Empty & 23 & (20) & 5 & $(10.4)$ \\
\hline Containing food & 92 & $(80)$ & 43 & $(89.6)$ \\
\hline Frequency of invertebrates & 23 & 25 & 17 & 39.5 \\
\hline Frequency of fish & 84 & 91.3 & 35 & 81.4 \\
\hline Fish: & & & & \\
\hline Mallotus villosus & 2 & 2.2 & & \\
\hline Boreogadus saida & 50 & 54.3 & 10 & 23.3 \\
\hline Gadidae & 1 & 1.1 & & \\
\hline Pungitius pungitius & 1 & 1.1 & & \\
\hline Myoxocephalus quadricornis & 2 & 2.2 & & \\
\hline Ammodytes hexapterus & 19 & 20.6 & 25 & 58.1 \\
\hline Ammodytes $\mathrm{sp}$ & 8 & 8.7 & 3 & 7.0 \\
\hline Lycodes $s p$ & & & 1 & 2.3 \\
\hline Sphyraena argentea & 1 & 1.1 & & \\
\hline Pleuronectidae & & & 1 & 2.3 \\
\hline Unidentifiable & 4 & 4.3 & 1 & 2.3 \\
\hline Invertebrates: & & & & \\
\hline Annelida & & & & \\
\hline "Polychaetes" & 5 & 5.4 & & \\
\hline Arthropoda & & & & \\
\hline Cumacea. & 1 & 1.1 & 1 & 2.3 \\
\hline Isopoda & 2 & 2.2 & & \\
\hline Amphipoda & & & & \\
\hline Gammaridea, species \#1 & & & 1 & 2.3 \\
\hline Gammar1dea, species \#3 & 3 & 3.3 & & \\
\hline Gammaridea, unidentifiable & & & 1 & 2.3 \\
\hline Decapoda & & & & \\
\hline Hyas coarctatus & 1 & 1.1 & & \\
\hline Chionocetes opilio & & & 1 & 2.3 \\
\hline Telmessus cheiragonus & & & 1 & 2.3 \\
\hline Pandalus goniurus & 1 & 1.1 & & \\
\hline P. borealis & 1 & 1.1 & & \\
\hline Eualus gaimardi & 1 & 1.1 & & \\
\hline$\overline{\text { Unidentifiable crab }}$ & & & 3 & 7.0 \\
\hline $\begin{array}{l}\text { Insecta } \\
\text { Mallophaga }\end{array}$ & 1 & 1.1 & & \\
\hline Siphonaptera & 2 & 2.2 & & \\
\hline Lepidoptera larva & & & 1 & 2.3 \\
\hline Insect Iarva & 1 & 1.1 & & \\
\hline Unidentifiable invertebrate & 12 & .23 .0 & 3 & 7.0 \\
\hline Pebbles & 8 & 8.7 & 14 & 32.6 \\
\hline Plant fibers, grasses, sedges & 10 & 10.9 & 6 & 13.9 \\
\hline A.lgae & 1 & 1.1 & 2 & 4.6 \\
\hline
\end{tabular}


TABLE 25. Stomach analyses of glaucous gulls. Numbers in the per cent column indicate the number of "filled" stomachs in which the food item was represented. Figures in parentheses represent frequency in the total number of stomachs examined.

\begin{tabular}{|c|c|c|c|c|}
\hline & fles, & $\frac{\text { natures }}{\text { ggs }}, \cdot \cdots$ & Nes: & ings \\
\hline & No. & $\%$ & No. & $\%$ \\
\hline Total examined & 12 & & 11 & \\
\hline Empty & 2 & $(16.7)$ & 1 & $(9.1)$ \\
\hline Containing food & 10 & $(83.3)$ & 10 & $(90.9)$ \\
\hline Frequency of invertebrates & 6 & 60.0 & 4 & 40.0 \\
\hline Frequency of vertebrate & 8 & & & \\
\hline $\begin{array}{l}\text { remains (not including eggs) } \\
\text { Frequency of fish }\end{array}$ & $\begin{array}{l}8 \\
5\end{array}$ & $\begin{array}{l}80.0 \\
50.0\end{array}$ & $\begin{array}{l}5 \\
5\end{array}$ & $\begin{array}{l}50.0 \\
50.0\end{array}$ \\
\hline Frequency of eggs (murres?) & 1 & 10.0 & 3 & 30.0 \\
\hline Frequency of murre chicks & 5 & 50.0 & & \\
\hline Fish: & & & & \\
\hline Boreogadus saida & 2 & 20.0 & 2 & 20.0 \\
\hline$\overline{\text { Gadidae }}$ & & & 1 & 10.0 \\
\hline Gasterosteidae & & & 1 & 10.0 \\
\hline Myoxocephalus quadricornis & 1 & 10.0 & & \\
\hline Ammodytes hexapterus & 2 & 20.0 & & \\
\hline Unidentifiable fish & 1 & 10.0 & & \\
\hline Invertebrates: & & & & \\
\hline Coelenterata & & & & \\
\hline Anthozoa (sea anemone) & 2 & 20.0 & & \\
\hline Arthropoda & & & & \\
\hline Crustacea & & & & \\
\hline Unidentifiable crab & 2 & 20.0 & & \\
\hline Unidentifiable crustacean & 1 & 10.0 & & \\
\hline Insecta & & & & \\
\hline Lepidoptera, larva & & & $I$ & 10.0 \\
\hline Carabid beetle & & & 1 & 10.0 \\
\hline Diptera (tendipedidae, & & & & \\
\hline arult and larva) & & & 1 & 10.0 \\
\hline Echinodermatá & & & & \\
\hline Asteriodea (?) & 1 & 10.0 & & \\
\hline Grass or sedge & 1 & 10.0 & & \\
\hline Unidentifiable vegetation & 1 & 10.0 & & \\
\hline Pebbles & 4 & 40.0 & 8 & 80.0 \\
\hline
\end{tabular}


Table 26. Percentage analysis of Glaucous Gull pellets, Cape Thompson, Alaska, 1959 and 1960.

\begin{tabular}{|c|c|c|c|c|c|c|c|c|c|c|}
\hline Jate & $\begin{array}{l}\text { June } \\
1-15\end{array}$ & $\begin{array}{l}\text { June } \\
16-30\end{array}$ & $\begin{array}{l}\text { July } \\
1-15\end{array}$ & $\begin{array}{l}\text { July } \\
16-31\end{array}$ & $\begin{array}{l}\text { Aug. } \\
1-15\end{array}$ & $\begin{array}{l}\text { Aug. } \\
16-31\end{array}$ & $\begin{array}{l}\text { Sept. } \\
1-15\end{array}$ & $\begin{array}{l}\text { Sept. } \\
16-30\end{array}$ & $\begin{array}{l}\text { Date } \\
\text { Unknown }\end{array}$ & Total \\
\hline Number of pellets & 6 & 57 & 23 & 19 & 3 & 52 & 65 & 9 & 20 & 254 \\
\hline Murre shicks & $50 \%$ & $9 \%$ & $17 \%$ & $53 \%$ & & $83 \%$ & $80 \%$ & $56 \%$ & $55 \%$ & $52 \%$ \\
\hline Vurre zdults & & 7 & & & $67 \%$ & 6 & 12 & 23 & & 7 \\
\hline $\begin{array}{l}\text { Murre - Age } \\
\text { unknown }\end{array}$ & 17 & 56 & 65 & 26 & & 10 & 12 & & 45 & 30 \\
\hline Kittiwake chicks & 50 & & & & & & & & & 3 \\
\hline Kittiwake adults & & & & & & & & & & \\
\hline $\begin{array}{c}\text { Kittiwake - age } \\
\text { unknown }\end{array}$ & 33 & 21 & 9 & 11 & 33 & 8 & 3 & 23 & 5 & 11 \\
\hline Murre eggs & & 11 & 17 & 63 & 67 & 17 & 12 & 12 & 5 & 17 \\
\hline Plant material & & 16 & 39 & 11 & & 4 & 3 & & 10 & 10 \\
\hline Mammal remains & & & 13 & 16 & & & & & 5 & 3 \\
\hline $\begin{array}{c}\text { Invertebrate } \\
\text { remains }\end{array}$ & & 5 & 4 & 47 & & 2 & 2 & & & 6 \\
\hline Pebbles & & 8 & 17 & & & & & & & \\
\hline
\end{tabular}


source in the nutrition of glaucous gulls; and, with the exception of very early and very late in the season, virtually all of the food of this species is drawn directly or indirectly from the colonies.

During the appropriate season, almost all of the food of glaucous gulls is derived from the eggs and young of murres and, to a lesser extent, from the eggs and young of other species, excepting only those crevice-nesting species which are well protected from predation: The data probably do not accurately reflect the fraction of eggs eaten, since the birds peck open the shell to feed and do not seem to accidentally ingest very much shell material nor shell membranes.

During all parts of the breeding season, the carcasses of murres and kittiwakes dead from rock-fall injuries are eaten. Carcasses which have been eaten by glaucous gulls are readily identifiable by the gulls' habit of turning the skin inside out, sometimes as far as the rhamphotheca of the bill. Carcasses form a relatively more important fraction of the food in the early part of the season, when large numbers are found on the grounded shore ice where the birds have died after being injured in rock-falls. Plant material in the samples was most often ingested passively along with other food items, but berries did occasionally occur in the samples as a food item. In contrast to situations reported by Belopolski (1957), berries did not form an important fraction of the food of glaucous gulls at Cape Thompson during any of the years of study. Microtine rodents were taken occasionally ( 3 per cent of the pellets examined). The whole body of data and field observations seems to indicate that glaucous gulls go to the least trouble possible in securing food and that when acceptable material is available for scavenging, this is the primary source of nutrition.

It was not always possible to be sure whether fish remains found in a sample were eaten as such knowingly by the gull or whether they were taken in within the stomachs of another food species. In any event, even though early in the season glaucous 
gulls were seen feeding on fish thawing out of the sea ice, fish formed a surprisingly small fraction of the total food.

\section{Miscellaneous Species}

Because of small sample sizes, the food habits of several species do not warrant detailed commentary. Results of analyses of these species are tabulated in Table 27.

Community Metabolism

The structure of the ecosystem in which the sea birds play a role is diagrammed in Fig. 15. For purposes of illustration, the organisms in the ecosystem are:divided into "Primary Consumers" and "Secondary Consumers." Actually, of course, the organisms used as food by my "Primary Consumers" are themselves consumers at various levels in the oceanic food web. It is not possible to consider the marine food web in detail, and for convenience I will use these admittedly imprecise terms.

It has been possible to establish certain quantitative expressions of material and energy flow in terms of wet biomass, but a more incisive analysis of caloric and chemical relationships must await more precise knowledge of the energy balance in the species involved. It is evident that comprehensive experimental work is needed and that such work must be done under experimental conditions appropriate to the specific environmental milieu of the colonies under study. This need is pointed up by the greatly varying data and estimates of food consumption for murres from different localities. On the Murman coast (Belopolski, 1957), food consumption of adult murres is estimated at about 60 grams per day and "chicks" at 20 grams per day. On Novaya Zemly.a (Uspenski,1956) 
TABLE 27. Stomach analyses of miscellaneous species. Numbers in the per cent column indicate the per cent of filled stomachs in which the food item was represented. Figures in parentheses represent frequency in the total number of stomachs examined.

No. Per Cent

\section{Horned puffin}

Total examined 17

Empty

Containing food

9

Frequency of invertebrates

8

Frequency of fish

Fish:

Mallotus villosus

Gadidae

Boreogadus saida

Triglops

Ammodytes hexapterus

Ammodytes sp.

Unidentifiable fish

$(75.0)$

Invertebrates:

Porifera

Polychaete

Unidentifiable crustacean

12.5

1

12.5

37.5

12.5

25.0

12.5

25.0

Pebbles

12.5

25.0

12.5

12.5

\section{Pelagic cormorant}

Total examined 2

Empty

Containing food

Frequency of invertebrates 2

Frequency of fish

$\frac{1}{2}$

1

1

Fish:

Boreogadus saida

Ammodytes sp. 1

50.0

Chirolophus

polyactocephalus

1

50.0

Invertebrates:

Crustacea

Telmessus cheirogonus

Yandalus goniurus

P. hypsinotus

Crangonidae

Spirontocaris (2 ssp.)

50.0
50.0
50.0



100.0
100.0
50.0
50.0
50.0


(TABLE 27, continued)

No. Per Cent

Black guillemot

Total examined 1

Empty

Containing food

Frequency of invertebrates

Frequency of fish

0

$1 \quad 100.0$

$1 \quad 100.0$

$1 \quad 100.0$

Fish:

Boreogadus saida Gadidae

$1 \quad 100.0$

$1 \quad 100.0$

Invertebrates:

Polychaete

1

100.0

Pigeon guillemot

Total examined 1

Empty 0

Containing food

Frequency of invertebrates

$1 \quad 100.0$

Frequency of fish

1

100.0

1

100.0

Fish:

Boreogadus saida

Chirolophus sp.

$1 \quad 100.0$

$1 \quad 100.0$

Unidentifiable invertebrate

1

100.0

Herring gull

Total examined

Unidentifiable crustacean

Pebbles

1

$1 \quad 100.0$

$1 \quad 100.0$

Hybrid (?) Glaucous-ilaucous-winsed gul I

Total examined

Boreogadus saida

Ammodytes hexapterus

Tufted puffin

Total examined

Containing food

Frequency of invertebrates

Frequency of fish

Fish:

Boreogadus saida

Cottidae (?)

Invertebrates:

Pteropod
1

1

1

100.0

100.0
2

$2 \quad 100.0$

$1 \quad 50.0$

$2 \quad 200.0$

$2 \quad 100.0$

$1 \quad 50.0$

1

50.0 


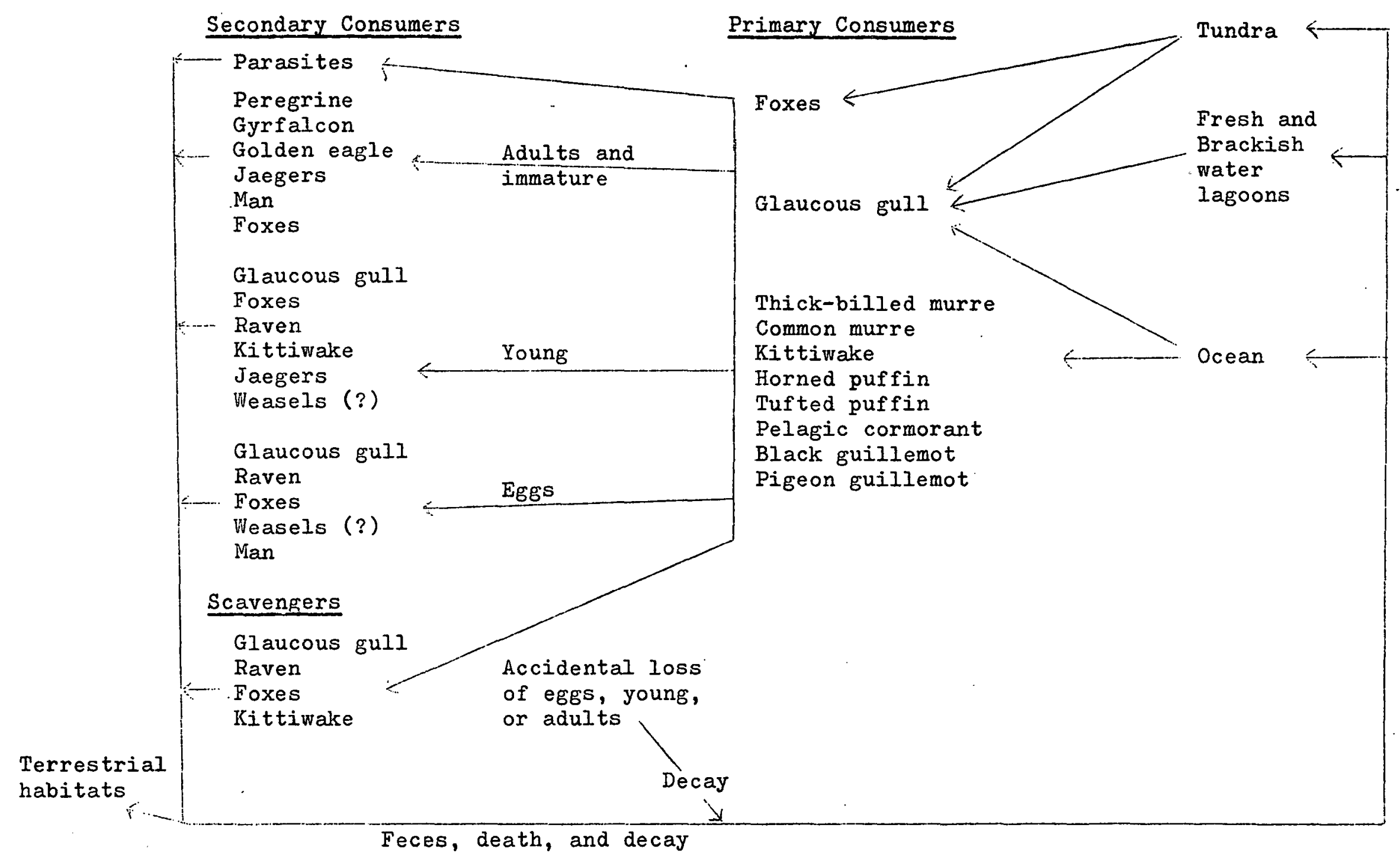

Figure 15. Structure of the ecosystem of the Cape Thompson, Alaska, sea-bird cliffs 
adults were estimated to consume 100 grams per day and "chicks" 30-45 grams. In the Seven Islands Sanctuary (Kaftanovski, 195I) daily food intake of adults is listed as 30 grams, although, as pointed out by Belopolski (1957) and by the author himself, this is certainly too low. Tuck and Squires (1955) conducted feeding experiments on chicks on Akpatok Island in Ungava Bay and concluded that chicks eat approximately one-half their body weight in food per day. The same authors estimate food consumption of adults in this locality at about one-quarter of the body weight per day. It appears likely that the primary factor in determining food consumption in specific localities is environmental temperature which acts to shift the energy balance of the birds.

Table 28 contains calculations of the food consumption of most species important in the terrestrial segment of the ecosystem at Cape Thompson. It has been necessary to make certain assumptions in calculating the figures compiled in this table. It was not possible from more or less eroded otoliths and other food fragments in the stomachs, pellets, and feces which comprised the food habits samples, to determine the wet weight of food taken in by either adults or young at Cape Thompson. Similarities in the breeding phenology of the Cape Thompson colonies and the Akpatok Island colonies as reported by Tuck and Squires (op. cit.) suggest that the environment as a whole is similar to that at Cape Thompson. Accordingly, I have used their figures in tentative calculations of the biomass of food at Cape Thompson. Lacking data on the energy balance of the other species, I have used the same proportions for all species nesting at Cape Thompson. In predatory species of birds (peregrines, gyrfalcons, and golden eagles) I have assumed one "kill" per day (.96 kg which is an average of the mean weights of thickbilled and common murres in this locality) even though the whole carcass is not eaten. 
Table 28. Biomass and food consumption at the Cape Thompson colonies in 1960

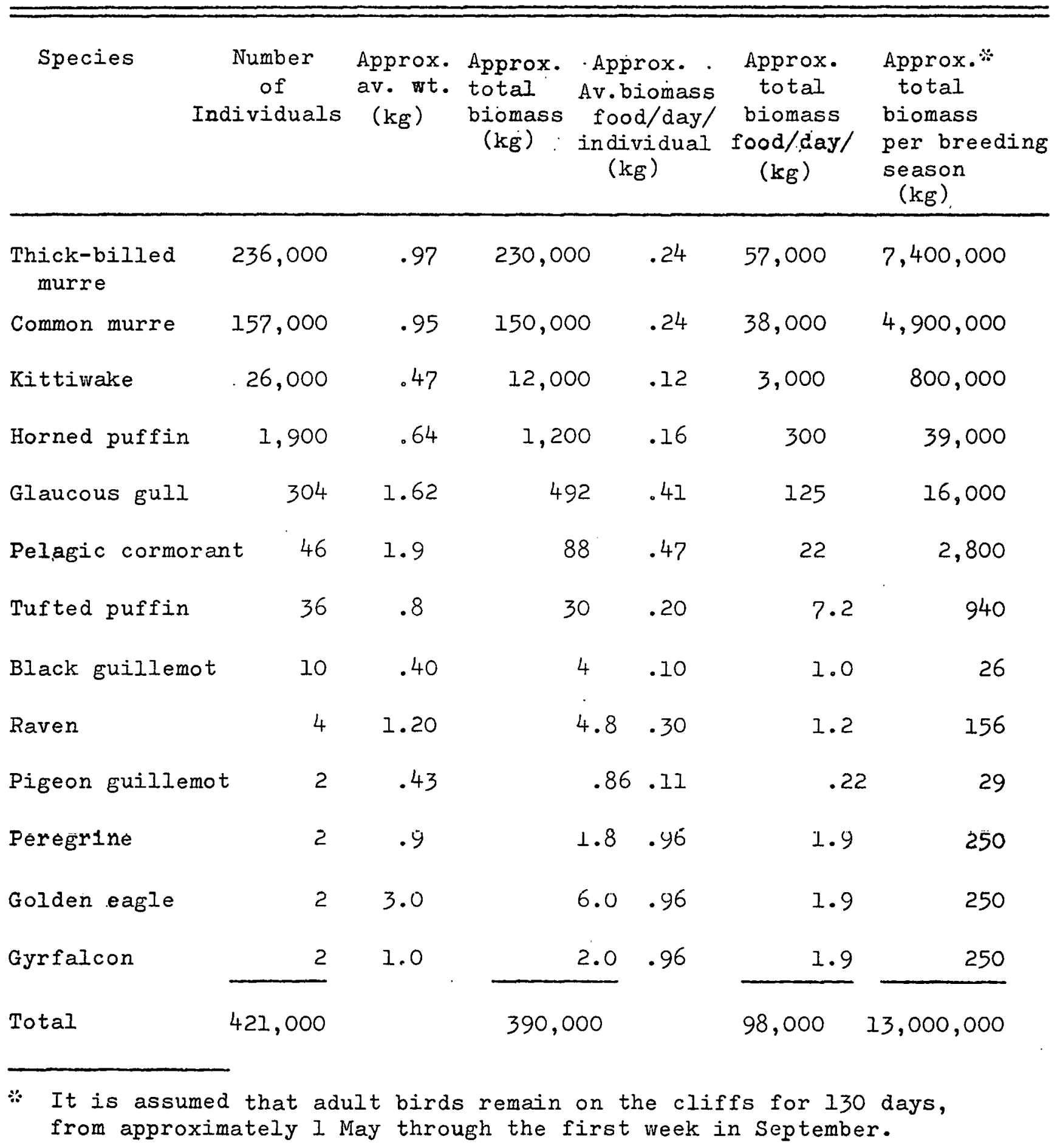


At least two families of red foxes preyed regularly on the eggs, young, and crippled or dead adults of sea bird species. Fifty-five to 60 glaucous gull nests were regularly preyed upon so intensively that no young fledged. Eggs were taken gradually over the incubation period the foxes, and some hatched. The chicks were then gradually removed as well. Other species nested in more inaccessible sites and were not heavily preyed upon. Fledgling murres were eaten at the bases of the cliffs if they did not succeed in reaching the water. Dead and injured chicks and adults were regularly eaten on the beaches, and on numerous occasions foxes were seen carrying food away, presumably to den sites. One den was observed during all three summers and food remains were observed repeatedly at the den mouth. There is insufficient basis for calculating the biomass of various food items ingested by foxes.

Both the eggs and adults of murres are exploited by man but not to an intensive degree. Other species, either as eggs or adults, are scarcely ever eaten. Each year Eskimos from Point Hope and less frequently from Kivalina come to the Cape Thompson cliffs to collect eggs. During the three seasons in which we have been able to observe them, the eggs taken have numbered about 2,000. Adult murres are killed in relatively small numbers by these Eskimos, generally from the ledges with .22 caliber rifles. In 1959 these adults prohahly numbered less than thirty. In 1960 about 135 adults were taken; but in 1961 virtually none was killed, because the party succeeded in killing a beluga (Delphinapterus leucas) early in the visit and the motivation to kill murres was evidently lowered. Most eggs and adults are taken hark to the village to be eaten. Parasitic, long-tailed, and pomarine jaegers have all been observed to prey. to a certain extent on the sea bird colonies, but their role is insignificant in the community metabolism. Normally this predation seems to be confined to occasional predation on eggs 
and nestlings, but in one case an immature parasitic or pomarine jaeger was seen to attack and kill an immature kittiwake on the water.

The uncertainties arising from ignorance of energy balance become even more critical in the case of chicks, and for this reason no attempt is made to calculate total food consumption for chicks of all species. In the case of murres, the experiments of Tuck and Squires (1955) give some basis for calculation. They determined that 13.4 grams of food were required for each gram of weight gain at Akpatok Island. Lacking data on food consumption of kittiwake chicks in this area, I have used the same figures as for murres. In calculating the number of murre chicks in Table 27, I have, in the absence of reliable data from Cape Thompson, used the data of Tuck (1960) from Cape Hay ( 41 per cent breeding success) as reasonably typical of murre colonies. Weights of kittiwake fledglings were not obtained, but since they return to the nest repeatedly after the initial flight, it is assumed that they attain approximately the adult weight before finally leaving the nest. Food consumption of murre and kittiwake chicks based on these premises is given in Table 29.

Uspenski (1956) calculated the total food utilization of two million adult thick-billed murres and their offspring during the 4-month breeding season at Novaya Zemlya at 25,000 metric tons. Turk (1.960), referring to the work of Tuck and Squires at Akpatok Island, states that the food consumption of murres is about twice as high at Akpatok Island as in Novaya Zemly.a. Since I have used the data of Tuck, the data as presented here will, of courşe, be higher per bird than at Novaya Zem a. The annual food consumption at Cape Thompson as calculated by these means is about 13,000 metric tons. 
TABLE 29. Food consumption of murre and kittiwake chicks at Cape Thompson through the nestling period. These figures do not, of course, include chicks which survived for only part of the nestling period.

\begin{tabular}{|c|c|c|c|c|c|c|}
\hline Species & $\begin{array}{l}\text { Number } \\
\text { of } \\
\text { Chicks } \\
\text { Fledging }\end{array}$ & $\begin{array}{l}\text { Weight at } \\
\text { hatching } \\
\text { (data from } \\
\text { Uspenski, } \\
\text { 1956) } \\
(\mathrm{g})\end{array}$ & $\begin{array}{l}\text { Average } \\
\text { weight at } \\
\text { fledging } \\
\text { at Cape } \\
\text { Thompson }\end{array}$ & $\begin{array}{c}\text { Weight } \\
\text { gain }\end{array}$ & $\begin{array}{l}\text { Food } \\
\text { cons. } \\
\text { /ind. }\end{array}$ & $\begin{array}{l}\text { Total } \\
\text { food } \\
\text { cons. } \\
\text { for } \\
\text { colonies } \\
(\mathrm{kg})\end{array}$ \\
\hline $\begin{array}{l}\text { Thick-billed } \\
\text { murre }\end{array}$ & 97,000 & 70.3 & 121.5 & 51.2 & 686.1 & 66,000 \\
\hline $\begin{array}{l}\text { Common } \\
\text { murre }\end{array}$ & 64,000 & 75.8 & 179.9 & 104.11 & $1,394.9$ & 89,000 \\
\hline Kittiwake & 32,000 & 37.5 & 468.1 & 430.64 & $4,770.0$ & 153,000 \\
\hline
\end{tabular}


SUMMARY

The sea cliffs in the vicinity of Cape Thompson support over 400,000 sea birds which maintained essentially stable populations during the three years of study. Nine species are regularly represented as breeders and are listed below in order of decreasing abundance. Numbers given are abundances as determined in 1960.

$\begin{array}{lr}\text { Thick-billed murre } & 236,000 \\ \text { Common murre } & 157,000 \\ \text { Black-legged kittiwake } & 26,000 \\ \text { Horned puffin } & 1,900 \\ \text { Glaucous gull } & 304 \\ \text { Pelagic cormorant } & 46 \\ \text { Tufted puffin } & 36 \\ \text { Black guillemot } & 10 \\ \text { Pigeon guillemot } & 2\end{array}$

Dates of periodic phenomena were determined for most species during all years. The phenologies of the most important species are summarized in Fig. 16. In general, the colonies are active from about I May through September though weather and ice conditiuns may modify this pattern.

The breeding biology of all of the sea bird species has been investigated to degrees varying with the importance of the species in the ecosystem. Comparisons have been made with the results of other workers in other parts of the world when meaningful in the light of differing environmental factors.

The broad outlines. of the trophic structure of the ecosystem in which the sea birds take part have been worked out. A simplified diagram is presented in Fig. 17. Almost all of the nutrition for the sea cliff colonies is drawn from the sea and is calculated to be about 13,000 metric tono wet biomase per breeding season. Many of the details of the food habits of sea bird species have been determined. 


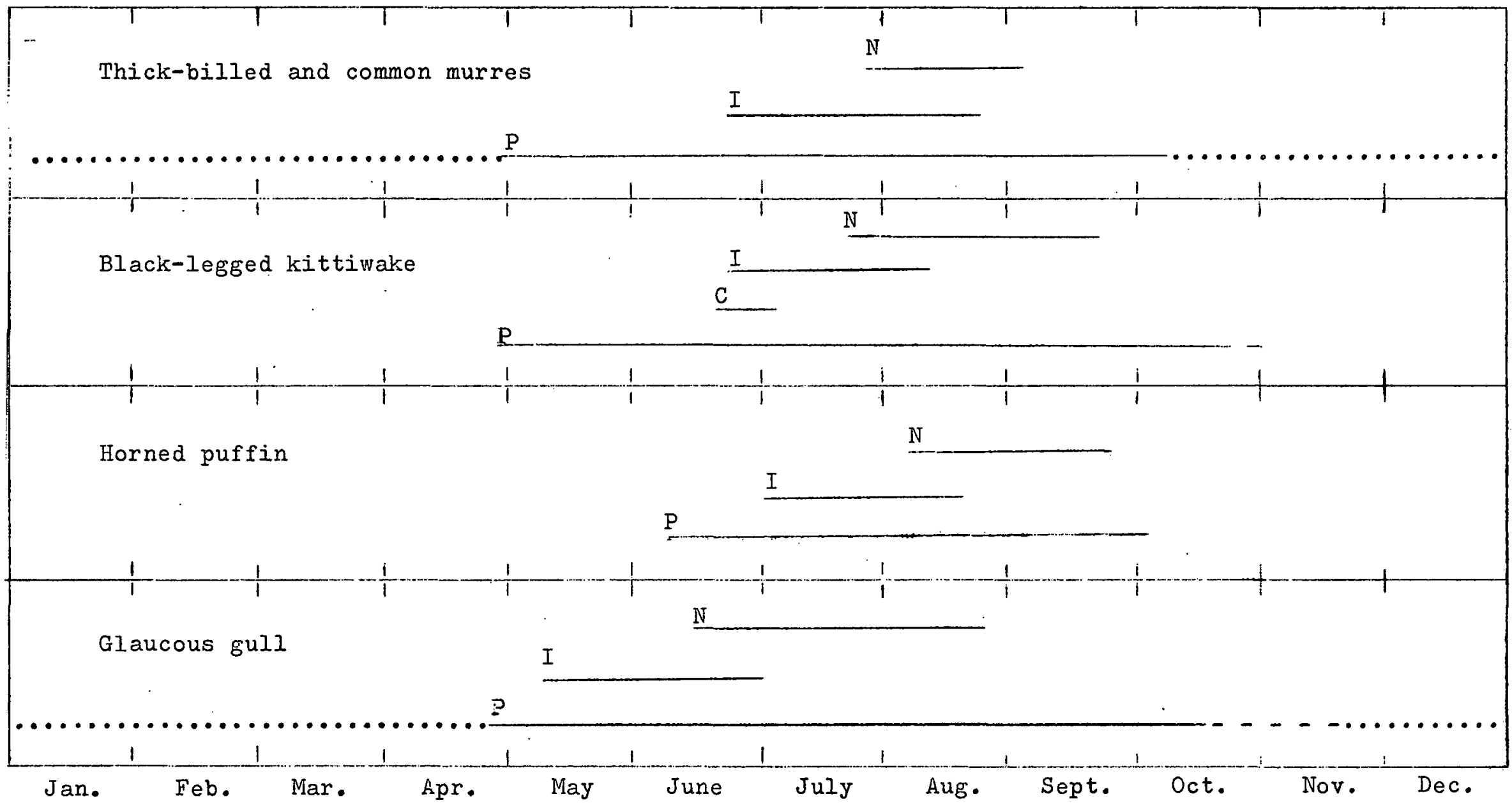

The ends of the lines represent the extremes observed during the three years of study (see text for variability).
$P$ Presence in area
- Presence at cliffs
- Probable prèsence at cliffs
... Presence in nearby areas in small numbers
C Period of nest construction
I Period of egg-laying and incubation
$N$ Period of hatching and nestling life

Figure 16. Diagram of the phenology of the principal species at Cape Thompson. 


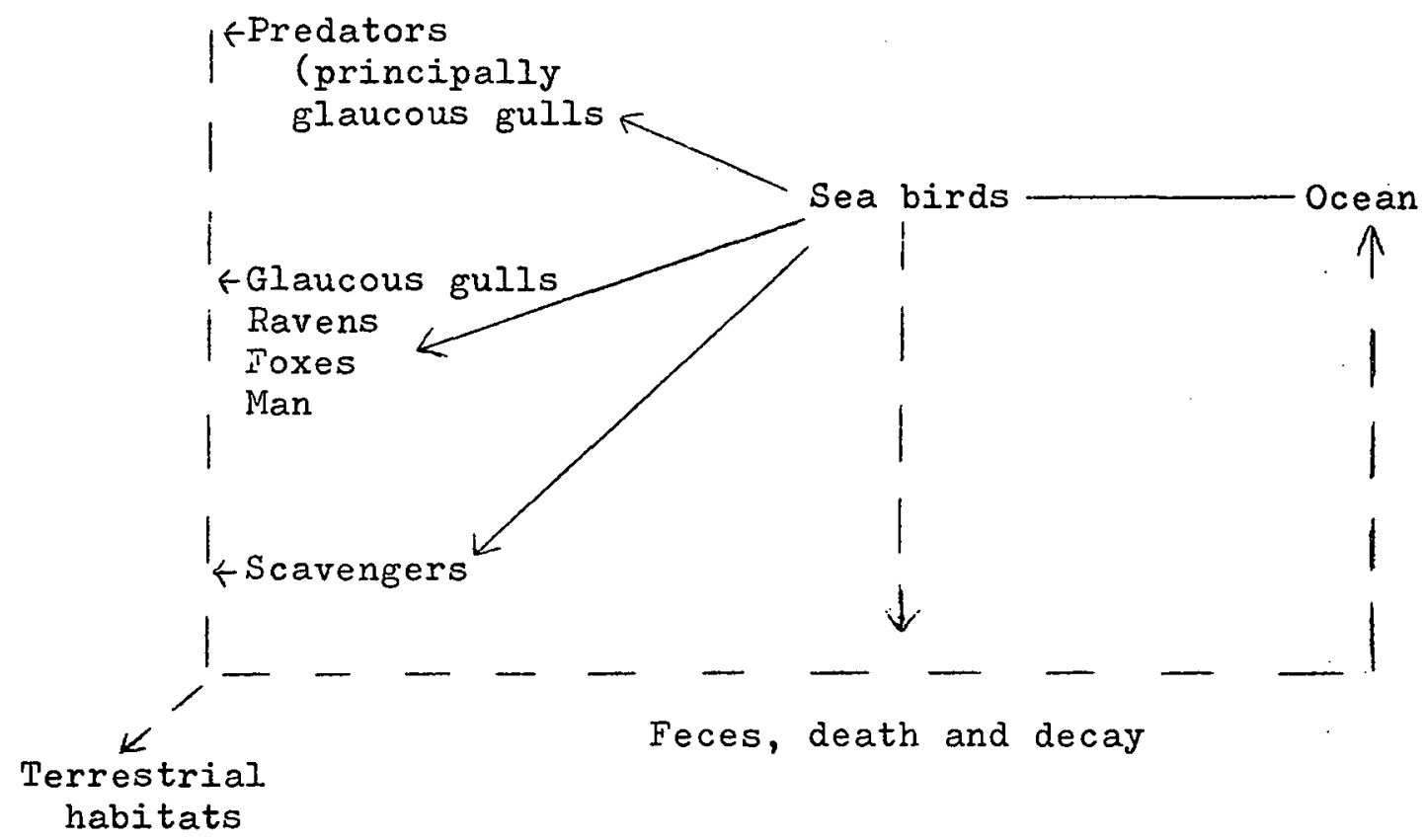

Figure 17. Simplified diagram of the food web at the Cape Thompson colonies. 
Alverson, D. I., N. J. Wilimovsky and F. Wilke. 1960. A preliminary report on marine investigations of the Chukchi Sea -- August 1959. Project Chariot Progress Report, U. S. Atomic Energy Commission. $44 \mathrm{p}$.

Bailey, A. M. 1925. A report on the birds of northwestern Alaska and regions adjacent to Bering Strait. Condor 27: pt. II, 62-67; pt. III, 101-109; pt. IV, 164-17I.

1948. Birds of arctic Alaska. Colorado Mus. Nat. Hist. Popular Series, no. 8. 317 p.

Belopolski, I. O. 1957. Ecology of colonial sea'birds of the Barents Sea. [In Russian]. Izdatel'stvo Academia Nauk SSSR, Moskva-Leningrad. $460 \mathrm{p}$.

Boyd, J. M. 196l. The gannetry of St. Kilda. J. Animal Ecol. 30: $117-136$.

Cade, T. J. 1952. Note on the birds of Sledge Island, Bering Sea, Alaska. Condor 52: 51-54.

Coulson, J. C. and E. White. 1958a. The effect of age on the breeding biology of the kittiwake Rissa tridactyla. Ibis 100: 40-51.

1958b. Observations on the breeding of the kittiwake. Bird study 5: 74-83.

Cullen, E. 1957. Adaptations of the kittiwake to cliff nesting. Ibis 99: 275-302.

Fay, F. H. and T. J. Cade. 1959. An ecological analysis of the avifauna of St. Lawrence Island, Alaska. Univ. Calif. Publ. zool. 63(2): 73-150.

Gabrielson, I. N. and F. C. Lincoln. 1959. Birds of Alaska. The Stackpole Co., Harrisburg, and The Wildl. Mgmt. Inst., Wash., D. C. $922 \mathrm{p}$.

Grinnell, J. 1900. Birds of the Kotzebue Sound region, Alaska. Pac. Coast Avifauna 1: 1-80.

IIopper, C. Io 1881. Roport of the cruise of the U. S. Revenue Steamer Corwin in the Arctic Ocean. U. S. Govt. Print. Off., Wash., D. C.

1884. Report of the cruise of the U. S. Revenue Steamer Thomas Corwin in the Arctic Ocean 1881. U. S. Govt. Print. Offl, Wash. D. C. 147 p. 
Hudson, G. E. 1957. Birds observed in the Kotzebue Sound area of Alaska during the summer of 1956. Murrelet 38(3): 26-29.

Kaftanovski, Yu. M. 1938. Colony nesting of the murres and factors causing the death of eggs and nestlings. [In Russian]. Zoologicheskii Zhurnal 17(4): 695-705.

\section{Studies on comparative characteristics} of the reproduction of some murre species. [In Russian]. Trudy Gosudarstvennogo Zapovednika "Sem'Ostrovov." Glavnoe Upravlenie po zapovednikam pri SNK RSFSR. Vol. I.

Kay, G. T. 1947. The young guillemot's flight to the sea. Brit. Birds. 40: 156-157.

Keighley, J. and R. M. Lockley. 1948. The incubation and fledging periods of the razorbill. Brit. Birds 41: 113-114.

Kenyon, K. W. and J. W. Brooks. 1960. Birds of Little Diomede Island, Alaska. Condor 62(6): 457-463.

Krasovski, S. K. 1937. Studies of the biology of the thickbilled murre. [In Russian]. Trudy Arkticheskogo Instituta Biologiya 77: 32-92.

Muir, J. 1917. The cruise of the Corwin. Houghton Mifflin, New York. $279 \mathrm{p}$.

Nelson, E. W. 1883. Birds of Bering Sea and the Arctic Ocean. p. 55-118. In Cruise of the Revenue Marine Steamer, Corwin, in Alaska and N.W. Arctic Ocean in 1881. U. S. Govt. Print. Off., Vash., D. C.

Pennycuick, C. J. 1956. Observations on a colony of Brunnich's guillemot Uria lomvia in Spitzbergen. Ibis 98: 80-99.

Perry, R. 1940. Lundy, isle of puffins. Lindsay Drummond, London.

Ridgeway, R. 1919. The birds of north and middle America, pt. VIII. U. S. Govt. Print. Off., Wash., D. C. 852 p.

Shuntov, V. P. Migration and distribution of marine birds in southeastern Bering Sea during spring-summer season. Zoologiộskii Zhurnal 40(7): 1058-1069.

Storer, R. W. 1952. A comparison of variation, behavior and evolution in the sea bird genera Uria and Cepphus. Univ. Calif. Publ. Zool. 52(2): 12l-222.

Tschanz, B. 1959. Zur Brutbiologie der Trottellumme (Uria aalge Pont.). Behavior 14: 1-100. 
Tuck, L. M. 1960. The murres, Queen's Printer, Ottawa. 260 p.

and $H_{0}$ J. Squires. 1955. Food and feeding habits of Brunnich's murre (Uria lomvia lomvia) on Akpatok Island. J. Fish. Res. Bd. Can. 781-792.

Uspenski, S. M. Ptich'i bazary Novoi Zemli (the bird bazaars of Novaya Zemlya). Izdatel'stvo Akademia Nauk SSSR (English transl. Can. Wildl. Serv., Translations of Russian Game Reports No. 4.) Queen's Printer, Ottawa. $159 \mathrm{p}$.

Witherby, H. F., F. C. R. Jourdain, N. F. Ticehurst, and B. W. Tucker. 1941. The handbook of British birds. Vol. 5. Witherby, London. $333 \mathrm{p}$.

Wolfe, J. N. chmn. 1960. Bioenvironmental features of the Ogotoruk Creek area, Cape Thompson, Alaska. Div. Biol. Med., U. S. Atomic Energy Commission, Wash., D. C. 183 p. 